Pacific Northwest

National Laboratory

Operated by Battelle for the

U.S. Department of Energy

\title{
Performance Evaluation of Industrial Hygiene Air Monitoring Sensors, Revision 1
}

\author{
A.D. Maughan \\ J.A. Glissmeyer \\ J.C. Birnbaum
}

January 2005

Prepared for the U.S. Department of Energy

under Contract DE-AC05-76RL01830 
PNNL-14967, Rev. 1

\title{
Performance Evaluation of Industrial Hygiene Air Monitoring Sensors, Revision 1
}

\author{
A. David Maughan \\ John A. Glissmeyer \\ Jerome C. Birnbaum
}

January 2005

Prepared for

the U.S. Department of Energy

under Contract DE-AC05-76RL01830

Pacific Northwest National Laboratory

Richland, Washington 99352 


\begin{abstract}
Tests were performed to evaluate the accuracy, precision and response time of certain commercially available handheld toxic gas monitors. The tests were conducted by PNNL in the Chemical Chamber Test Facility for CH2MHill Hanford Company. The instruments were tested with a set of dilute test gases including ammonia, nitrous oxide, and a mixture of organic vapors (acetone, benzene, ethanol, hexane, toluene and xylene). The certified gases were diluted to concentrations that may be encountered in the outdoor environment above the underground tank farms containing radioactive waste at the U.S. Department of Energy's Hanford site, near Richland, Washington. The challenge concentrations are near the lower limits of instrument sensitivity and response time. The performance test simulations were designed to look at how the instruments respond to changes in test gas concentrations that are similar to field conditions. The instruments evaluated are listed by the type of challenge gas: hydrocarbons (ppb-RAE, Area-RAE, 580 EZ); ammonia (Manning EC-P2, iTX - Industrial Scientific Corporation, MIRAN SapphIRe XL); and nitrous oxide (MIRAN SapphIRe XL).
\end{abstract}





\section{Acknowledgments}

The authors wish to acknowledge the support of all those who helped plan and conduct the verification test, analyze the data, and prepare this report. In particular, we recognize Norma van Houten who validated data collected in the laboratory for spreadsheet transcription accuracy, and Rosanne Aaberg and John T. Hayes, who converted spreadsheet data into figures and tables and performed statistical analyses. 



\section{Contents}

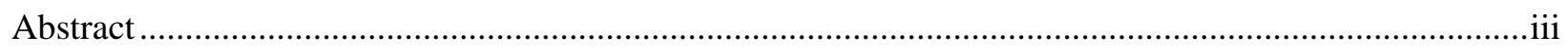

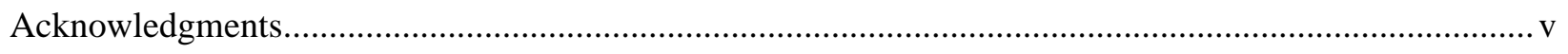

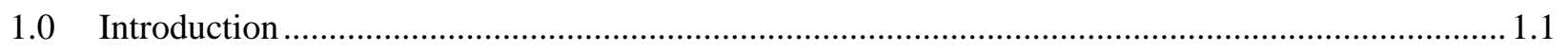

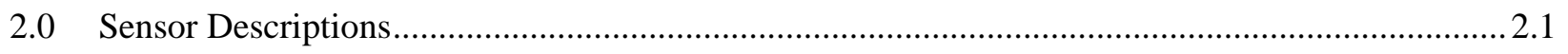

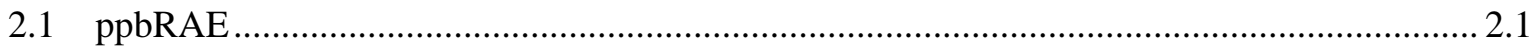

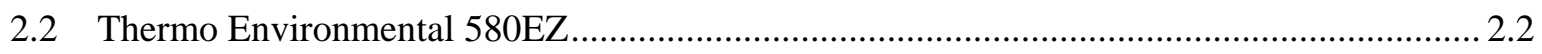

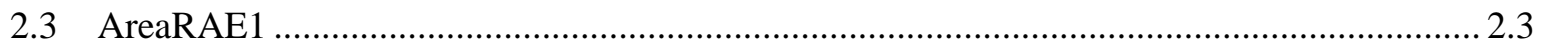

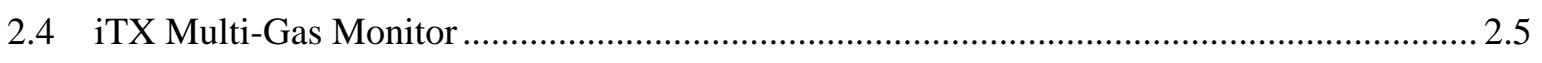

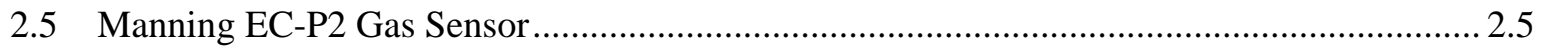

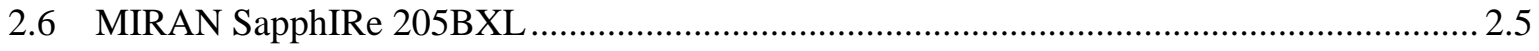

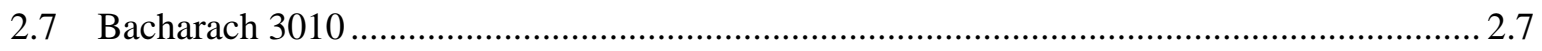

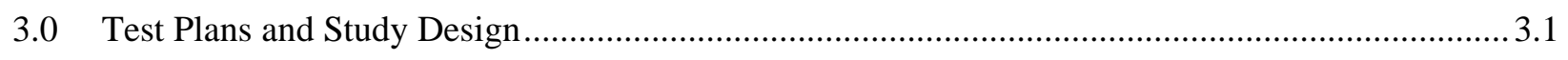

3.1 Methods for General Stepped Releases ........................................................................ 3.1

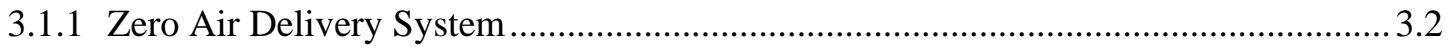

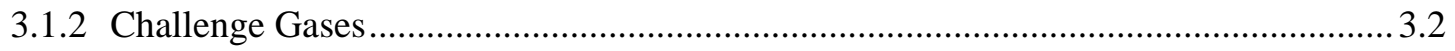

3.1.3 Collapsible Chamber............................................................................................ 3.3

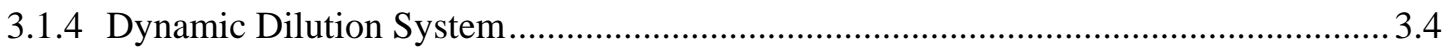

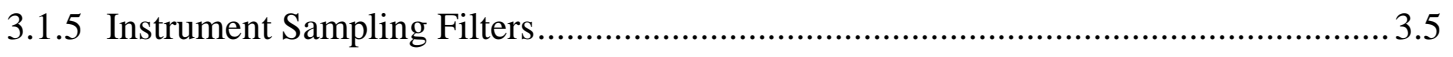

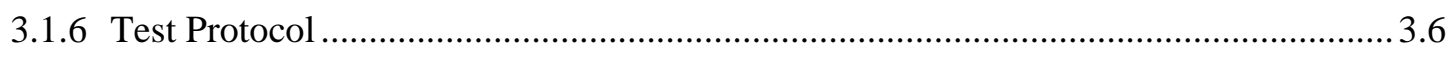

3.2 Method for Transient Release Test.................................................................................... 3.8

3.2.1 Instruments and Target Gas Concentrations .......................................................... 3.8

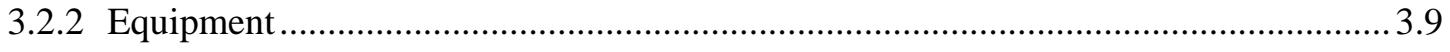

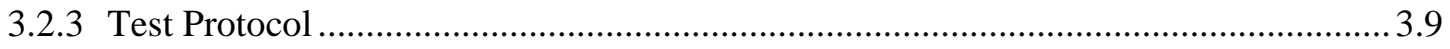




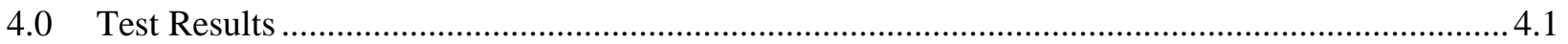

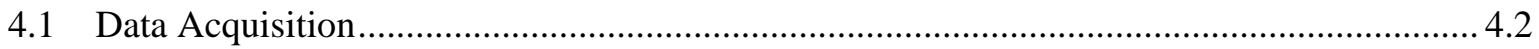

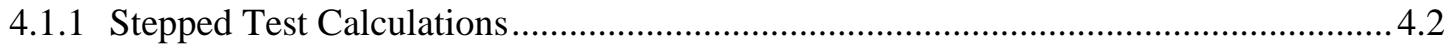

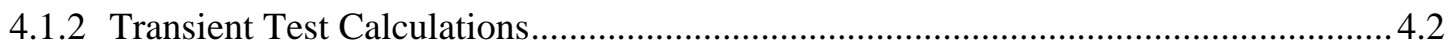

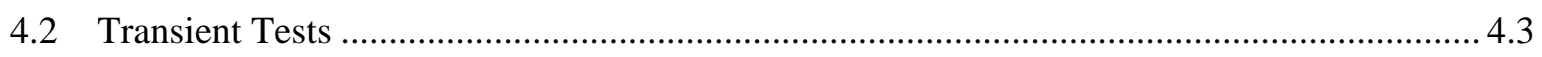

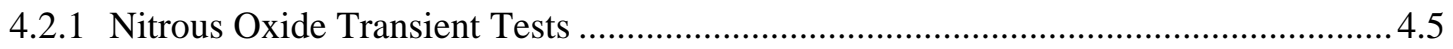

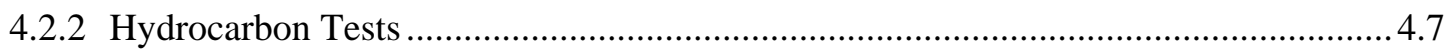

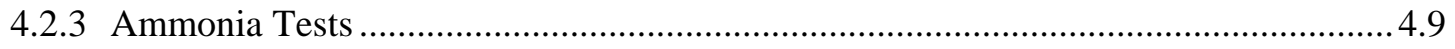

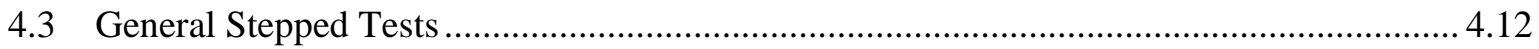

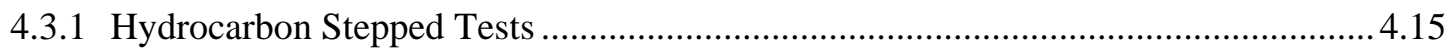

4.3.2 Ammonia Stepped Tests ................................................................................ 4.16

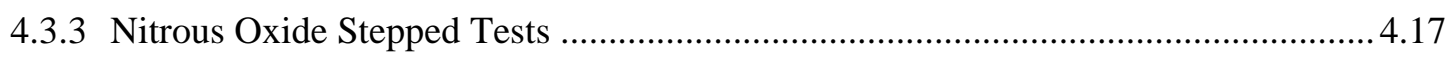

4.3.4 Graphs of Stepped Test Results ........................................................................... 4.18

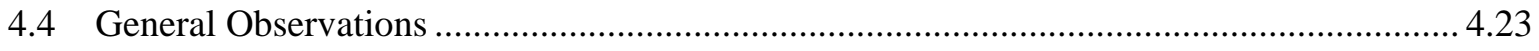

4.4.1 Use of MIRAN Chemical Filters ............................................................................ 4.23

4.4.2 Instrument Sample Inlet Flow and Use of Filters ..................................................24

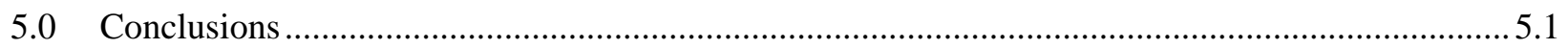

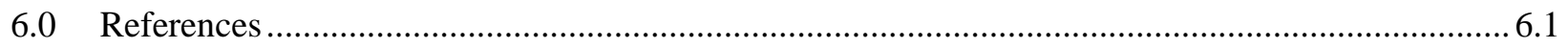

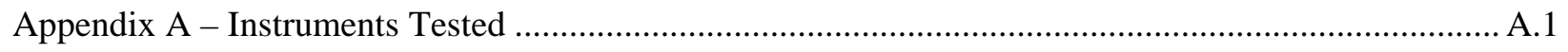

Appendix B - Mass Flowmeters Used in Dynamic Dilution System .................................................. B.1

Appendix C - Methods Used to Calculate Accuracy and Precision ......................................................... C.1

Appendix D - Estimated Lag Times in Tests …................................................................................. D.1

Appendix E - Data Analyzed for Stepped Tests of Instruments …........................................................1 


\section{Figures}

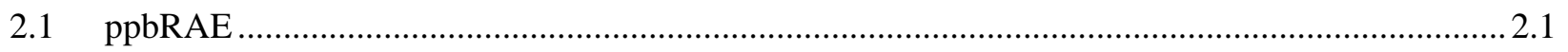

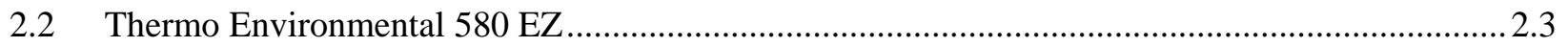

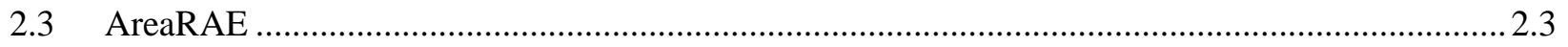

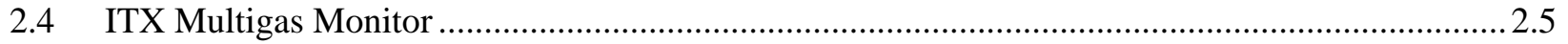

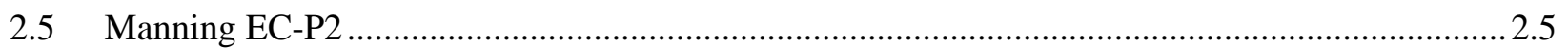

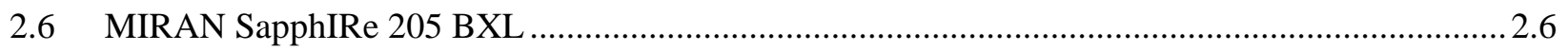

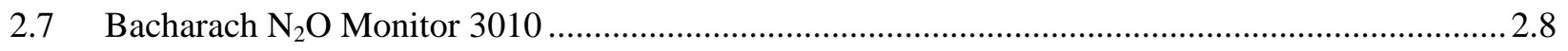

3.1 Aadco Pure Air System in the PNNL Chamber Laboratory ........................................................... 3.2

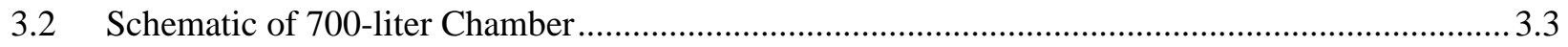

3.3 Dynamic Dilution System as Used for Transient Tests................................................................... 3.4

3.4 First Glass Manifold with Five Ports and Mixing Column ....................................................... 3.5

3.5 Second-Generation Manifold Constructed of PVC and ABS Plastic Fittings and

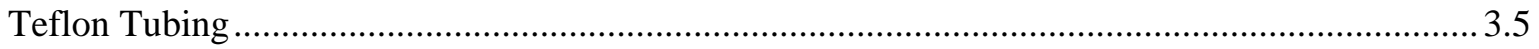

3.6 ppb-RAE with 25-mm Filter Holder …….................................................................................. 3.6

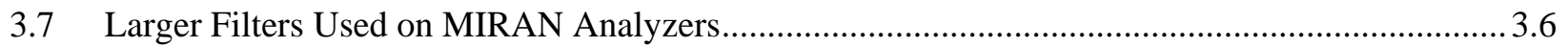

3.8 Illustration of ppb-RAE Challenge at Hydrocarbon Levels ........................................................ 3.7

3.9 Third-Generation Stainless Steel Mixer and Manifold.................................................................. 3.9

3.10 Typical Series of Four 50-ppm Nitrous Oxide 5-Minute Challenges for the MIRAN Instrument - Data Acquired at 1-Second Intervals.......................................................................11

4.1 Illustration of Points Used in Pulse Tests ................................................................................... 4.3

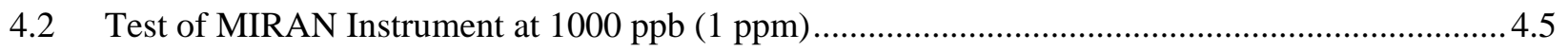

4.3 T-3 MIRAN Nitrous Oxide Pulse at 25 ppm (actual = 24.97) ................................................... 4.6

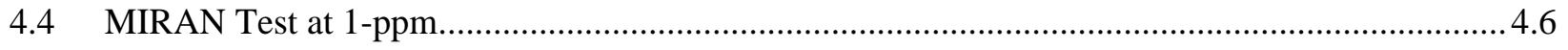

4.5 ppb-RAE and Area-RAE Challenges at 2-ppm Hydrocarbons ..................................................... 4.7

4.6 Hydrocarbon Challenges of ppb- and Area-RAE Instrument at 11.3 ppm................................... 4.8

4.7 ppb-RAE and Area-RAE Challenges at 104-ppm Hydrocarbon Level........................................ 4.8

4.8 Ammonia at 25 ppm Pulsed to an iTX Instrument ................................................................... 4.10

4.9 Ammonia Pulse at 50-ppm Ammonia for Area-RAE and iTX Air Monitors ............................. 4.10

4.10 1-ppm Ammonia Gas Challenge of the iTX Instrument .............................................................11 
4.11 Range of Hydrocarbon Concentrations Exposed to Typical ppb-RAE and 580-

EZ Monitors

4.12 iTX and EC-P2 Ammonia Sensors at Several Ammonia Concentrations

4.13 iTX Challenge with Various Ammonia Concentrations - Note the effects on the ppb-RAE and 580-EZ, which are designed to measure hydrocarbons.

4.14 Two MIRAN Analyzers Respond to Concentrations of Nitrous Oxide

4.15 Fourteen Tests for Hydrocarbon, Ammonia, and Nitrous Oxide Responses.

5.1 ppb-RAE Relative Accuracy versus Concentration ...................................................................... 5.4

5.2 iTX Relative Accuracy versus Concentration ............................................................................ 5.4

5.3 MIRAN Relative Accuracy versus Concentration ................................................................... 5.5

\section{Tables}

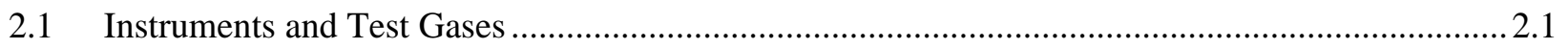

2.2 Characteristics of PID-based Instruments .................................................................................... 2.2

2.3 Characteristics of Instruments with Electrochemical Sensors .......................................................2.4

2.4 Characteristics of the MIRAN IR-based Instrument ..................................................................... 2.7

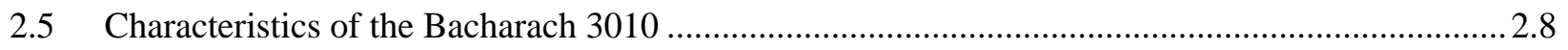

3.1 Physical Properties of Gases Selected for Performance Tests......................................................3.3

3.2 NIST Traceable Certified Calibration Gases used in Tests (Matheson Tri-gas) ............................ 3.3

3.3 Instruments Tested and Target Concentrations …...................................................................... 3.9

4.1 Identity and Schedule of Performance Tests Conducted on Sensors.............................................. 4.1

4.2 PNNL Chamber Laboratory* Testing for Transient Gaseous Releases ......................................... 4.4

4.3 Transient Test Summary for MIRAN Pulses of Nitrous Oxide .................................................. 4.7

4.4 Transient Test Summary for Mixed Hydrocarbon Pulses ............................................................. 4.9

4.5 Transient Test Summary for Ammonia Pulses............................................................................ 4.12

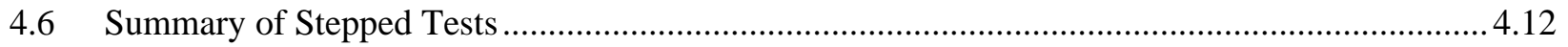

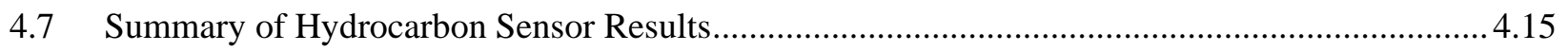

4.8 Summary of Ammonia Sensor Results for Stepped Tests ........................................................ 4.17

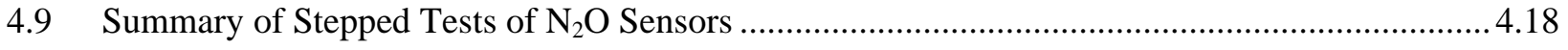

4.10 Measured Instrument Flowrates, Filters, Inlet Sample Lines .................................................... 4.26 
5.1 Acceptable Tolerance Values for Test Instruments .................................................................... 5.1

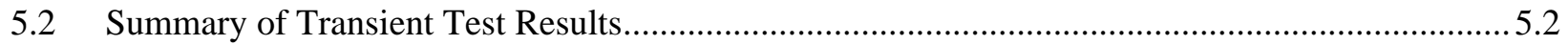

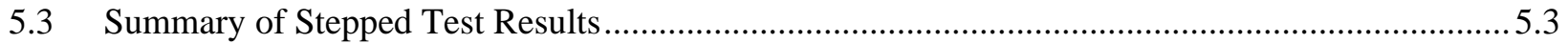




\subsection{Introduction}

Tests were performed to evaluate the accuracy, precision and response time of seven handheld toxic gas monitors: the ppb RAE, the AREA RAE, the EZ-580, the EC-P2, the iTX, the MIRAN SapphIRe XL, and the Bacharach 3010. The tests were conducted by staff from the Pacific Northwest National Laboratory (PNNL) in the Chemical Chamber Test Facility for CH2M-Hill Hanford Company. The instruments were tested with a set of dilute test gases including ammonia, nitrous oxide, and a mixture of organic vapors (acetone, benzene, ethanol, hexane, toluene, and xylene). The gases were diluted to concentrations that may be encountered in the outdoor environment above the underground tank farms containing radioactive waste at the U.S. Department of Energy's Hanford Site, near Richland, Washington. These concentrations are near the lower limits of instrument sensitivity and response time.

The instrument performance parameters addressed in this report include the following:

- accuracy

- precision

- detection limits

- quickness of response

- limited interference effects.

All instruments tested were within maintenance and calibration schedules established by CH2M-Hill. PNNL was given no specific performance criteria to work toward for the evaluation. Each instrument was stepped through operations that were deemed to be similar to those seen in the field. The sensors were tested as they were received from the field-no preliminary calibrations were performed and no special handling was done. It was assumed that the performance evaluation should reflect day-to-day operations seen by an industrial hygiene technician when he or she picked up the equipment. For example, the sample inlet filters installed in each instrument when they were received by PNNL, whether clean or exposed, were used in the testing. Tests were run with the charges found on the batteries, rather than taking time to charge them before testing.

The results of independent performance tests are often compared to the specifications supplied by the instrument manufacturers; however, those specifications are mostly very general. The calibration stickers on each sensor list sample ranges and tolerances. For the purpose of these tests, the tolerances (the apparent allowable uncertainties in measurement concentrations) given on the calibration stickers were used as performance criteria.

Emphasis was also placed on timely sensor response. If a concentration was released very quickly and lasts for only seconds (primarily because of outdoor wind gusts and directional shifts), would the sensor respond and correctly document this release? 
The following report describes each instrument tested (Section 2.0) and the test plans and study design (Section 3.0), provides test results (Section 4.0), and states conclusions (Section 5.0). Appendix A gives specifications of each instrument; Appendix B gives specifications for the mass flowmeters used in the study; Appendix C provides methods of accuracy and precision; and Appendixes D and E gives test data for gas lag-times and performance, respectively. 


\subsection{Sensor Descriptions}

This report provides testing results for six instruments that are used to monitor ammonia, nitrous oxide, and volatile total hydrocarbons. Table 2.1 lists the instruments tested and the test gases for which they were evaluated. The individual instruments are described in the following subsections.

Table 2.1. Instruments and Test Gases

\begin{tabular}{||l|l|l|}
\hline \multicolumn{1}{|c|}{ Gas Measured } & \multicolumn{1}{|c|}{ Model } & \multicolumn{1}{c|}{ Manufacturer } \\
\hline Total Hydrocarbons & RAE System \\
\hline & ppb RAE & RAE Systems \\
\hline & AREA RAE & Thermo Environmental Instruments \\
\hline & EZ-580 & Manning Systems, Inc. \\
\hline Ammonia & EC-P2 & Industrial Scientific Corporation \\
\hline & iTX & Thermo Environmental Instruments \\
\hline & MIRAN SapphIRe XL & \\
\hline Nitrous Oxide & \multicolumn{2}{|l}{} \\
\hline & MIRAN SapphIRe XL & Thermo Environmental Instruments \\
\hline & Bacharach 3010 & Bacharach, Inc. \\
\hline
\end{tabular}

\section{$2.1 \operatorname{ppbRAE}^{(\mathrm{a})}$}

The ppbRAE, shown in Figure 2.1, is a volatile organic compound (VOC) monitor that uses a photoionization detector (PID). It provides part-per-billion sensitivity of VOCs. The handheld unit aspirates a sample at $400 \mathrm{~mL} / \mathrm{min}$ into the sensing volume, where the stream is illuminated by a high voltage ( 9.8 or $10.6 \mathrm{eV})$ ultraviolet lamp (ppb-RAE Manual 2001). A fraction of the organic molecules absorb the high energy light and eject a negatively charged electron, thereby forming a positively charged molecular ion. The charged particles produce a current that is measured by the sensor electrodes.

The response from a PID is nonspecific, i.e., the instrument cannot tell what gas it is responding to. A compound's identity has to be known if quantitative results are desired. It can be calibrated for one compound, for example, isobutylene. Then, using calibration standards for other compounds, response factors can be determined so the other compounds can be quantified.

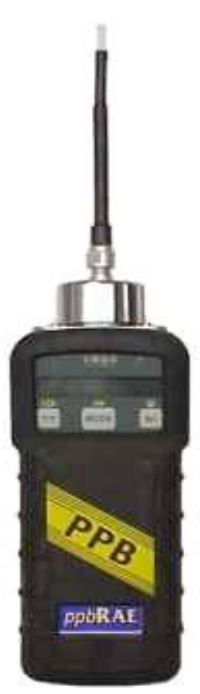

Figure 2.1. ppbRAE

(a) RAE Systems, Sunnyvale, CA. 
The ppbRAE uses a patented dual channel photoionization sensor. It is generally used with a particulate filter on the inlet probe. A small charcoal absorber can be attached to the inlet to remove most of the VOCs for zeroing the instrument. The response time (T90) is given as less than 5 seconds to indicate a concentration of $90 \%$ of full scale. The operational scales, sensitivity and operating parameters from the sales literature are summarized in Table 2.2. The instrument contains a data-logging capability, which facilitates the collection and downloading of measurement data. The unit can store eight two-point calibration curves. It also contains a table of response factors that can be used to adjust readings for a known gas.

Table 2.2. Characteristics of PID-based Instruments

\begin{tabular}{|c|c|c|}
\hline Manufacturer & RAE systems & Thermo Environmental \\
\hline Model & ppb RAE & OVM 580EZ \\
\hline Species detected & VOCs & VOCs \\
\hline Principal of operation & Photo ionization detector (PID) & PID \\
\hline Sample flow rate & $400 \mathrm{~mL} / \mathrm{min}$ & $275 \mathrm{~mL} / \mathrm{min}$ \\
\hline Operating Temperature & $14-113^{\circ} \mathrm{F}$ & not stated \\
\hline \multicolumn{3}{|l|}{$\mathrm{NH}_{3}$ range (resolution) } \\
\hline \multicolumn{3}{|l|}{$\mathrm{N}_{2} \mathrm{O}$ range (resolution) } \\
\hline VOC range (resolution) & 0-999 ppb (1ppb) & $\begin{array}{l}0-100 \mathrm{ppm}(0.1 \mathrm{ppm}) \\
\text { isobutylene }\end{array}$ \\
\hline VOC range (resolution) & 0.01-9.99 ppm (0.01 ppm) & $\begin{array}{l}100-2000 \mathrm{ppm}(1 \mathrm{ppm}) \\
\text { isobutylene }\end{array}$ \\
\hline VOC range (resolution) & 0.1-199.9 ppm (0.1 ppm) & \\
\hline Accuracy & $\pm 20 \mathrm{ppb}$ or $\pm 10 \%$ of reading & not stated \\
\hline Response time & $<5 \mathrm{sec}$ & $4 \mathrm{sec}$ \\
\hline $\begin{array}{l}\text { Calibration } \\
\text { requirements }\end{array}$ & daily check & $\begin{array}{l}\text { daily check and routine } \\
\text { calibration }\end{array}$ \\
\hline $\begin{array}{l}\text { Minimum detectable } \\
\text { amount }\end{array}$ & $5 \mathrm{ppb}$ & $0.1 \mathrm{ppm}$ benzene in air \\
\hline Dimensions (HWD) & $8.2^{\prime \prime} \times 3 "$ x 2" & $10^{\prime \prime} \times 4.2^{\prime \prime} \times 3.5^{\prime \prime}$ \\
\hline Weight & $19.5 \mathrm{oz}$ & $3 \mathrm{lb}$ \\
\hline
\end{tabular}

\subsection{Thermo Environmental 580EZ ${ }^{(\mathrm{a})}$}

The Model 580EZ, Figure 2.2, is a handheld organic vapor monitor with data-logging capability. The sensor is a PID and has a minimum detectable reading of $0.1 \mathrm{ppm}$ in the lowest range $(0-100 \mathrm{ppm})$. The available PID lamps are at the $10.6 \mathrm{eV}$ and $11.8 \mathrm{eV}$ energy levels (Model 580 EZ Manual 1998).

(a) Thermo Environmental Instruments, Inc. Franklin, MA. 
The ambient air is drawn in through a probe and a water/particulate trap. It then passes through the detector, which houses the PID lamp, a "bias" electrode, and a collector. Because the PID detector is essentially nondestructive, the sample stream expelled from the instrument can feed a polymer bag or absorbent tube for compound identification offline. An optional charcoal trap can be used on the inlet to check the zero in the field.

Two-point or three-point calibrations can be stored in memory. A three-point calibration is used to account for nonlinearity and improve accuracy if a wide concentration range (exceeding a 500-ppm range) is expected. A table of response factors can be stored in the 580EZ's memory. Table 2.2 summarizes the instrument's capabilities, based on information given in its sales literature.

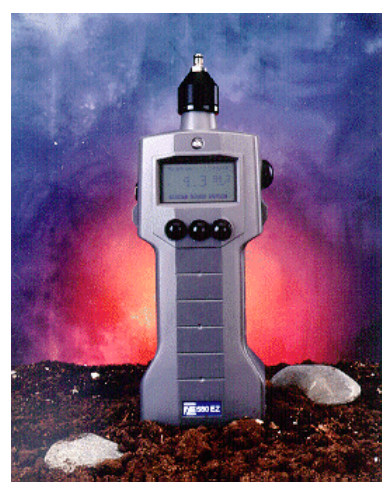

Figure 2.2. Thermo Environmental $580 \mathrm{EZ}$

Two-point or three-point calibrations can be stored in memory. A three-point calibration is used to account for nonlinearity and improve accuracy if a wide concentration range (exceeding a 500-ppm range) is expected. A table of response factors can be stored in the 580EZ's memory. Table 2.2 summarizes the instrument's capabilities, based on information given in its sales literature.

\subsection{AreaRAE $^{(\mathrm{a})}$}

The AreaRAE, shown in Figure 2.3, is a portable multi-gas monitor with display and data-logging capability (Area-RAE Manual 2002). It is configurable with up to five sensors. The sensors available include:

- a PID detector for VOCs, using either 10.6 or 11.7 eV ultraviolet lamps

- substance-specific electrochemical sensors (ES) for inorganic compounds

- a catalytic bead sensor for combustible gases in the 0-100 LEL range

- an electrochemical sensor for oxygen.

The sampled air is drawn through a filter and distributed through the sensors in parallel. Table 2.3 summarizes key operating parameters and capabilities based on the manufacturer's literature. Ammonia can be monitored with either a PID or an ES; however, with different ranges of sensitivity. An ammonia-specific ES is available. A PID sensor is not specific for ammonia and VOCs would interfere with ammonia measurements.

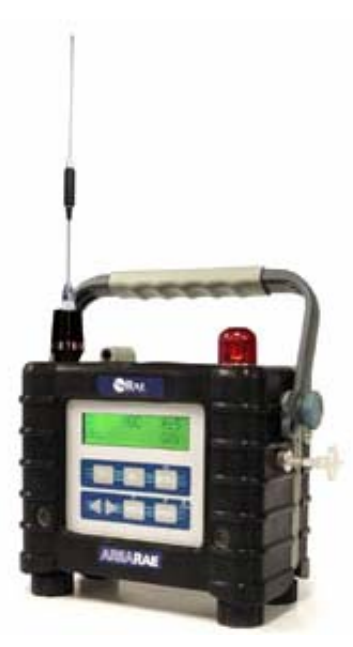

Figure 2.3. AreaRAE

(a) RAE Systems, Sunnyvale, CA. 
Table 2.3. Characteristics of Instruments with Electrochemical Sensors

\begin{tabular}{|c|c|c|c|}
\hline $\begin{array}{l}\text { Manufacturer } \\
\text { Model }\end{array}$ & $\begin{array}{l}\text { Industrial Scientific } \\
\text { ITX Multi-Gas Monitor }\end{array}$ & $\begin{array}{l}\text { Manning Systems } \\
\text { EC-P2 Gas Sensor }\end{array}$ & $\begin{array}{l}\text { RAE systems } \\
\text { AreaRAE }\end{array}$ \\
\hline Species detected & Combustible and toxic gases & Toxic gases & $\begin{array}{l}\text { VOCs, oxygen, CO, } \\
\text { Ammonia, other inorganics }\end{array}$ \\
\hline Principal of operation & $\begin{array}{l}\text { electrochemical and catalytic } \\
\text { diffusion }\end{array}$ & electrochemical sensors & $\begin{array}{l}\text { PID, LEL, } \mathrm{O}_{2} \text {, catalytic } \\
\text { bead, and electrochemical } \\
\text { sensors }\end{array}$ \\
\hline Sample flow rate & $1000 \mathrm{~mL} / \mathrm{min}$ & $236 \mathrm{~mL} / \mathrm{min}$ & 300 or $400 \mathrm{~mL} / \mathrm{min}$ \\
\hline $\begin{array}{l}\text { Operating } \\
\text { Temperature Range }\end{array}$ & $\begin{array}{l}-4-122^{\circ} \mathrm{F} \text { for toxics and } \\
\text { oxygen, } 32-104^{\circ} \mathrm{F} \text { for LEL } \\
\text { sensor }\end{array}$ & $0-120^{\circ} \mathrm{F}$ & $-4-113^{\circ} \mathrm{F}$ \\
\hline $\begin{array}{l}\mathrm{NH}_{3} \text { range } \\
\text { (resolution) }\end{array}$ & 0-200 ppm (1 ppm) & 0-500 ppm (1 ppm) & 0-50 ppm (1ppm) \\
\hline \multicolumn{4}{|l|}{$\begin{array}{l}\mathrm{N}_{2} \mathrm{O} \text { range } \\
\text { (resolution) }\end{array}$} \\
\hline $\begin{array}{l}\text { VOC range } \\
\text { (resolution) }\end{array}$ & 10000 ppm (50 ppm) & & $\begin{array}{l}\text { 0-200 ppm (0.1 ppm) \& } \\
\text { 200-2000 ppm (1ppm) }\end{array}$ \\
\hline $\begin{array}{l}\text { LEL range } \\
\text { (resolution) }\end{array}$ & $0-100 \%$ LEL (1\%) & & 0-100\% LEL (1\%) \\
\hline $\mathrm{O}_{2}$ range (resolution) & Oxygen $0-30 \%$ vol (0.1\%) & Oxygen $0-25 \%$ & $0-30 \%(0.1 \%)$ \\
\hline CO range (resolution) & 999 ppm (1 ppm) & $0-1000 \mathrm{ppm}$ & 0-500 ppm (1 ppm) \\
\hline $\begin{array}{l}\mathrm{H}_{2} \mathrm{~S} \text { range } \\
\text { (resolution) }\end{array}$ & 499 ppm (1 ppm) & $0-200 \mathrm{ppm}$ & 0-100 ppm (1 ppm) \\
\hline NO range (resolution) & 499 ppm (1 ppm) & $0-500 \mathrm{ppm}$ & 0-250 ppm (1 ppm) \\
\hline $\mathrm{Cl}_{2}$ range (resolution) & 0.2-50 ppm (1 ppm) & $0-5 \mathrm{ppm}$ & 0-10 ppm (0.1 ppm) \\
\hline $\begin{array}{l}\mathrm{ClO}_{2} \text { range } \\
\text { (resolution) }\end{array}$ & 0-1 ppm (0.01 ppm) & $0-5$ ppm & \\
\hline Accuracy & not stated & generally $5 \%$ of reading & not stated \\
\hline Response time & not stated & $\mathrm{T}_{90}$ of final value $2 \mathrm{~min}$ & $\begin{array}{l}\text { 10-sec VOCs, } 20 \text { - to } 60-s \\
\text { inorganic, } 150-\text { ammonia, } \\
\text { 15-s Oxygen }\end{array}$ \\
\hline $\begin{array}{l}\text { Calibration } \\
\text { requirements }\end{array}$ & monthly field calibration & every 6 months & daily check \\
\hline Dimensions (HWD) & $4.8^{\prime \prime} \times 3.2^{\prime \prime} \times 1.7^{\prime \prime}$ & $8.5^{\prime \prime} \times 5^{\prime \prime} \times 3.5^{\prime \prime}$ & $9.2^{\prime \prime} \times 5 " \times 9.2^{\prime \prime}$ \\
\hline Weight & $18.5 \mathrm{oz}$ & $1.8 \mathrm{lb}$ & $8.5 \mathrm{lb}$ \\
\hline
\end{tabular}




\section{4 iTX Multi-Gas Monitor ${ }^{(a)}$}

The ITX handheld toxic gas monitor, shown in Figure 2.4, accepts from 1 to 6 sensors at a time. Combustible gases (as methane) are measured with a catalytic diffusion sensor. Oxygen and toxic gases are measured with ES sensors (iTX Manual 2003). The user can change sensors in the field, but the newly installed sensors must be calibrated. The unit has datalogging capability. Specific parameters and characteristics for the unit as configured for these tests (for ammonia monitoring) are given in Table 2.3.

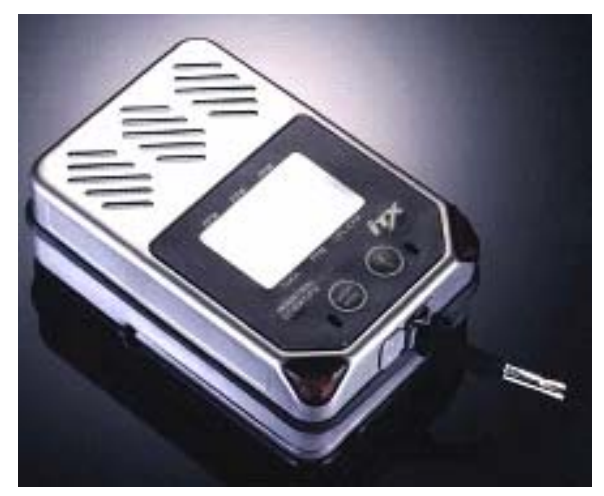

Figure 2.4. ITX Multigas Monitor

\subsection{Manning EC-P2 Gas Sensor ${ }^{(\mathrm{b})}$}

The EC-P2, shown in Figure 2.5, is another handheld gas monitor that uses ES sensors for specific gases. Individual ES sensors are equipped with calibration and alarm data in memory. This obviates the need for recalibration or reprogramming each time a sensor is changed in the field to monitor a different compound. The unit has data-logging capability. For these tests, the unit was configured to monitor ammonia. Operating characteristics (EC-P2 Manual) for this configuration are listed in Table 2.3.

\subsection{MIRAN SapphIRe 205BXL ${ }^{(\mathrm{c})}$}

The MIRAN SapphIRe, shown in Figure 2.6, is a portable ambient air analyzer containing a single-beam infrared spectrophotometer. Compounds absorb infrared radiation at characteristic wavelengths that resonate with molecular vibration frequencies. Because each type of molecular bond vibrates at a characteristic wavelength, if a molecule is exposed to electromagnetic energy at the same wavelength, some of the energy is absorbed by the bond as it resonates with the impinging energy. Because most compounds have multiple types of bonds, they often have multiple absorption wavelengths. The software in the instrument can identify the presence of compounds by monitoring either one certain wavelength, a set of wavelengths, or an entire spectrum. While the absorption wavelengths identify the compounds, the intensity identifies the concentration.

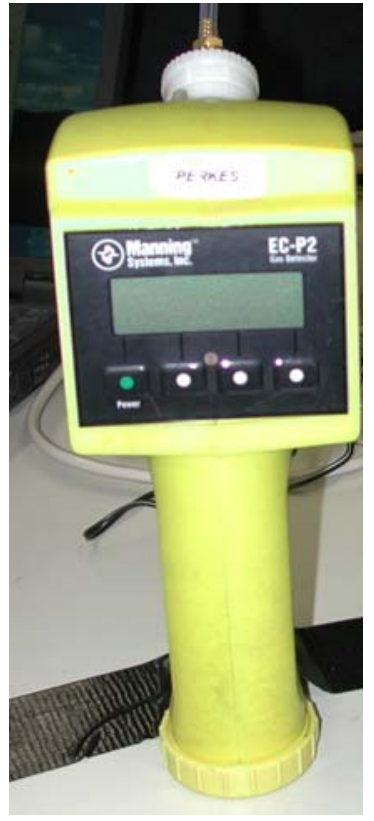

Figure 2.5. Manning EC-P2

(a) Industrial Scientific Corporation, Oakdale, PA.

(b) Manning Systems, Inc., Lenexa, KS.

(c) Thermo Electron Corporation, Environmental Instruments, Franklin, MA. 
Compounds with absorbance in the wavelength range of 7.7 to 14.1 microns can be measured with the MIRAN's linear variable wavelength IR generator. From a scan of this range of wavelengths, the onboard compound library and computational algorithms can identify specific compounds in a mixture, even if there is some overlap in the absorption peaks. The instrument can generate narrow wavelength bands to quantify the concentration of an expected compound. Also, built-in fixed band pass filters enable monitoring of selected compounds below the variable wavelength range, such as nitrous oxide.

The user can select illumination pathlengths of 0.5 and

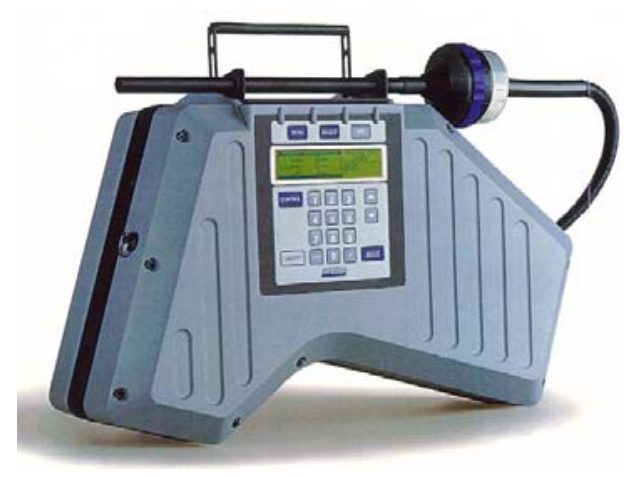

Figure 2.6. MIRAN SapphIRe 205 BXL 12.5 meters. The instrument has a library of single and multicomponent calibrations. Measurement ranges and sensitivities vary with the compounds of interest. The MIRAN can perform temperature, pressure, humidity, and reference-gas compensations to the readings. The sample cell volume is $2.23 \mathrm{~L}$ and the sample flowrate is $14 \mathrm{Lpm}$. The sample cell windows are silver bromide. A particulate filter is used on the polyethylene intake wand to keep the sample cell clean. A chemical filter cartridge is added to the intake wand for setting zero during startup. Table 2.4 summarizes some of the operating parameters for the MIRAN. 
Table 2.4. Characteristics of the MIRAN IR-based Instrument

\begin{tabular}{|c|c|}
\hline Manufacturer & Thermo Electron \\
\hline Model & SapphIRe \\
\hline Species detected & Organic and inorganic gases \\
\hline Principal of operation & $\begin{array}{l}\text { infrared absorbance with } 0.5 \mathrm{~m} \text { and } \\
12.5 \mathrm{~m} \text { pathlengths }\end{array}$ \\
\hline Sample flow rate & $14 \mathrm{Lpm}$ \\
\hline Operating Temp. & $35-120^{\circ} \mathrm{F}$ \\
\hline $\mathrm{NH}_{3}$ range (resolution) & $0.7-500 \mathrm{ppm} \pm 20 \%$ reading \\
\hline $\mathrm{N}_{2} \mathrm{O}$ range (resolution) & $0.04-100 \mathrm{ppm} \pm 10 \%$ reading \\
\hline \multicolumn{2}{|l|}{ VOC range (resolution) } \\
\hline Acetone range (resolution) & $5-2000 \mathrm{ppm} \pm 5 \%$ reading \\
\hline Benzene range (resolution) & $2-200 \mathrm{ppm} \pm 10 \%$ reading \\
\hline Hexane range (resolution) & $0.25-500 \mathrm{ppm} \pm 25 \%$ reading \\
\hline Toluene range (resolution) & $\begin{array}{l}1-200 \text { ppm } \pm 15 \% \text { rdg } \& 4-1000 \\
\text { ppm } \pm 10 \% \text { rdg (long path); } 18-1000 \\
\pm 10 \% \text { rdg (short path) }\end{array}$ \\
\hline Xylene range (resolution) & $\begin{array}{l}1.3-200 \text { ppm \& } 7-2000 \text { ppm } \pm 15 \% \\
\text { rdg (long path); } 30-2000 \pm 10 \% \text { rdg } \\
\text { (short path) }\end{array}$ \\
\hline CO range (resolution) & $0.90-250 \mathrm{ppm} \pm 10 \%$ rdg \\
\hline Response time & $\begin{array}{l}\mathrm{T}_{90} \text { of final reading } 18 \mathrm{~s}, 40 \text { seconds } \\
\text { for four air changes in cell, } 20 \mathrm{~s} \text { for } \\
\text { single wavelength }\end{array}$ \\
\hline Dimensions (HWD) & $21.8 "$ x 14.4" x $7.6 "$ \\
\hline Weight & $24 \mathrm{lb}$ \\
\hline
\end{tabular}

\subsection{Bacharach 3010}

The Bacharach Monitor 3010 measures $\mathrm{N}_{2} \mathrm{O}$ gas using infrared methods (Bacharach Manual 2003). See Table 2.5 for specifications and Figure 2.7 for an illustration. 
Table 2.5. Characteristics of the Bacharach 3010

\begin{tabular}{|l|l|}
\hline Range and resolution & 0 to 1,000 ppm for $\mathrm{N}_{2} \mathrm{O}, 5$-ppm resolution. \\
\hline Accuracy & $\pm 10 \%$ of reading or \pm 10 ppm, whichever is greater \\
\hline Zero drift & $\begin{array}{l}\text { Typically }<20 \text { ppm over } 8 \text { hours a constant } \\
\text { Temperature }\end{array}$ \\
\hline Battery life & Up to 8 hours per charge \\
\hline Battery recharge time & Approximately 2 hours \\
\hline Sensor & Dual wavelength IR cell \\
\hline Operating temperature & 59 to $77^{\circ} \mathrm{F}$ (15 to $\left.25^{\circ} \mathrm{C}\right)$ \\
\hline Relative humidity & 0 to $99 \%$, non-condensing \\
\hline Dimensions & 5.5 inches long, 2.6 inches wide, 0.8 inch high \\
\hline Weight & 8 ounces (230 grams) \\
\hline Construction & High impact ABS case \\
\hline
\end{tabular}

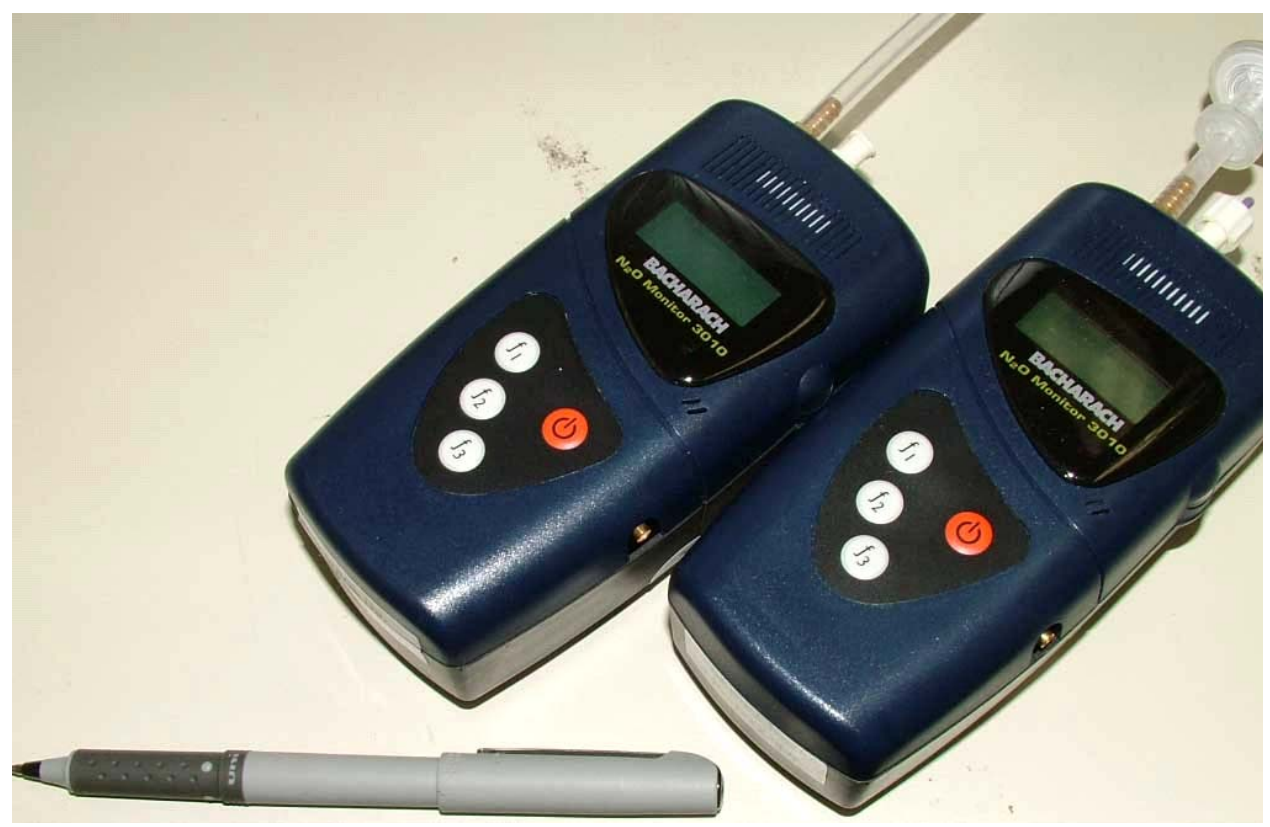

Figure 2.7. Bacharach $\mathrm{N}_{2} \mathrm{O}$ Monitor 3010 


\subsection{Test Plans and Study Design}

The performance tests described in this report were conducted from March to September of 2004 on the commercial sensors described in Section 2.0. The first series of tests is denoted the General Stepped Tests. In this series, the instruments were exposed to steady gas concentrations in stepwise fashion. Each test run started at zero ppm and progressed to higher concentrations. Each concentration level was held constant for several minutes. The objectives were to assess

- the response to zero concentration

- the accuracy and precision to constant concentration and

- the warm-up time from being switched on to the first reading.

Following the General Tests, additional tests, called Transient Tests, were performed to demonstrate the response of each instrument to rapid concentration changes. Gas-monitor sensors used in the field can be subjected to instantaneous concentration changes, possibly caused by wind-direction changes and gusts. In the Transient Tests, selected sensors were subjected to concentration changes in the laboratory that were measured in time frames of seconds. The methods for these two series of tests are detailed in this section.

\subsection{Methods for General Stepped Releases}

The General Test method was to expose one or more instruments to known concentrations of the challenge gases. The known gas concentrations were created from purchased standards diluted in a controlled manner with pure air. For the first tests, the known concentrations were created in a collapsible chamber, from which the test instrument drew a sample stream. However, this method became cumbersome, so a dynamic dilution system was used for the remainder of the tests. In this system, one or more instruments could be simultaneously exposed to progressively increasing gas concentrations. Here the capabilities for sensors to respond to reasonably quick concentration changes was evaluated along with assessments of precision and accuracy. These tests severely taxed most instruments because of their intrinsic delayed response times.

The monitors' accuracy was assessed by determining the degree of agreement with compressed gas standards blended with pure air. Precision was assessed in terms of the repeatability of the measurements. Interference effects were qualitatively addressed by challenging the monitors with the other available gas standards. Zero drift was assessed by supplying the monitors with purified laboratory air.

The equipment and methodology used in the tests, including the zero air delivery system, the challenge gases, the collapsible chamber, and the dynamic dilution system, are described below. 


\subsubsection{Zero Air Delivery System}

The Aadco $737^{(\mathrm{a})}$ zero air systems in the Chamber Laboratory, shown in Figure 3.1, can reliably provide dilution air, in quantities of several hundred liters per minute, that is essentially devoid of all hydrocarbons including methane as well as oxidants and acids (e.g., sulfur oxides, nitrogen oxides, carbon monoxide) at concentrations above part-per-trillion levels. High-purity nitrogen gas, also available in the lab, was used during several tests to verify the zero readings.

Compressed air delivered to the Chamber Lab is supplied by an oil-less rotary screw pump. This air is processed to remove any oil, particles, water, or organic carbon compounds prior to delivery to the Aadco systems. The Aadco system uses molecular sieves and a thermo-oxidizer to clean the air to approximately 99.9995 percent pure air. Only nitrogen, oxygen, and a small amount of carbon dioxide are allowed to pass. This purified air contains 20 to 21 percent oxygen.

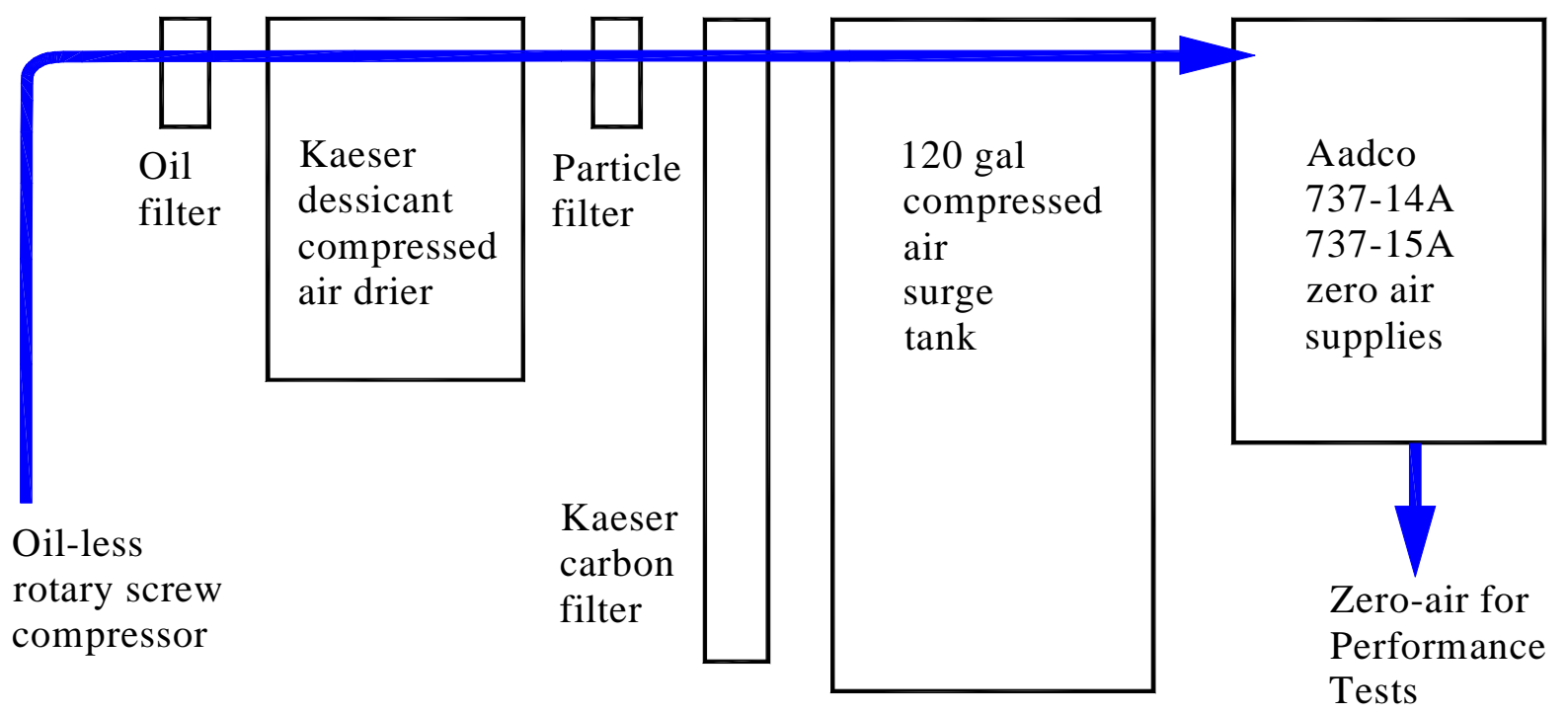

Figure 3.1. Aadco Pure Air System in the PNNL Chamber Laboratory

\subsubsection{Challenge Gases}

The chemicals shown in Table 3.1, selected as the challenge gases for the sensors, were chosen from a larger list provided by CH2M-Hill Hanford Group because they were readily available from suppliers.

Certified standards of the ammonia, nitrous oxide, and a blend of the six hydrocarbons were made up by Matheson Tri-gas Incorporated. The "certified-plus" gases were obtained as the gas in a balance of zero air. The concentration of these gas standards was established by the manufacturer within the accuracies shown in Table 3.2.

(a) Advanced Analytical Device Company, Cleves, Ohio. 
Table 3.1. Physical Properties of Gases Selected for Performance Tests

\begin{tabular}{|l|c|c|c|c|c|c|c|c||}
\hline \hline Chemical & $\begin{array}{c}\text { Chemical } \\
\text { Formula }\end{array}$ & CAS \# & $\begin{array}{c}\text { Formula } \\
\mathbf{W t} \\
(\mathbf{g} / \mathbf{m o l e})\end{array}$ & $\begin{array}{c}\text { Density } \\
(\mathbf{g} / \mathbf{m L})\end{array}$ & $\begin{array}{c}\text { m.p. } \\
\left({ }^{\mathbf{0}} \mathbf{C}\right)\end{array}$ & $\begin{array}{c}\text { b.p. } \\
\left({ }^{\mathbf{0}} \mathbf{C}\right)\end{array}$ & $\begin{array}{c}\text { Vapor } \\
\text { Vansity }\end{array}$ & $\begin{array}{c}\text { pressure } \\
\text { (torr) }\end{array}$ \\
\hline Ammonia & $\mathrm{NH}_{3}$ & $7664-41-7$ & 17.030 & 0.6818 & -78 & -33 & 0.597 & 7,510 \\
\hline Nitrous oxide & $\mathrm{N}_{2} \mathrm{O}$ & $10024-97-2$ & 44.013 & & -91 & -87 & 1.53 & 42,900 \\
\hline Hexane* & $\mathrm{C}_{6} \mathrm{H}_{14}$ & $110-54-3$ & 86.177 & 0.6548 & -95 & 69 & 3 & 130 \\
\hline Benzene* & $\mathrm{C}_{6} \mathrm{H}_{6}$ & $71-43-2$ & 78.113 & 0.8786 & 5.5 & 80 & 2.77 & 95 \\
\hline Toluene* & $\mathrm{C}_{6} \mathrm{H}_{5} \mathrm{CH}_{3}$ & $108-88-3$ & 92.140 & 0.8670 & -93 & 111 & 3.14 & 22 \\
\hline Xylenes* & $\mathrm{C}_{6} \mathrm{H}_{4}\left(\mathrm{CH}_{3}\right)_{2}$ & $1330-20-7$ & 318.501 & 0.8620 & -50 & 140 & 3.7 & 5.1 \\
\hline Ethanol* & $\mathrm{C}_{2} \mathrm{H}_{5} \mathrm{OH}$ & $64-17-5$ & 46.069 & 0.7890 & -114 & 78 & 1.6 & 59 \\
\hline Acetone* & $\mathrm{CH}_{3} \mathrm{COCH}_{3}$ & $67-64-1$ & 58.080 & 0.7857 & -94 & 56 & 2 & 181 \\
\hline
\end{tabular}

Table 3.2. NIST Traceable Certified Calibration Gases used in Tests (Matheson Tri-gas)

\begin{tabular}{|l|c|c|l|l||}
\hline Certified Gas & $\begin{array}{c}\text { Concentration } \\
\text { (ppm) }\end{array}$ & $\begin{array}{c}\text { Certified } \\
\text { Accuracy }\end{array}$ & $\begin{array}{c}\text { Cylinder } \\
\text { Number }\end{array}$ & Valid \\
\hline Ammonia & 1034 & $\pm 2 \%$ & SX32577 & $4 / 5 / 04$ to 3/25/05 \\
\hline Hydrocarbons & & & & $4 / 6 / 04$ to $4 / 6 / 05$ \\
\hline Acetone & 103.92 & $\pm 2 \%$ & SX-16387 & $4 / 6 / 04$ to $4 / 6 / 05$ \\
\hline Benzene & 97.56 & $\pm 2 \%$ & SX-16387 & $4 / 6 / 04$ to $4 / 6 / 05$ \\
\hline Ethanol & 101.60 & $\pm 2 \%$ & SX-16387 & $4 / 6 / 04$ to $4 / 6 / 05$ \\
\hline Hexane & 100.73 & $\pm 2 \%$ & SX-16387 & $4 / 6 / 04$ to $4 / 6 / 05$ \\
\hline Toluene & 99.92 & $\pm 2 \%$ & SX-16387 & $4 / 6 / 04$ to $4 / 6 / 05$ \\
\hline Xylenes & 98.87 & $\pm 2 \%$ & SX-16387 & $4 / 6 / 04$ to $4 / 6 / 05$ \\
\hline Nitrous oxide & 101 & $\pm 2 \%$ & AS60518 & $4 / 6 / 04$ to 4/6/07 \\
\hline
\end{tabular}

\subsubsection{Collapsible Chamber}

Early in the performance testing, a 700-liter Teflon chamber, diagrammed in Figure 3.2, was filled using blended gas-zero air streams to provide a supply of a test gas at a desired concentration. To maintain a constant concentration, the chamber collapses as the test instrument draws air from it. Although this procedure worked, it required considerable time to purge the Teflon chamber in order to obtain a baseline level prior to refilling it for the next experiment. Consequently, the remaining experiments were conducted using the dynamic dilution system.

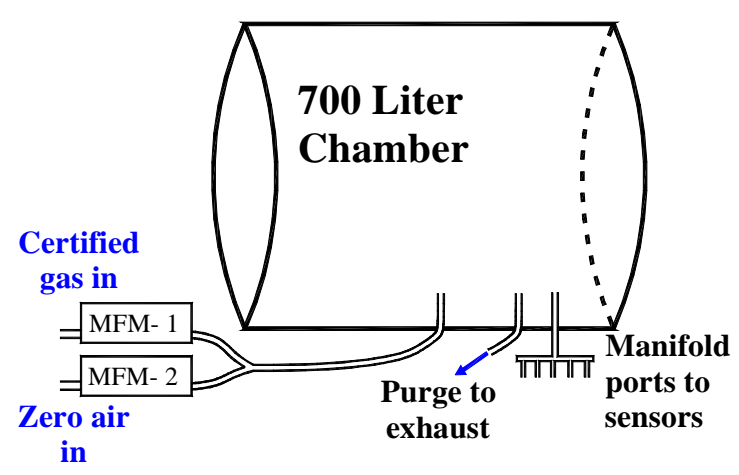

Figure 3.2. Schematic of 700-liter Chamber 


\subsubsection{Dynamic Dilution System}

The dynamic dilution system supplied known gas and pure air streams to a mixer or a simple manifold that allowed the monitors to sample the same gas. The experimental setup, shown schematically in Figure 3.3, was essentially the same for both General and Transient Tests. In the General Stepped Tests the sample lines were generally longer. A manual precision needle valve was used instead of a pneumatic valve. The manifold, shown in Figure 3.3 for Transient Tests, consisted of a 9.5-inch length of thinwalled, 3/4-inch-diameter (ID) 316 stainless steel tubing, with 1/4-inch (OD) tubing connections on each end. The manifold had three arms made of 1/4-inch-diameter tubing: two closely spaced tubes are the sampling points from which sample gas was withdrawn by the monitors.

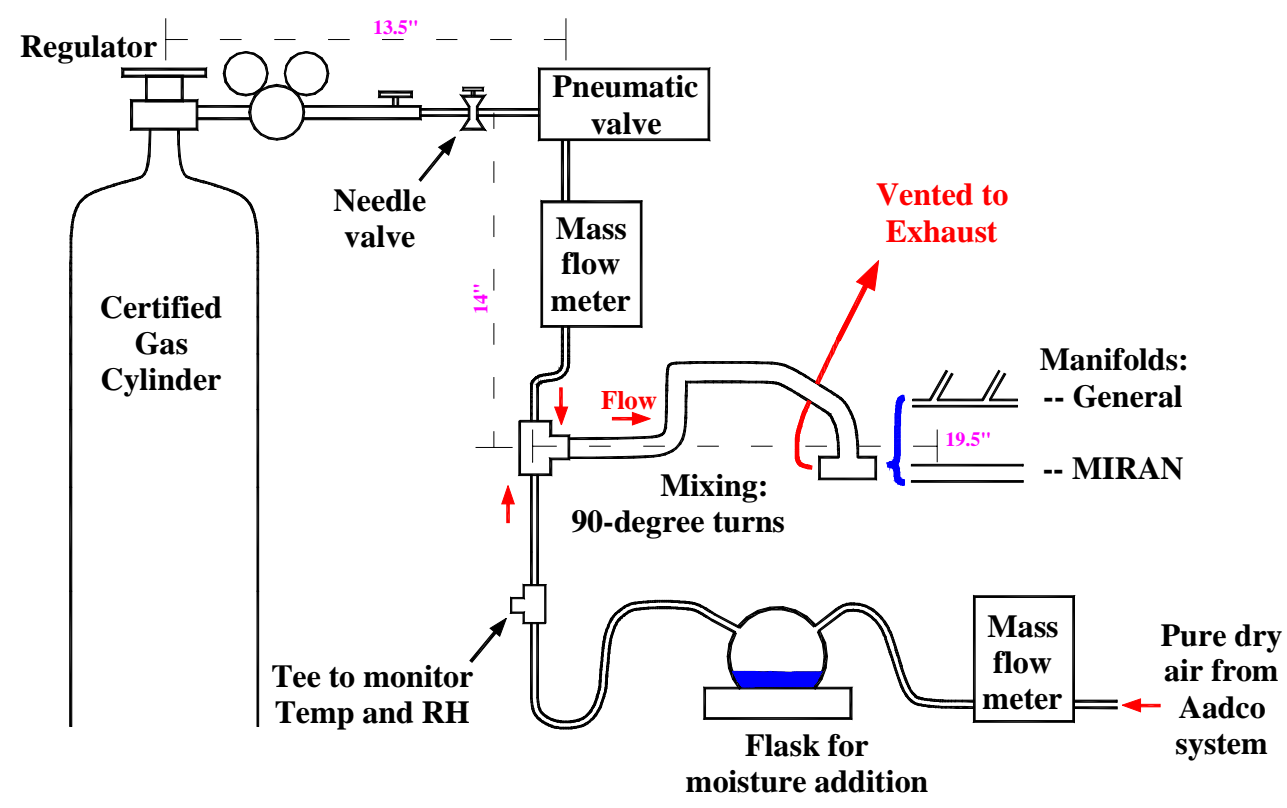

Figure 3.3. Dynamic Dilution System as Used for Transient Tests

The excess gas mixtures were vented through a "Tee" connection on the exit of the manifold. Needle valves were connected to this "Tee," as shown in Figure 3.3. One- and two-stage Swagelok needle valves were used to adjust standard gas flows for blending through the dilution system shown in Figure 3.3. The regulator on the Aadco supply system was sufficient to adjust the zero air flow. The two-staged valves were used to meter desired low-flow dilutions.

Figure 3.4 shows the initial dilution manifold used for the stepped chamber tests. A manifold with a higher flowrate capacity was required for the MIRAN testing, so a new manifold was built with larger diameter plastic tube fittings, as shown in Figure 3.5.

The delivered calibration gas concentration was controlled by the flowmeters used to control the flow of standard and dilution streams. Certified mass flowmeters were used for this purpose. Details of the units used for this purpose are given in Appendix B. 


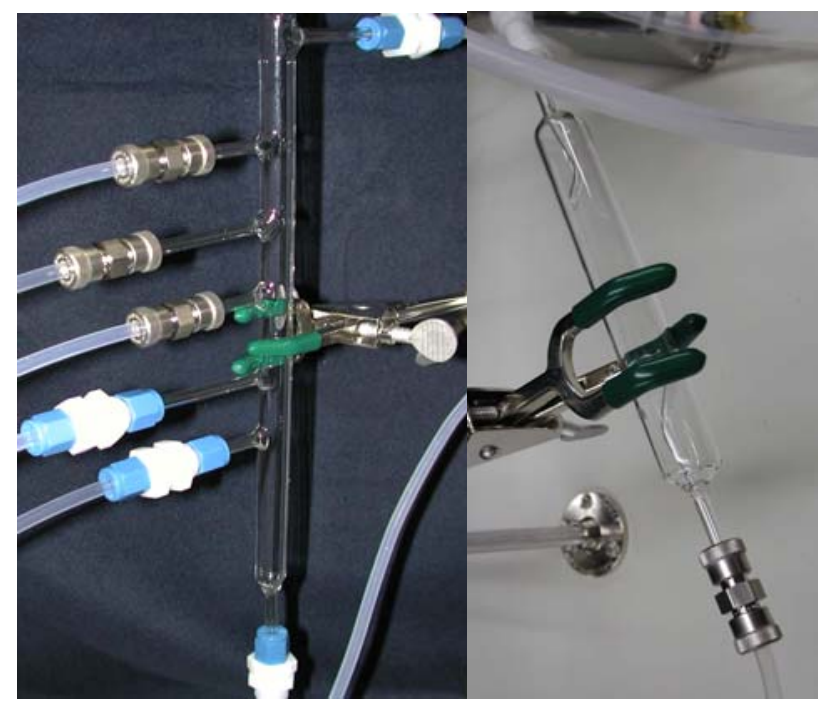

Figure 3.4. First Glass Manifold with Five Ports and Mixing Column

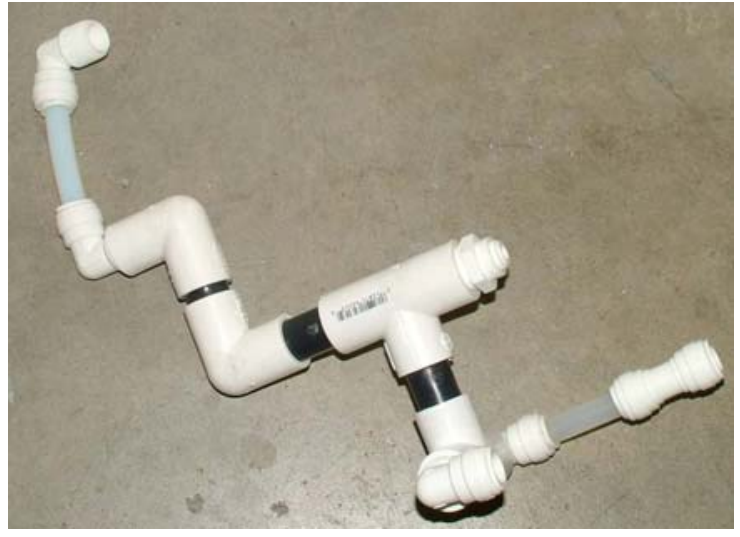

Figure 3.5. Second-Generation Manifold Constructed of PVC and ABS Plastic Fittings and Teflon Tubing

Initially, all sample transfer lines from the dynamic diluter to the instruments were constructed of Teflon or lined with Teflon. As testing progressed, two exceptions were allowed: 1) for nitrous oxide and hydrocarbon tests, it made no difference whether Teflon, plastic, or stainless steel lines were used, and 2) for ammonia, there was an apparent absorption on the Teflon sample line surfaces. Marrin (2004) recommended using stainless steel fittings and short sample lines for tests involving low part-per-million ammonia concentrations. Mukhtar et al. (2003) have tested the loss of ammonia at low ppm concentrations when flowing through Teflon lines. Interestingly, they found that about $1 \mathrm{ppm}$ of ammonia was lost regardless of the length of tubing used or the inlet concentration. Mukhtar et al. also found that using low density polyethylene plastic tubing resulted in significant sample loses. Similar test results were not found for the flow of ammonia through stainless steel. A number of corrosion fact sheets found on the internet (e.g., www.fpsmith.com/sscorrs.htm) show that stainless steel is adequate for contact with ammonia. However, the site http://fantes.com/stainless_steel.htm recommends against cleaning stainless steel cookware with ammonia. Nonetheless, as the work progressed, sample lines in contact with the test gases were switched to stainless steel. Also, the MIRAN instruments had a requirement for a line and fitting internal diameter of at least $1 / 2$-inch to minimize the possibility of a drop in inlet flow, so there was a shift from $1 / 4$-inch to larger bore tubing and fittings.

\subsubsection{Instrument Sampling Filters}

Most of the instruments were delivered to PNNL with filters to be used to treat the sample stream drawn into the instrument. The filters are used to remove particles from the sample stream. These filters were of two types. The first type used with most of the instruments was a 25-mm diameter Zefluor ${ }^{\mathrm{TM}}$ filters (P/N P5PL025, $1.0 \mu \mathrm{m}$ ) in a white in-line filter holder, shown in Figure 3.6. 


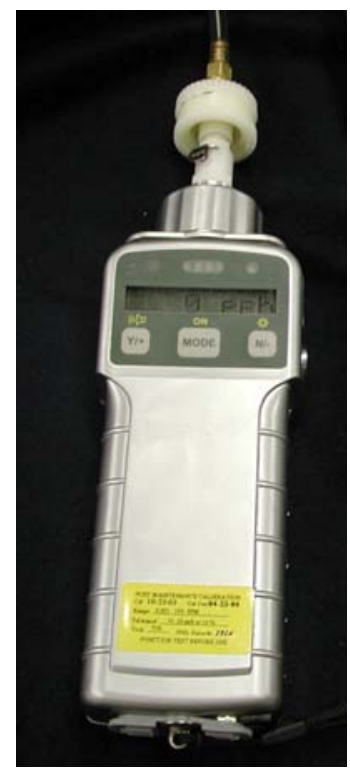

Figure 3.6. ppb-RAE with 25-mm Filter Holder
Larger chemical and particulate filters (Figure 3.7) were supplied with the MIRAN instruments. The instruments tested were newly purchased and were supplied with new chemical and particulate filters, which were protected within Ziplok plastic bags to prevent environmental contamination. The chemical filters are of particular note because they are used in the field to zero the MIRAN instrument. The supplied chemical filters were kept in ziplok bags to minimize their exposure to air when not in use. These filters were used in early tests but not in later tests because they could not match the zero levels obtained using Aadco zero air. A discussion of these filters is found in Section 4.0 below.

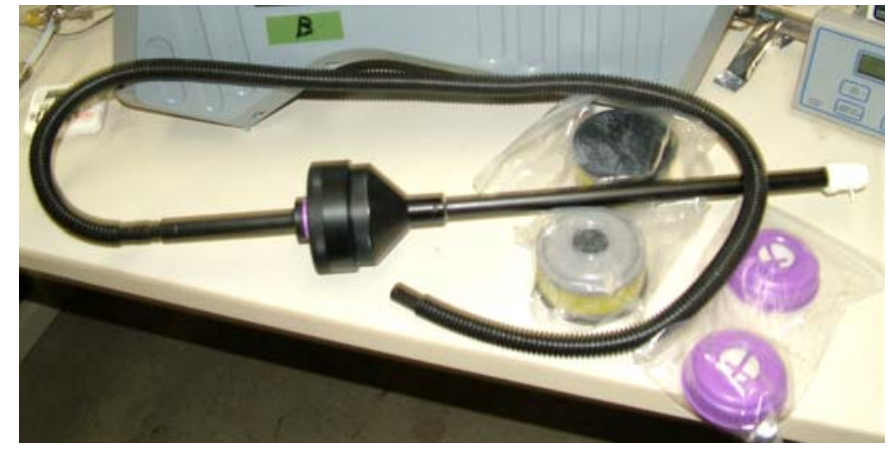

Figure 3.7. Larger Filters Used on MIRAN Analyzers

\subsubsection{Test Protocol}

The instruments under test were connected to the collapsible chamber or the manifold of the dynamic dilution system. Test gas was blended prior to starting the instruments. The instruments were initially zeroed using Aadco pure zero air before the test gas was added in progressively increasing concentrations with time. The concentration was held steady at each target concentration for 2 to 10 minutes while instrument readings were obtained, usually at 1-minute intervals. Figure 3.8 is an example of the series of readings obtained in such an exposure run.

When tests were conducted and extra manifold ports were available, other sensors were set up and operated to observe their responses to gases that they were not designed to measure. These tests were limited because only three gases were used (ammonia, a hydrocarbon mixture, and nitrous oxide). In rigorous interference testing, gases with similar chemical structures or homologous hydrocarbons that are expected to be present in the measurement area would be used. In most cases, the additional sensors were simply added to available manifold ports and operated through the series of concentration challenges. In other runs, after the designated gas challenges were completed, other test gases were introduced to observe if the sensors responded.

The manifold design called for a continuous flow of zero air through the manifold system that was sufficient to exceed the combined sample flow requirements of all sensors. So, prior to supplying a test 


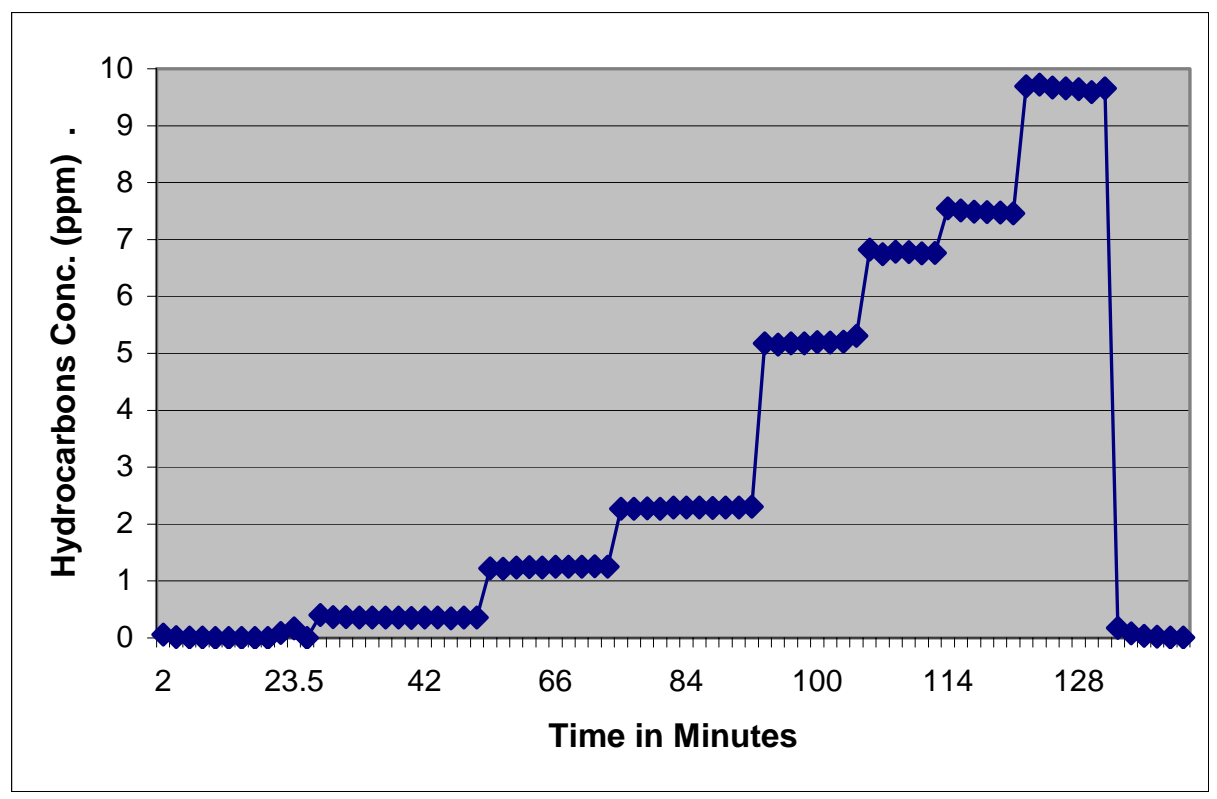

Figure 3.8. Illustration of ppb-RAE Challenge at Hydrocarbon Levels

gas and or an interferent gas, the instruments should have displayed a stable baseline reading. At least 2 minutes of stable baseline readings were observed before any tests were conducted. A positive chemical interference reading was interpreted as a drift in readings for over 2 minutes, either up or down in concentration from that observed prior to the addition of the second gas.

Following the challenges, the instruments were operated on zero air to verify that they returned to a stable baseline reading similar to that seen prior to the testing. If there was a question, the gas and interferent gas challenge were repeated.

Performance tests began when the commercial instruments were received, inspected, and operated by PNNL staff so that each monitor's performance could be assessed. PNNL staff became familiar with the monitors largely from using online manuals and by inspections of the sensors. Some training was provided by CH2M-Hill staff as the instruments were delivered. Technical service representatives of the manufacturer of each sensor were contacted by phone for an overview of each instrument type.

Log books were used to record the challenge concentrations and setup conditions for each test. To the extent possible, tests were run using multiple sensors, whether they responded to the test gas or not, attached to a common manifold. This practice expedited the tests when one or more sensors responded to a test gas, and it allowed for information on interference characteristics of nonresponsive test sensors. However, it required manually recording "simultaneous" 1-minute interval instrument readings from instrument displays for the several instruments by more than one staff member. This caused a problem with recording pertinent information in log books because multiple loose sheets were needed to record the data, these are included in Appendix A of this report. 
The instrument accuracy and precision were calculated following standard statistical methods, as outlined in Appendix C.

\subsection{Method for Transient Release Test}

This test was designed to demonstrate the performance of industrial hygiene field-instrument performance for transient releases. The simulations were designed to test the sensor response to a mix of hydrocarbons, ammonia, and nitrous oxide over a range of concentrations in order to answer the question, "How effectively can the instruments detect transient releases?”

The test method and equipment were adapted from the General Tests described above. The key difference was that the instruments were exposed to pulses of the challenge gases. The duration of the pulses and the concentration levels were varied. The key result was the response time. Although it is normal for the instrument manufacturers to reference the T90 (the response time required to rise to $90 \%$ of full-scale), the full-scale concentrations are not of value from an industrial hygiene perspective since most control levels or regulatory limits are much lower. This evaluation was designed to test the responses at the limit of detection and at or near industrial hygiene occupational exposure limits (OELs), action and alarm levels, and regulatory limits. Instrument accuracy and precision were additional results that could be extracted from the data.

\subsubsection{Instruments and Target Gas Concentrations}

The instruments tested are those used for the General Tests described in Section 2.0. The serial numbers of the actual instruments provided by CH2MHill Hanford Group are listed in Appendix B. The test gases were as follows:

- hydrocarbon mix: ethanol, acetone, benzene, toluene, xylene, and hexane

- ammonia

- nitrous oxide.

The instrument types and the target test concentrations are given in Table 3.3. 
Table 3.3. Instruments Tested and Target Concentrations

\begin{tabular}{||c|c|c||}
\hline \multicolumn{3}{||}{ Example of gas/air blends used for sensors tested } \\
\hline Zero Air Mass Flow Meter (L/min) & Test Gas MFM (cc/min) & (Target ppm) \\
\hline Nitrous Oxide: MIRAN & 150 & 1 \\
\hline 15 & 4935 & 25 \\
\hline 15 & 14705 & 50 \\
\hline 15 & & 1 \\
\hline Ammonia: iTX, Area RAE, MIRAN & 25 & 25.02 \\
\hline 25.9 & 620 & 49.99 \\
\hline 25 & 1270 & 0.012 \\
\hline 25 & 2 & 1.98 \\
\hline Hydrocarbon Mixtures ppb-RAE, Area-RAE & 25.04 \\
\hline 100 & 66 & 100.5 \\
\hline 20 & 650 & \\
\hline 15 & 3000 & \\
\hline
\end{tabular}

\subsubsection{Equipment}

The equipment used was mostly the same as that used for the General Tests. An important addition was using a pneumatic valve (Nor Cal Model 040518-20) used with an Omron H3YN 10-minute timer to facilitate the instantaneous starts and stops of gas flow for the timed releases in the transit tests. The valve was located in the dynamic dilution system shown in Figure 3.3. The mixer and manifold for the nitrous oxide tests was as shown in Figure 3.5. For the other gases, a stainless steel manifold was built as shown on Figure 3.9. To connect from the manifold to the instrument being tested, short sections of Teflon or stainless steel tubing were used.

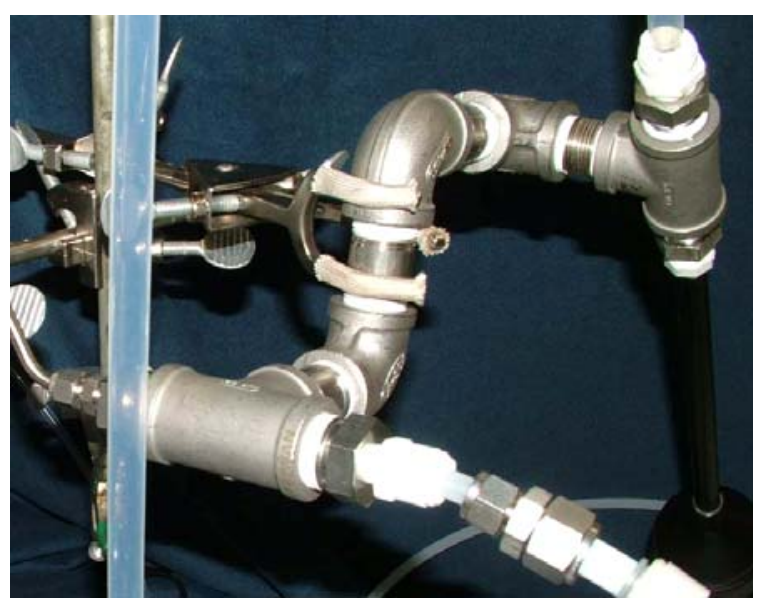

Figure 3.9. Third-Generation Stainless Steel Mixer and Manifold

\subsubsection{Test Protocol}

The instruments being tested were exposed to short-term changes in gas concentrations, as described above. The instruments were connected to the test-gas manifold for sampling. The flow rate of test gas and pure dilution air through the manifold were kept in excess of that needed for all of the connected instruments so that flows to individual instruments were unhindered. The test-gas stream was produced 
by dilution of certified standard gases with pure dry air. Moisture was added to bring the humidity of the pure air stream to a range of about 20 to 30\%, consistent with that observed for the Hanford Area. The blending was controlled using certified mass flowmeters.

Pure air from the Aadco system was flowing through the manifold prior to, during, and after the test pulses. A pulse of the test gas was initiated with the pneumatic valve. Needle valves were used to set the gas flow rates and the flow rates were measured with the certified mass flow meters. Succeeding pulses were started after the previous readings returned to the baseline. The exception to this was the ammonia injection. Ammonia tends to stick to internal surfaces and sample lines. In some cases, generally when high concentration pulses were introduced, it required 30 minutes to 1 hour before the trace returned to the baseline. Data collection was generally continued until the instrument's concentration reached the pre-test reading or until a new equilibrium was reached.

The internal data-loggers in the sensors were used to verify test responses and sensor performance during the short-duration challenges. Data acquisitions at 1-second intervals were used for all tests to respond to the various challenges of instruments. Some respond quickly and reach their challenge concentration in seconds, and others require more than 1 minute to respond to the input gases. The data logged during the tests was used to calculate precision, accuracy, and response time.

Test parameters, including instrument settings and identifiers, e.g., serial numbers, were recorded for each test.

The $\mathrm{T}_{90}$ response time was used because it represents an amount of time that is very close to but slightly lower than a full-scale instrument response at the challenge concentration. This response time is defined as follows:

$$
\mathrm{T}_{90}=\text { time elapsed from the start of exposure to } 90 \% \text { of target response }
$$

This duration of time calculated for the $T_{90}$ represents the approximate number of seconds required before a reading indicated on the instrument display can be considered reliable. The following points are important:

- Instrument pre-test readings on zero air were observed.

- The pneumatic valve (see Figure 3.3) was opened to allow gas flow.

- A short time lag was observed representing the flow of gas to the sensor.

- A steep concentration rise occurred over a minimum of time.

- The concentration plateaus, depending on the pulse duration.

- The gas was shut off at the pneumatic valve, followed by a short concentration lag.

- The concentration dropped sharply and returned to baseline. 
The length of the pulse duration was adjusted to allow the concentration traces to plateau at an equilibrium level so that precision and accuracy values could be estimated. A 5-minute pulse duration was generally used for hydrocarbon and nitrous oxide tests, whereas 10- to 20-minute pulses were applied for ammonia. Figure 3.10 illustrates a typical test run repeated four times for nitrous oxide for the MIRAN analyzer.

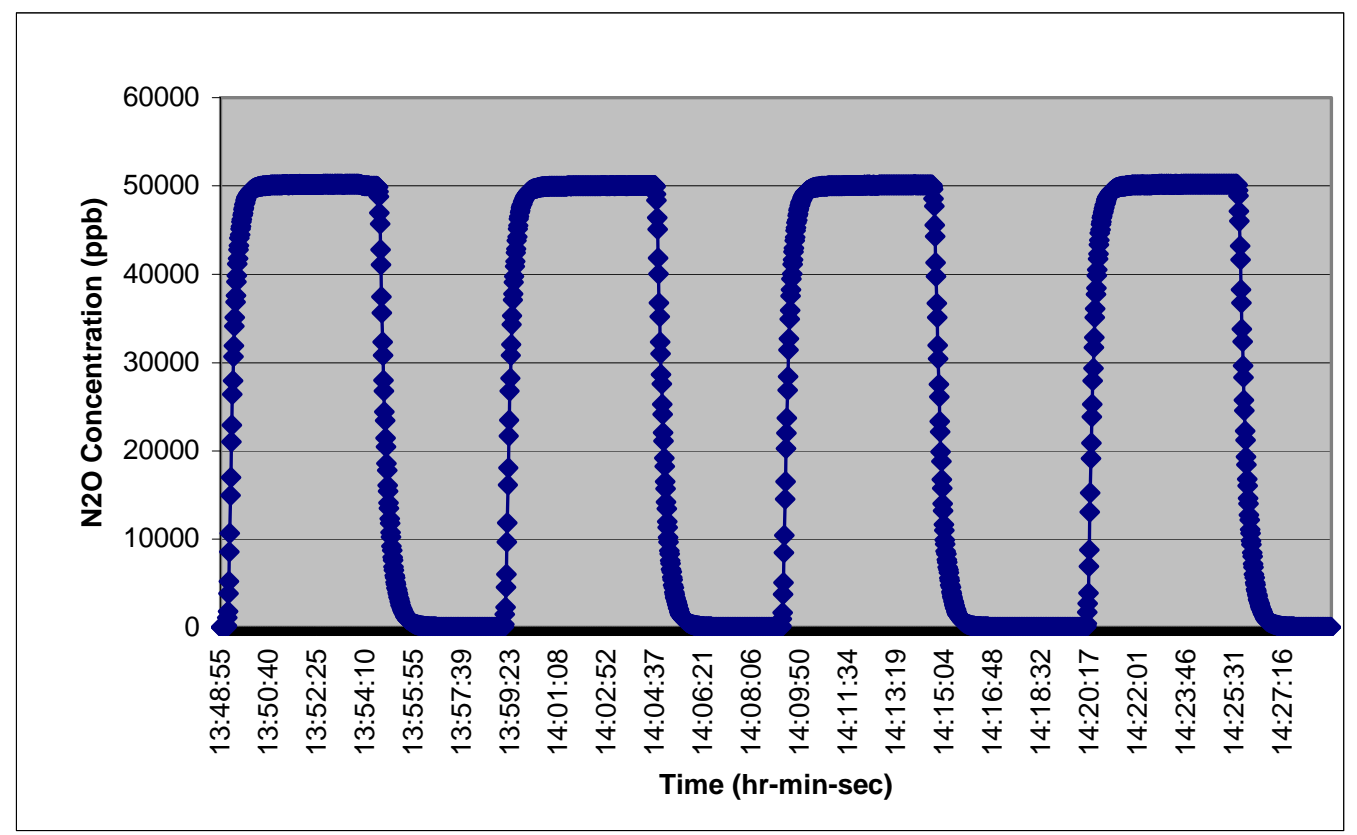

Figure 3.10. Typical Series of Four 50-ppm Nitrous Oxide 5-Minute Challenges for the MIRAN Instrument - Data Acquired at 1-Second Intervals 


\subsection{Test Results}

The laboratory tests were designed to challenge the monitors over lower concentration regions of their nominal response ranges. The lab tests were aimed at quantifying the ranges of performance of the industrial hygiene monitors under conditions that were deemed close to those observed in the field. More specifically, the instrument responses were tested for response against changing stepped concentrations in the general tests and against very rapid concentration pulses in the transient tests. The work was performed according to the schedule shown in Table 4.1.

Table 4.1. Identity and Schedule of Performance Tests Conducted on Sensors

\begin{tabular}{|c|l|}
\hline Phase 1 Test Activity & Date Conducted \\
\hline General Tests & \\
\hline Hydrocarbons & April 2-15, 2004 \\
\hline Ammonia & April 15-May 5, 2004 \\
\hline Nitrous oxide & May 20-July 15, 2004 \\
\hline Transient Tests & \\
\hline Nitrous oxide & July 28-August 3, 2004 \\
\hline Ammonia & August 3-6, 2004 \\
\hline Hydrocarbons & September 2-9, 2004 \\
\hline
\end{tabular}

The reliability of the results is referenced to DOE pre-approved certified standards and to flow measurements by meters that were either purchased for or recertified for the tests.

Although every effort was made to keep procedures the same throughout the tests, some changes in sampling procedures occurred to accommodate the equipment received for testing. In early tests, all transfer lines and fittings were constructed of Teflon, glass, or stainless steel to avoid any absorptive losses of the test gases onto internal surfaces of valves, fittings, and lines. As the testing progressed, it was noted that some apparent wall-to-wall absorption was evident when ammonia was delivered to the instruments; consequently, the delivery system was reconstructed from all stainless steel components. Initially, the internal bore size of the sample lines was between 1/8- to 3/16-inch in order to reduce transfer-line volumes and residence times of PNNL gas delivery systems. But when the MIRAN analyzers were tested, it was obvious that these smaller lines limited performance, so larger $1 / 2$-inch OD lines were used to match those supplied by the vendor. The PNNL test-gas delivery system (lines, valves, mass-flow-meters, and manifolds) were made shorter for the transient tests in order to avoid lag times that were evident in the laboratory but not in field use of the instruments.

Initially, it was assumed that several identical sensors could be tested simultaneously, but field use of the industrial hygiene monitors was very high during the period of PNNL testing. Consequently, tests were made on available instruments. As the manifolds could usually accommodate multiple instruments, the available ports were filled with sensors whether or not they would typically respond to the test gas. This allowed for limited evaluation of interference effects. For example, if ammonia tests were set up using 
the Manning EC-PC and ISC-iTX instruments, two other ports were used to determine if the hydrocarbon sensors ppb-RAE and 580-EZ might also respond to ammonia.

\subsection{Data Acquisition}

Data acquisition for the general sensor challenges included manually recording the data, generally at 1minute intervals, from the digital displays as the testing progressed. Sampling conditions and any pertinent testing activities were documented. These manual readings were written in log books or on sheets of paper for later review and data analyses. When multiple instrument readings were recorded over time, it was necessary to use separate sheets of paper because access to a logbook was limited.

Data acquisition for instruments undergoing transient testing used internal data-logging capabilities found in each sensor. The sensor response for 1-second intervals was transferred as comma-separated files to a laptop computer via a RS232 link so that the data could be reviewed in Excel and summarized. The corresponding dilutions of test gases with run start and end times were documented for the test instruments in a logbook. Synchronizing the times between the sensor, the computer, and a stopwatch were problematic because setting and adjusting the time to 1 second was tedious on most of the field instruments. Data traces were plotted in Excel after each run to show that the logging process had occurred correctly. Other data pertinent to flow measurements, such as the laboratory temperature and pressure and the internal sample delivery line temperature and relative humidity, were recorded in laboratory record books during each test.

\subsubsection{Stepped Test Calculations}

Instead of administering tests where gases were delivered to a sensor for the same time period for each level, the deliveries were somewhat randomized. Following the establishment of a baseline, obtained using only zero air, concentrations were stepped upwards, lingering perhaps for 2, 4, 6, or 10 minutes at each level before jumping to the next higher level. The purpose of this testing was to determine if a sensor could respond to the ever-changing concentrations expected during field measurements where wind-mixing occurs. This proved to be a rigorous test scheme.

The calculation of precision and accuracy for the general stepped tests was performed in Excel spreadsheets using the equations from Appendix C. The calculated precisions and accuracies are weighted according to the time spent at each level so that they are comparable.

\subsubsection{Transient Test Calculations}

These tests were similar to the procedures used to calibrate the air-monitoring instruments. The pulses administered over low, intermediate, and high concentrations were examined to look at the rise times required for a sensor to rise to $90 \%$ of the delivered gas blend. These tests determine whether or not the instrument is capable of measuring some amount of gas in the field that appears for a short time and is then almost immediately dispersed. A pneumatic switch, which opens and closes in microseconds, was used to administer the gas through the delivery system to the instrument. 
Figure 4.1 illustrates the way the calculations were made for the concentration pulses administered in the transient series. The gas pulse starts at Point 1 when the pneumatic valve is opened and then closes at the time corresponding to the lower-left triangle on the base after the designated time passes. The thick upper line shows the concentration of the test gas; the duration of the gas pulse corresponds to the start

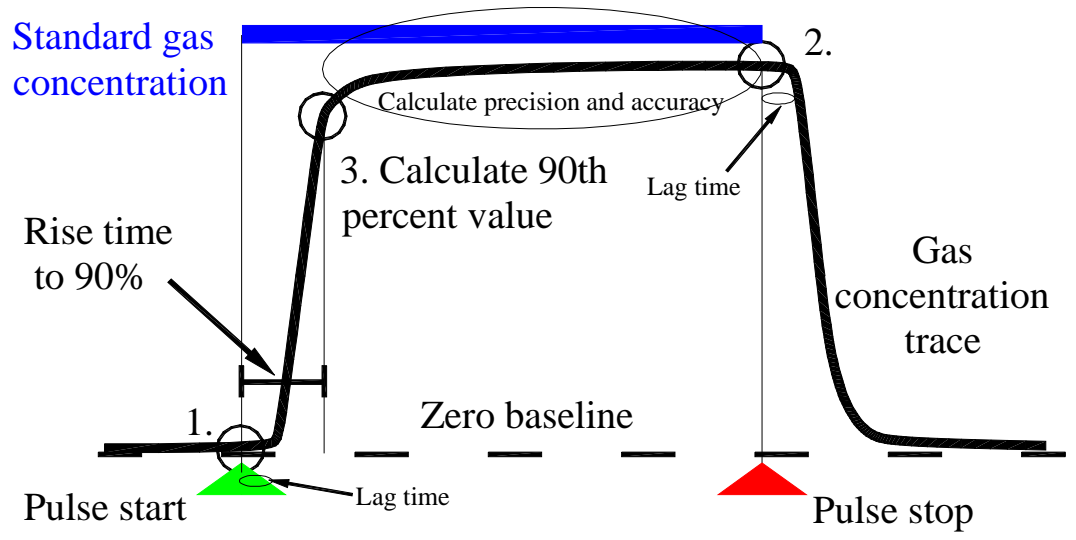

Figure 4.1. Illustration of Points Used in Pulse Tests and stop points. Ninety percent of the concentration of the test gas at Point 2 (when the pulse stops) is used to calculate the $90 \%$ value seen at Point 3. As the data was logged at 1-second intervals, the closest actual reading to the $90 \%$ point is flagged and illustrated in the test data plots. With the $90 \%$ value established, the rise time is the difference in time in seconds between Points 3 and 1. The accuracy and precision calculations are made using the values observed between Points 2 and 3 relative to the corresponding values of the certified gas concentrations and the test values from the pulse. It was important to check that the pulse traces returned to the zero baseline value to assess any observed instrumental drift.

Two points of lag time are noted. These relate to the PNNL test set-ups used in the experiments. They represent the several seconds of travel time needed for the test-gas zero-air blend to reach the industrial hygiene instrument after the pneumatic valve is actuated. It was noted that the MIRAN analyzer has an added lag time because of the several-liter-volume gas cell that must be exchanged with the incoming test-gas blend before readings are noted.

\subsection{Transient Tests}

Table 4.2 lists the schedule for the transient tests that were performed, including an identifier for each given test, start times, and dilution flow rates of test gases and zero air that were blended to calculate the challenge concentrations. These concentrations are consistent with the low, medium, and high concentrations seen earlier in Table 3.3. 
Table 4.2. PNNL Chamber Laboratory* Testing for Transient Gaseous Releases

\begin{tabular}{|c|c|c|c|c|c|c|c|}
\hline $\begin{array}{c}\text { Test } \\
\text { ID }\end{array}$ & $\begin{array}{l}\text { Dates } \\
(2004) \\
\end{array}$ & $\begin{array}{c}\text { Start } \\
\text { time }\end{array}$ & Instrument(s) & $\begin{array}{c}\text { Gas tested, } \\
\text { Activity } \\
\end{array}$ & $\begin{array}{c}\text { Test gas } \\
\text { conc. } \\
\text { (ppm) }\end{array}$ & $\begin{array}{c}\text { Test gas } \\
\text { flow, } \\
\text { (cc/min) }\end{array}$ & $\begin{array}{c}\text { Zero } \\
\text { air } \\
\text { flow, } \\
\text { (l/min) }\end{array}$ \\
\hline $\mathrm{T}-1$ & 28-Jul & -- & MIRAN & Data logging & -- & -- & -- \\
\hline $\mathrm{T}-2$ & 29-Jul & $12: 32$ & $"$ & $\mathrm{~N}_{2} \mathrm{O}$ & 1.01 & 151 & 15.01 \\
\hline $\mathrm{T}-3$ & $"$ & $16: 56$ & $"$ & $\mathrm{~N}_{2} \mathrm{O}$ & 24.97 & 4930 & 15.01 \\
\hline $\mathrm{T}-4$ & 30-Jul & $13: 49$ & $"$ & $\mathrm{~N}_{2} \mathrm{O}$ & 55.19 & 15.01 & 12.46 \\
\hline $\mathrm{T}-5$ & $"$ & $14: 32$ & $"$ & $\mathrm{~N}_{2} \mathrm{O}$ & 101 & 15.01 & 0 \\
\hline $\mathrm{T}-6$ & $"$ & -- & Bacharach & Preliminary eval. & -- & -- & -- \\
\hline $\mathrm{T}-7$ & 3-Aug & -- & MIRAN & Manifold evaluation & -- & -- & -- \\
\hline $\mathrm{T}-8$ & 4-Aug & $12: 20$ & $"$ & $\mathrm{NH}_{3}$ & 25.1 & 500 & 20.1 \\
\hline $\mathrm{T}-9$ & 6-Aug & $14: 49$ & $"$ & $\mathrm{NH}_{3}$ & 25.1 & 500 & 20.1 \\
\hline $\mathrm{T}-10$ & $"$ & -- & $"$ & Hydrocarbon tests & -- & -- & -- \\
\hline $\mathrm{T}-11$ & 2-Sep & $17: 28$ & $\begin{array}{c}\text { ppb-RAE, Area- } \\
\text { RAE }\end{array}$ & HCs & 1.97 & 66 & 20.1 \\
\hline $\mathrm{T}-12$ & 6-Sep & $10: 24$ & $"$ & HCs & 11.32 & 645 & 33.7 \\
\hline $\mathrm{T}-13$ & $"$ & $11: 18$ & $"$ & HCs & 104.8 & 1310 & 6.23 \\
\hline $\mathrm{T}-14$ & $"$ & $12: 58$ & $"$ & HCs & 31.55 & 344 & 6.23 \\
\hline $\mathrm{T}-15$ & $"$ & $14: 20$ & $"$ & HCs, & 0.018 & 1 & 33.85 \\
\hline $\mathrm{T}-16$ & 7-Sep & $16: 08$ & iTX, Area-RAE & $\mathrm{NH}_{3}$ & 1.04 & 25 & 24.92 \\
\hline $\mathrm{T}-17$ & $"$ & $16: 20$ & $"$ & $\mathrm{NH}_{3}$ & 2.07 & 50 & 24.92 \\
\hline $\mathrm{T}-18$ & $"$ & $16: 36$ & $"$ & $\mathrm{NH}_{3}$ & 3.1 & 75 & 24.92 \\
\hline $\mathrm{T}-19$ & $"$ & $17: 00$ & $"$ & $\mathrm{NH}_{3}$ & 25.1 & 620 & 24.92 \\
\hline $\mathrm{T}-20$ & 8-Sep & $15: 59$ & $"$ & $\mathrm{NH}_{3}$ & 25.1 & 620 & 24.92 \\
\hline $\mathrm{T}-21$ & $"$ & 8:08 & $"$ & $\mathrm{NH}_{3}$ & 50.22 & 1272 & 24.92 \\
\hline $\mathrm{T}-22$ & 9-Sep & $12: 24$ & $"$ & $\mathrm{NH}_{3}$ & 1.01 & 25.3 & 25.95 \\
\hline $\mathrm{T}-23$ & $"$ & $14: 41$ & $"$ & $\mathrm{NH}_{3}$ & 25.06 & 621 & 25 \\
\hline $\mathrm{T}-24$ & $"$ & $16: 05$ & ppb-RAE & HCs & 0.015 & 2.5 & 103.64 \\
\hline
\end{tabular}




\subsubsection{Nitrous Oxide Transient Tests}

Some example data plots are shown below. The plots selected for this document satisfy general target concentration levels laid out in Table 3.3. Comments will be made for some plots when they are considered necessary.

Figure 4.2 shows four repeats of a 1-ppm challenge. The components explained in Figure 4.1 are seen here along with the values for precision, accuracy, and rise times. Again, each pulse was started at the time indicated by the green triangle and stopped at the red triangle. Each red circle along the concentration plot trace represents a data point acquired and logged by the MIRAN instrument for each second of time. The rise times can be estimated by counting the data points where they are spread out and individually visible. The blue lines at the tops of the pulses represent the concentrations of the delivered certified nitrous oxide gas. The values that step down, from left to right, show how the gas flow was adjusted down from $1050 \mathrm{ppb}$ to $1000 \mathrm{ppb}$ on the right. When the pneumatic value first opens (at the green triangle), there is a slightly increased pressure in the nitrous oxide cylinder regulator. This pressure quickly drops and stabilizes within about 2 minutes. This pressure represents an increased initial flow that is compensated for by manually adjusting the needle value. This adjustment was required in most tests. However, comparative statistics were run using the actual values shown above versus simply applying the final input gas concentration in the calculations of precision and accuracy. It was found in several tests that the correction was less than $1 \%$. Consequently, all follow-on calculations are based on the simpler straight-line assumption of the certified gas concentration.

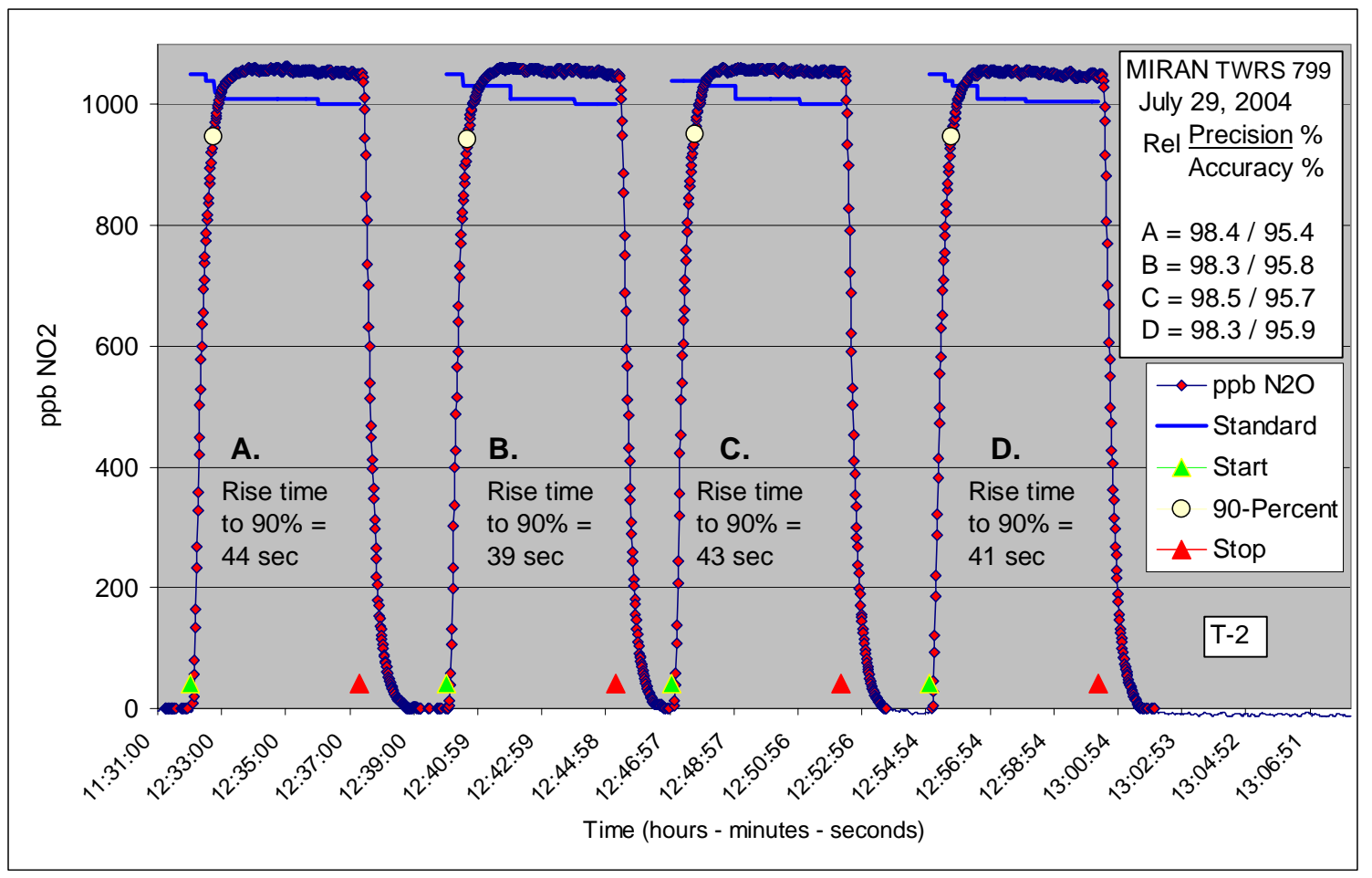

Figure 4.2. Test of MIRAN Instrument at $1000 \mathrm{ppb}(1 \mathrm{ppm})$ 
The precision and accuracy values are all very close, indicating that the tests were well controlled and highly repeatable. The rise times are also close for the MIRAN runs.

Figure 4.3, a pulse without the data workup, shows how well-behaved the MIRAN analyzer is relative to data collection. The instrument, which shows no baseline drift, achieves the level of 25-ppm within about 60 seconds and holds that level, thus accounting for the high precision characteristic of this instrument.

However, Figure 4.4 shows for a 34-second pulse, how the MIRAN is limited when it may have a requirement to measure short-lived concentrations. For example, a 1-ppm pulse was administered for 34 seconds, during which time the instrument measured about $85 \%$ of the administered concentration.

A summary for the nitrous oxide tests for Runs T-2 to T-5 are shown in Table 4.3. Note that one additional run was made at a 101-ppm concentration level of nitrous oxide using the MIRAN analyzer. The MIRAN analyzer shows results that are high in precision and accuracy.

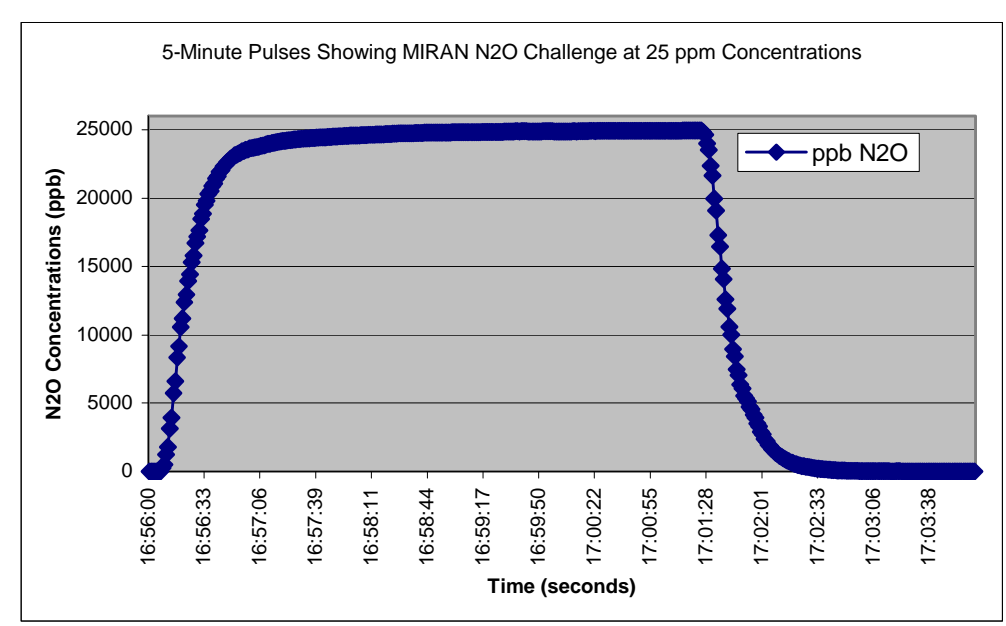

Figure 4.3. T-3 MIRAN Nitrous Oxide Pulse at 25 ppm (actual $=24.97)$

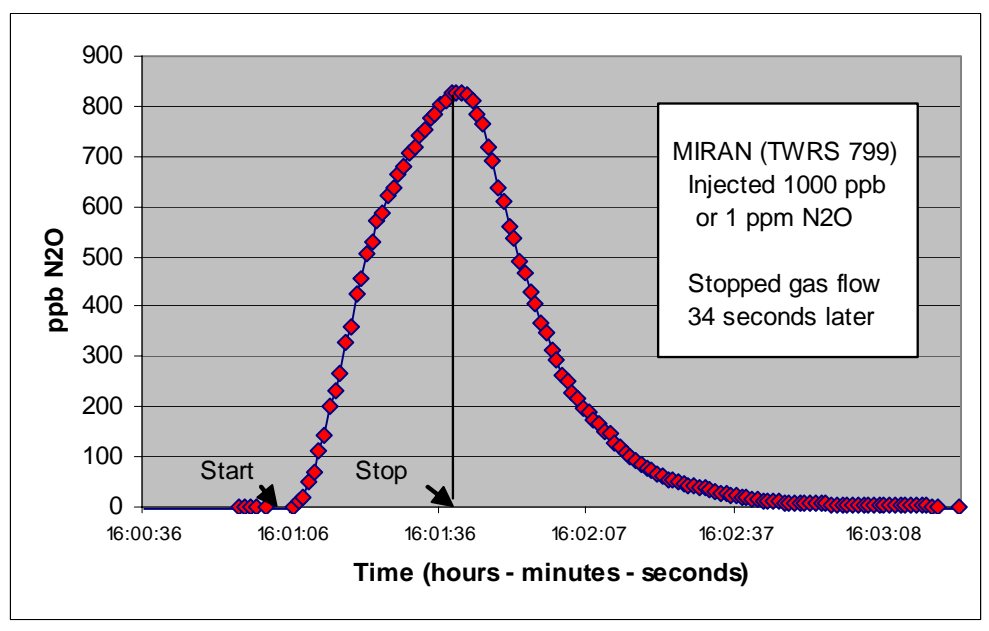

Figure 4.4. MIRAN Test at 1-ppm 
Table 4.3. Transient Test Summary for MIRAN Pulses of Nitrous Oxide

\begin{tabular}{|c|c|c|c|c|c|c|c|}
\hline $\begin{array}{c}\text { Trial } \\
\text { Number }\end{array}$ & \begin{tabular}{c|c|} 
Test \\
Concentration \\
\end{tabular} & Runs & $\begin{array}{l}\text { Relative } \\
\text { Accuracy }\end{array}$ & $\begin{array}{l}\text { Range of } \\
\text { Accuracy }\end{array}$ & \begin{tabular}{|c|} 
Relative \\
Precision \\
\end{tabular} & $\begin{array}{l}\text { Rise Ti } \\
\operatorname{Max}^{*} \mathrm{~F} \\
\end{array}$ & $\begin{array}{l}90 \% \text { of } \\
g\left(T_{90}\right)\end{array}$ \\
\hline & & & & & & T90 range & Avg T90 \\
\hline T-2 & $1 \mathrm{ppm}$ & 4 & $96 \%$ & $95.4 \%$ to $95.9 \%$ & $98.40 \%$ & 39 to $44 \mathrm{sec}$ & $42 \mathrm{sec}$ \\
\hline T-3 & $25 \mathrm{ppm}$ & 4 & $99 \%$ & $98.5 \%$ to $98.6 \%$ & $98.20 \%$ & 44 to $45 \mathrm{sec}$ & $45 \mathrm{sec}$ \\
\hline T-4 & $55 \mathrm{ppm}$ & 4 & $90 \%$ & $90.2 \%$ to $90.5 \%$ & $98.60 \%$ & 38 to $39 \mathrm{sec}$ & $38 \mathrm{sec}$ \\
\hline T-5 & $101 \mathrm{ppm}$ & 1 & $96 \%$ & $95.80 \%$ & $98.50 \%$ & $59 \mathrm{sec}$ & $59 \mathrm{sec}$ \\
\hline
\end{tabular}

\subsubsection{Hydrocarbon Tests}

The ppb-RAE and the Area-RAE were tested for their response to the certified mixture of hydrocarbons used here. Figures 4.5, 4.6, and 4.7 combine the traces for both instruments when they were challenged at the 2-, 11-, and 104-ppm levels. Again, the characteristic start and stop points are shown. Figure 4.5 shows a constant hydrocarbon input at $1.97 \mathrm{ppm}$. The detectors in the RAE hydrocarbon measuring instruments can acquire and log data at rates of one-second intervals - ppb-RAE is slightly faster than the Area-RAE. The lamp, the essential part of the photo-ionization detector device, has an uncertainty in output voltage that relates to about $0.1 \mathrm{ppm}$ in change for a newer instrument and up to about 0.2 percent in an older unit (Haag, 2004). This uncertainty is expressed as the cycling seen in the performance tests conducted at low ppm concentrations such as in Figure 4.5. This cycling raises possibilities for error in the identification of the locations of the $90^{\text {th }}$ percentile point of the graph as defined in Section 4.3.2 above. As defined here the 90th percentile point is the first number in the logged data series that is

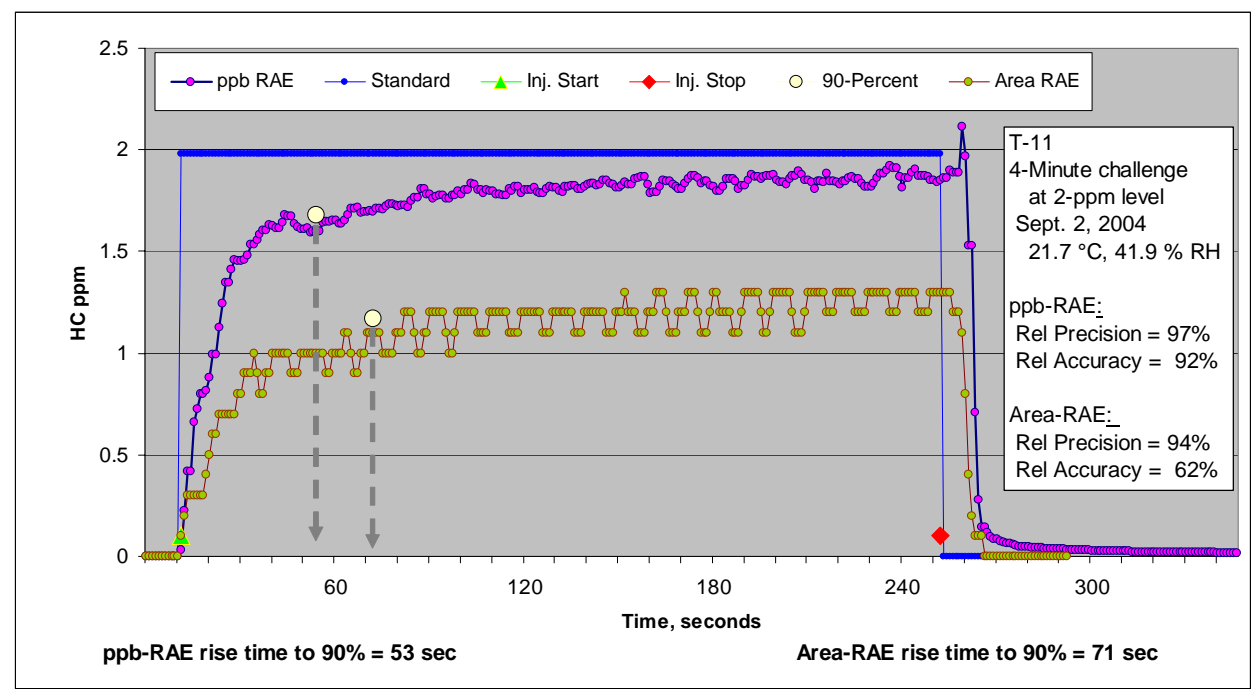

Figure 4.5. $\mathrm{ppb}-\mathrm{RAE}$ and Area-RAE Challenges at 2-ppm Hydrocarbons 


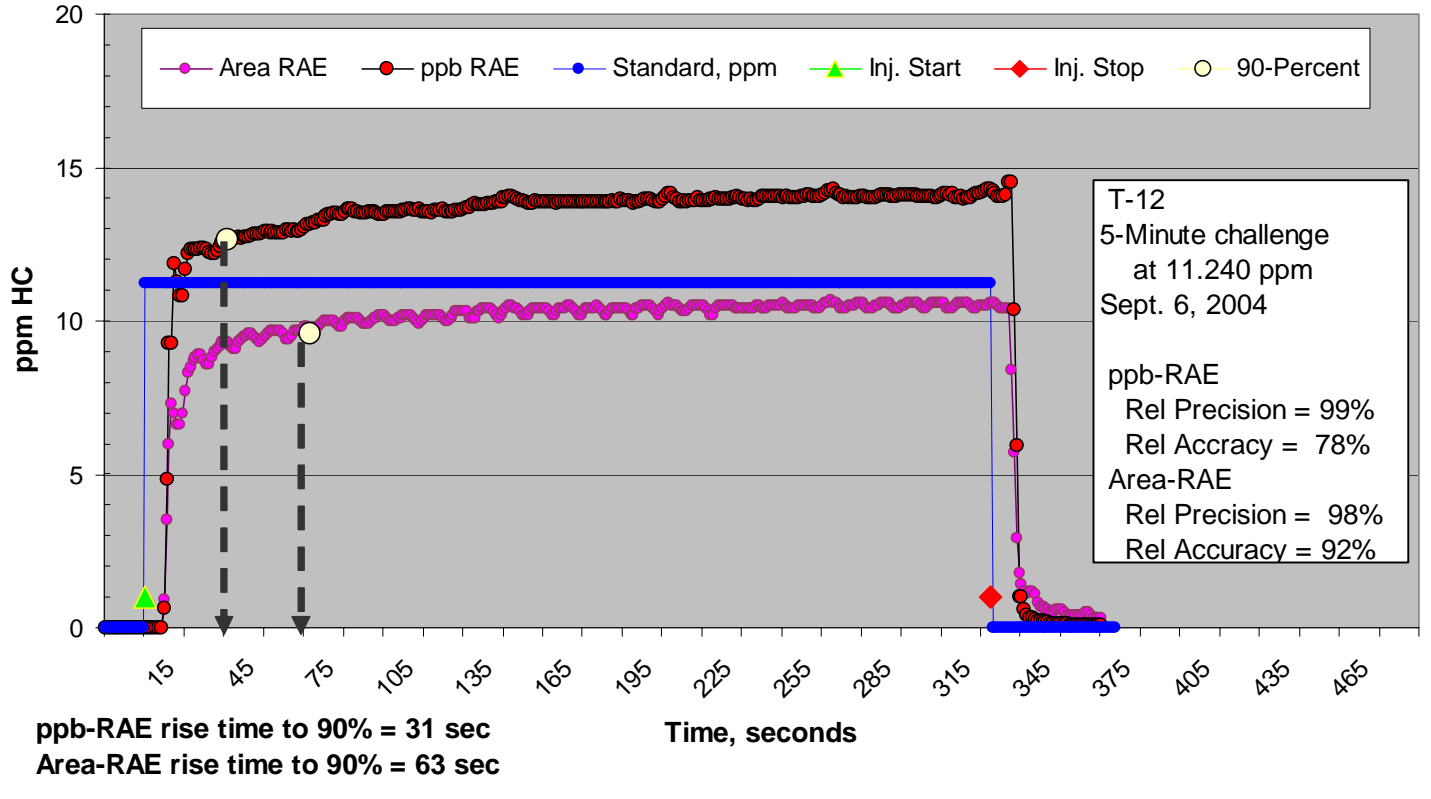

Figure 4.6. Hydrocarbon Challenges of ppb- and Area-RAE Instrument at $11.3 \mathrm{ppm}$

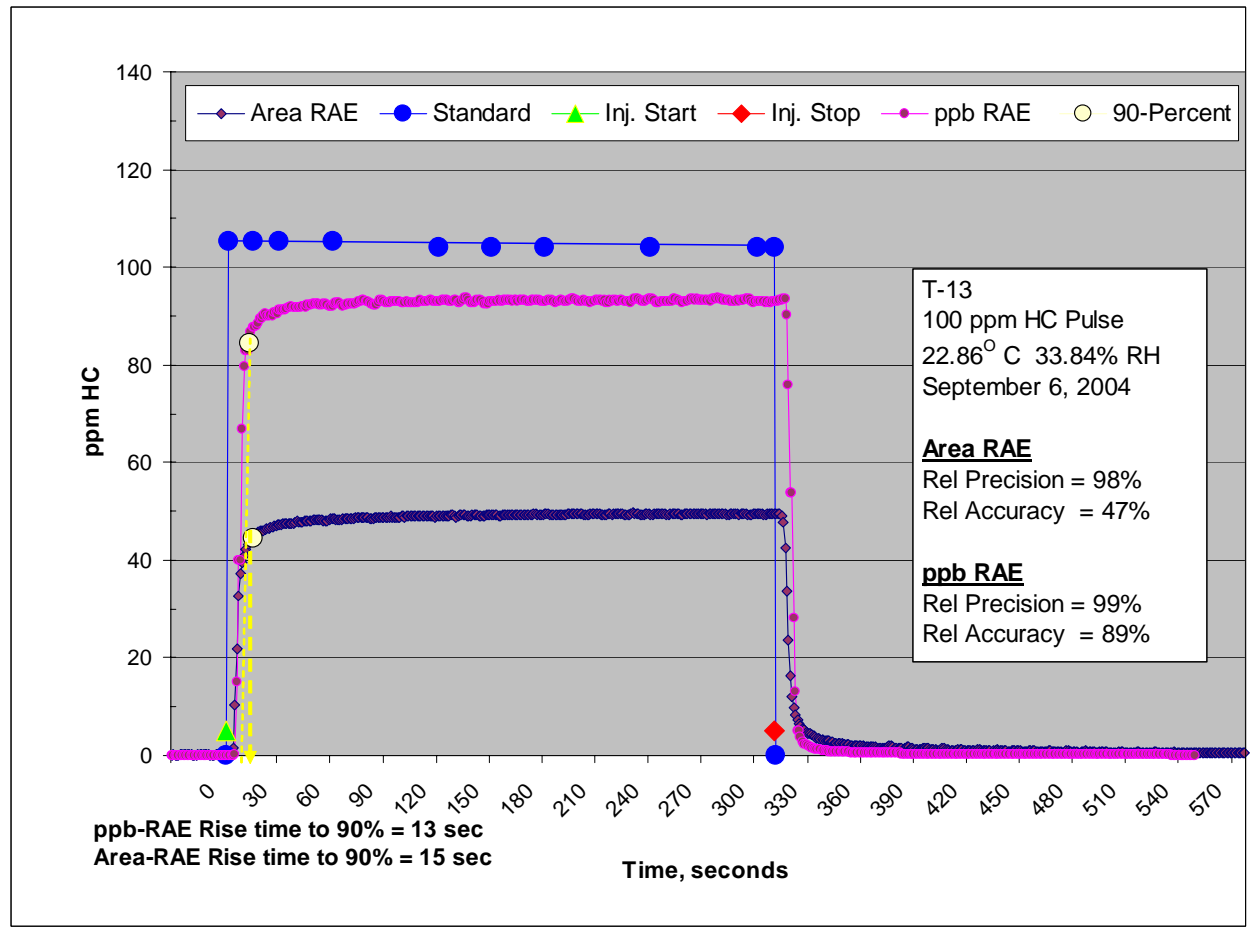

Figure 4.7. ppb-RAE and Area-RAE Challenges at 104-ppm Hydrocarbon Level 
closest to the calculated $90^{\text {th }}$ percentile point. Depending on whether the $90 \mathrm{TH}$ percentile point was found in the mid-point of the plot with scatter or on fringe, errors may be possible in estimating the rise time and the accuracy results.

It appears that a wrong run may have been included in Figure 4.7. The Area-RAE T-13 data are half of what was expected. However, no error was made according to notations in the laboratory logbook and in a review of the original data file that was transferred from the Area-RAE to the data computer. No reason was found in the laboratory test setup or in the data handling that could account for the low accuracy of the Area-RAE readings.

Table 4.4 summarizes the results for the hydrocarbons runs that were selected for presentation. Again the precision is high but the relative accuracy is lower, particularly for the Area-RAE.

Table 4.4. Transient Test Summary for Mixed Hydrocarbon Pulses

\begin{tabular}{|c|c|c|c|c|c|c|}
\hline $\begin{array}{l}\text { Trial } \\
\text { Number }\end{array}$ & $\begin{array}{c}\text { Test } \\
\text { Concentration }\end{array}$ & Sensor & Runs & $\begin{array}{c}\text { Relative } \\
\text { Accuracy }\end{array}$ & $\begin{array}{c}\text { Relative } \\
\text { Precision }\end{array}$ & $\begin{array}{l}\text { Rise Time to } \\
90 \% \text { of Max* } \\
\text { Reading (T90) }\end{array}$ \\
\hline \multirow[t]{2}{*}{$\mathrm{T}-11$} & $2 \mathrm{ppm}$ & ppb-RAE & 1 & $92 \%$ & $97 \%$ & $53 \mathrm{sec}$ \\
\hline & & Area-RAE & 1 & $62 \%$ & $94 \%$ & $71 \mathrm{sec}$ \\
\hline \multirow[t]{2}{*}{$\mathrm{T}-12$} & $11 \mathrm{ppm}$ & ppb-RAE & 1 & $78 \%$ & $99 \%$ & $31 \mathrm{sec}$ \\
\hline & & Area-RAE & 1 & $92 \%$ & $98 \%$ & $63 \mathrm{sec}$ \\
\hline \multirow[t]{2}{*}{$\mathrm{T}-13$} & 104 ppm & ppb-RAE & 1 & $89 \%$ & $99 \%$ & $13 \mathrm{sec}$ \\
\hline & & Area-RAE & 1 & $47 \%$ & $98 \%$ & $15 \mathrm{sec}$ \\
\hline
\end{tabular}

\subsubsection{Ammonia Tests}

The ammonia tests were problematic as seen in Figures 4.8 and 4.9. For all instrument challenges greater than about $2 \mathrm{ppm}$ ammonia, the readings exceeded the concentrations of the certified standards that were delivered during the tests. It is known that ammonia is reactive especially to various types of plastic tubing. For this reason, Teflon was used in all surfaces that were in contact with the gas. According to Mukhtar et al. (2003), there is also limited loss to Teflon so we reconfigured the gas delivery system so that contacted surfaces were made of stainless steel. Jack Marrin (2004), who blends ammonia gas standards for the U.S. EPA and others, recommended the use of stainless steel. Two answers may relate to the over-measurement of ammonia: 1) there is a consistent bias in the calibrations of ammonia sensors 


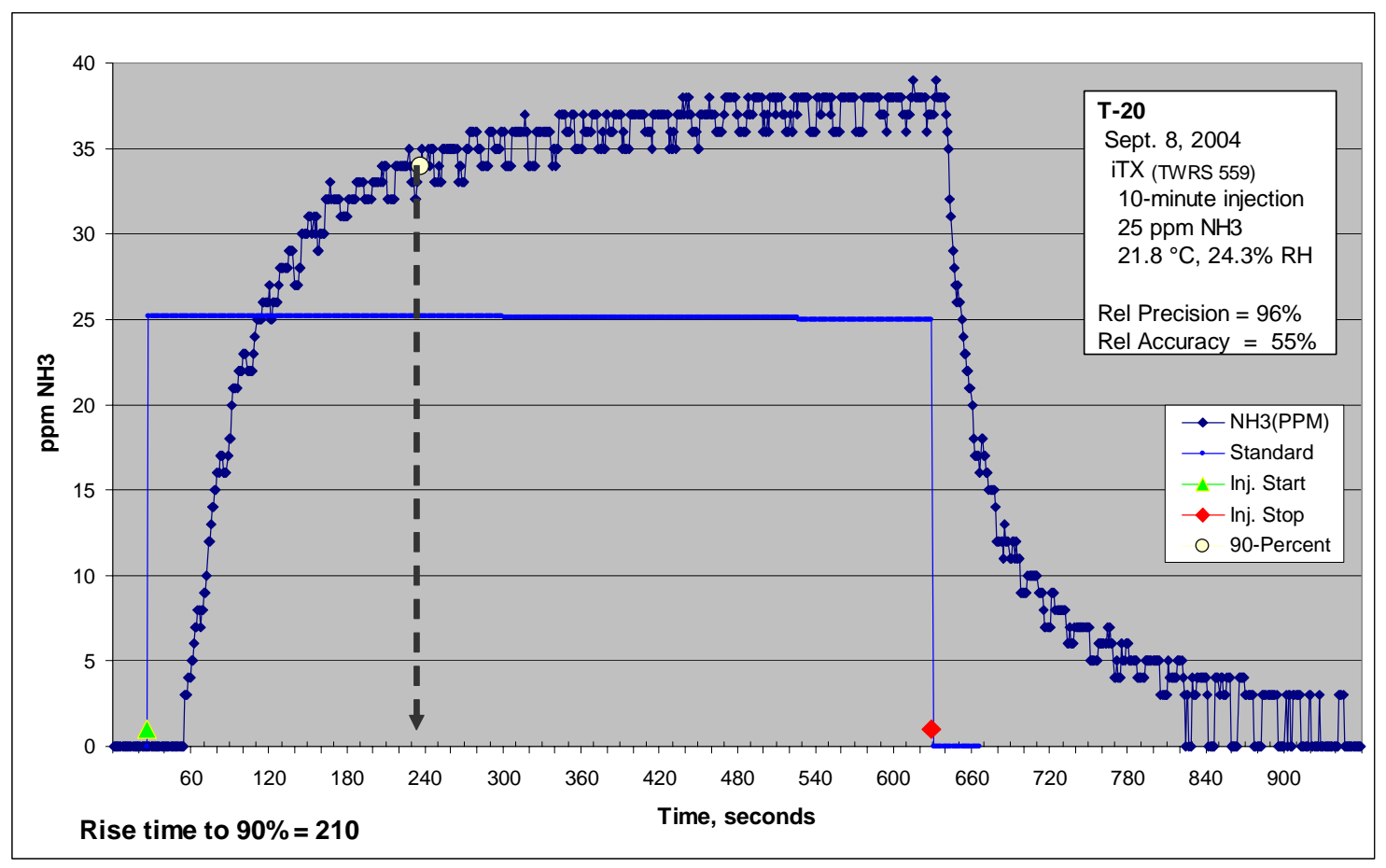

Figure 4.8. Ammonia at $25 \mathrm{ppm}$ Pulsed to an iTX Instrument

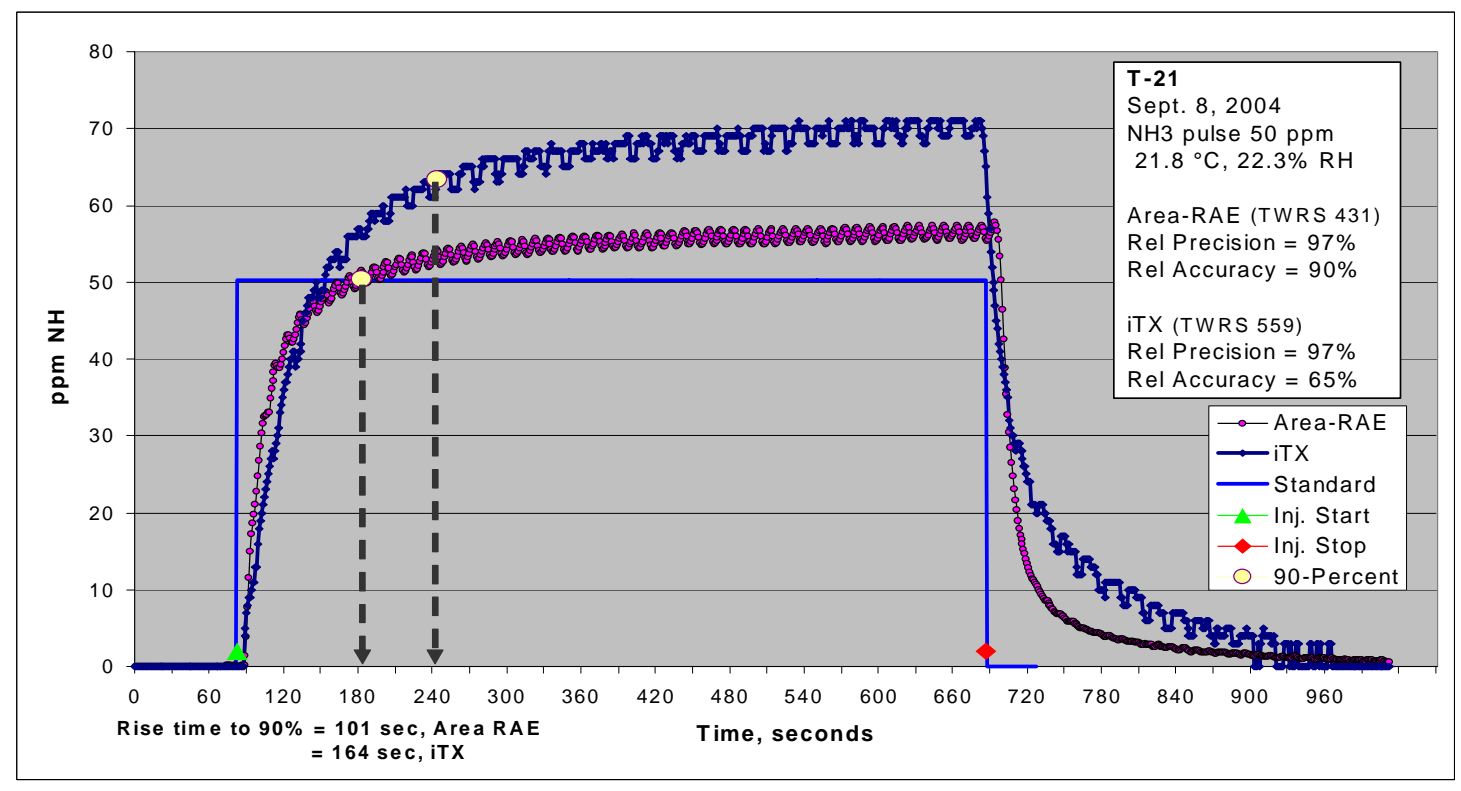

Figure 4.9. Ammonia Pulse at 50-ppm Ammonia for Area-RAE and iTX Air Monitors 
used by CH2M-Hill, 2) there may be absorption and release even from stainless steel surfaces that eventually establishes some equilibrium concentration - as new ammonia molecules enter the gas delivery equipment, older ones resuspend and are essentially double counted. This could account for the instrument readings that appear to be biased. This second option is real and can be corrected by first "pickling” the gas-delivery system with elevated concentrations of ammonia to saturate the sites before starting the actual instrument testing. "Pickling” was used in the performance testing.

Notice the slower rise and fall times associated with the measurement of ammonia and characterized by the greatly increased rise times. The bleeding or slow release of adsorbed ammonia molecules to contact surfaces accounts for these increased times. In the laboratory it was necessary to wait for 15 minutes to an hour to obtain a good baseline before starting the next pulse.

The ammonia trace, $\mathrm{T}-22$, in Figure 4.10 shows extreme cycling of the data points especially during the collection of ammonia at 1-ppm concentrations. Identifying the $90^{\text {th }}$ percentile point using visual searches fell apart because several points could have been selected from scatter that would meet our simple criteria. Consequently, two analyses of trend were performed, one to estimate the $90^{\text {th }}$ percentile point in its vertical extent and one in the horizontal extent. This more complicated mathematical treatment was required to lower the possibility for calculation errors in estimating the rise time and the relative precision and accuracy results.

Table 4.5 summarizes the ammonia data that was processed to obtain rise times and relative precision and accuracy information. As in other cases above, the precision values are excellent but the accuracies are noticeably lower.

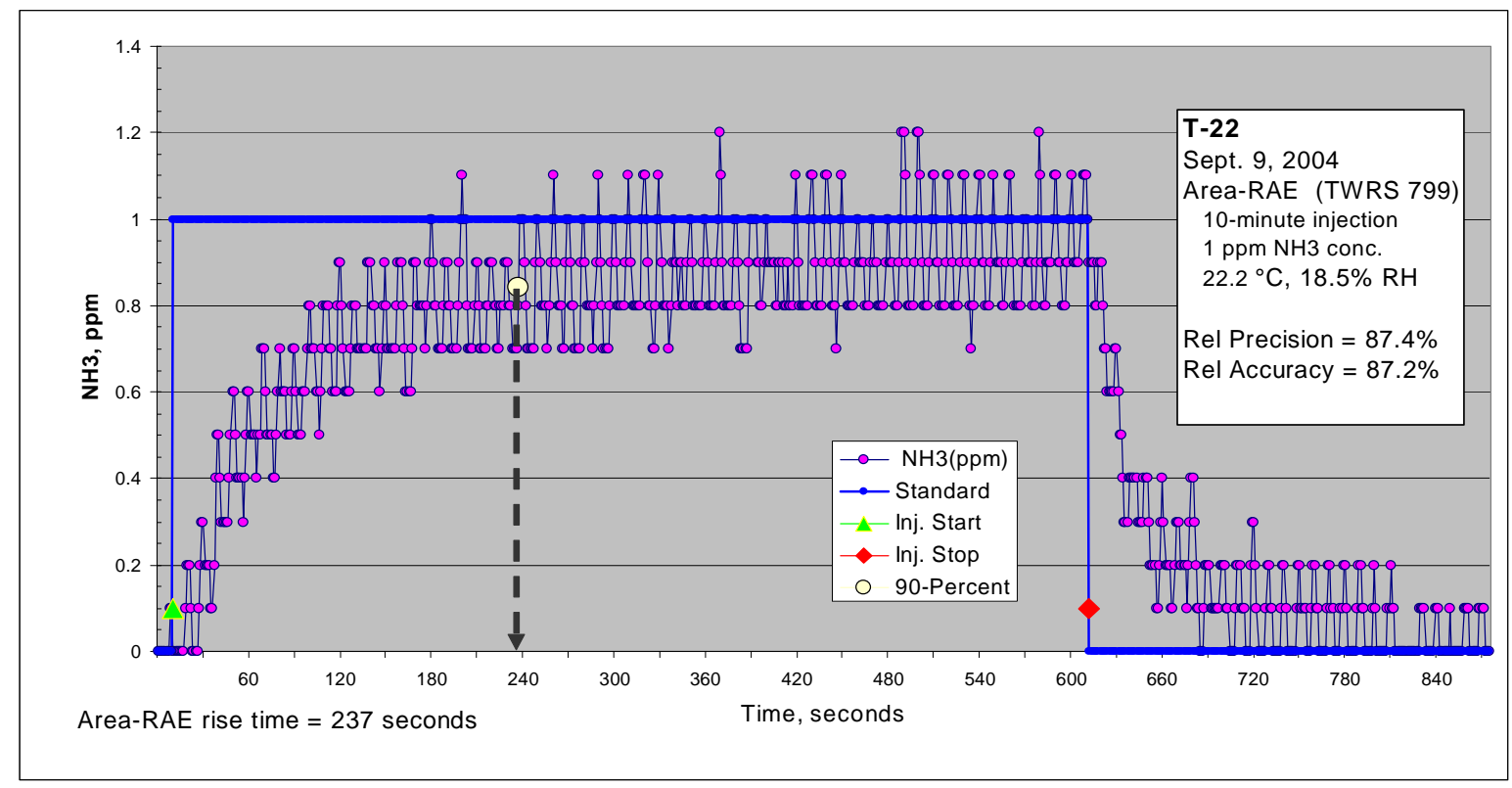

Figure 4.10. 1-ppm Ammonia Gas Challenge of the iTX Instrument 
Table 4.5. Transient Test Summary for Ammonia Pulses

\begin{tabular}{|c|c|c|c|c|c|c|}
\hline $\begin{array}{c}\text { Trial } \\
\text { Number }\end{array}$ & $\begin{array}{c}\text { Test } \\
\text { Concentration } \\
\end{array}$ & Sensor & Runs & $\begin{array}{c}\text { Relative } \\
\text { Accuracy }\end{array}$ & $\begin{array}{c}\text { Relative } \\
\text { Precision } \\
\end{array}$ & $\begin{array}{c}\text { Rise Time to } \\
90 \% \text { of } \\
\text { Max* Reading } \\
\left(\mathrm{T}_{90}\right) \\
\end{array}$ \\
\hline $\mathrm{T}-20$ & 25 ppm & iTX & 1 & $55 \%$ & $96 \%$ & $210 \mathrm{sec}$ \\
\hline \multirow[t]{2}{*}{$\mathrm{T}-21$} & $50 \mathrm{ppm}$ & iTX & 1 & $65 \%$ & $97 \%$ & $164 \mathrm{sec}$ \\
\hline & & Area-RAE & 1 & $90 \%$ & $98 \%$ & $101 \mathrm{sec}$ \\
\hline $\mathrm{T}-22$ & $1 \mathrm{ppm}$ & Area-RAE & 1 & $87 \%$ & $87 \%$ & 237 sec \\
\hline
\end{tabular}

\subsection{General Stepped Tests}

Table 4.6 summarizes general stepped tests that were run to evaluate the industrial hygiene sensors. Relative precision and accuracy values were calculated but not rise times. The data processed for the stepped tests is found in Appendix E.

Note that the Area-RAE was first provided to PNNL for the transient testing. This instrument was thus not available for the stepped tests described below.

Examples of instrumental responses are shown in Figures 4.11 to 4.14 for the three types of test gas. Figures 4.11 and 4.14 show that the hydrocarbon and nitrous oxide measuring instruments responded well to the delivered gases. Figure 4.11 shows that the ppb-RAE tracked the challenges well and responded very quickly and over a broad range of delivered concentrations (which are not shown in this figure). The 580-EZ, which is capable of measuring only levels that are above 1-ppm was clearly erratic below its detection range, but also hit-and-miss when challenged in the lower reaches of its detection range.

Table 4.6. Summary of Stepped Tests

\begin{tabular}{||l|l|l|l||}
\hline Test ID & \multicolumn{1}{|c|}{$\begin{array}{c}\text { Dates } \\
(\mathbf{2 0 0 4 )}\end{array}$} & \multicolumn{1}{|c|}{ Instruments } & \multicolumn{1}{|c|}{ Gas tested } \\
\hline S-1 & 14-Apr & ppb-RAE and 580-EZ, iTX and EC-P2 & HC-mix \\
\hline S-2 & 26-Apr & ppb-RAE and 580-EZ, iTX and EC-P3 & HC-mix \\
\hline S-3 & 26-Apr & ppb-RAE and 580-EZ, iTX and EC-P4 & HC-mix \\
\hline S-4 & 4-May & ppb-RAE and 580-EZ, iTX and EC-P5 & HC-mix \\
\hline
\end{tabular}


Table 4.6. (contd)

\begin{tabular}{|l|l|l|l||}
\hline Test ID & \multicolumn{1}{|c|}{$\begin{array}{c}\text { Dates } \\
(\mathbf{2 0 0 4})\end{array}$} & \multicolumn{1}{|c|}{ Instruments } & \multicolumn{1}{|c|}{ Gas tested } \\
\hline \hline S-5 & 4-May & ppb-RAE and 580-EZ, iTX and EC-P6 & HC-mix \\
\hline S-6 & 30-Apr & iTX and EC-P2 & ammonia \\
\hline S-7 & 4-May & iTX and EC-P2, ppb-RAE and 580-EZ & ammonia \\
\hline S-8 & 4-May & iTX and EC-P2, ppb-RAE and 580-EZ & ammonia \\
\hline S-9 & 4-May & iTX and EC-P2, ppb-RAE and 580-EZ & ammonia \\
\hline S-10 & 21-May & MIRAN B & Nitric oxide \\
\hline S-11 & 24-May & MIRAN A, MIRAN B & Nitric oxide \\
\hline S-12 & 28-May & MIRAN B & Nitric oxide \\
\hline S-13 & 31-May & MIRAN A, Bacharach & Nitric oxide \\
\hline S-14 & 31-May & MIRAN A, MIRAN B & Nitric oxide \\
\hline S-15 & 31-May & MIRAN A, MIRAN B & Nitric oxide \\
\hline \hline
\end{tabular}

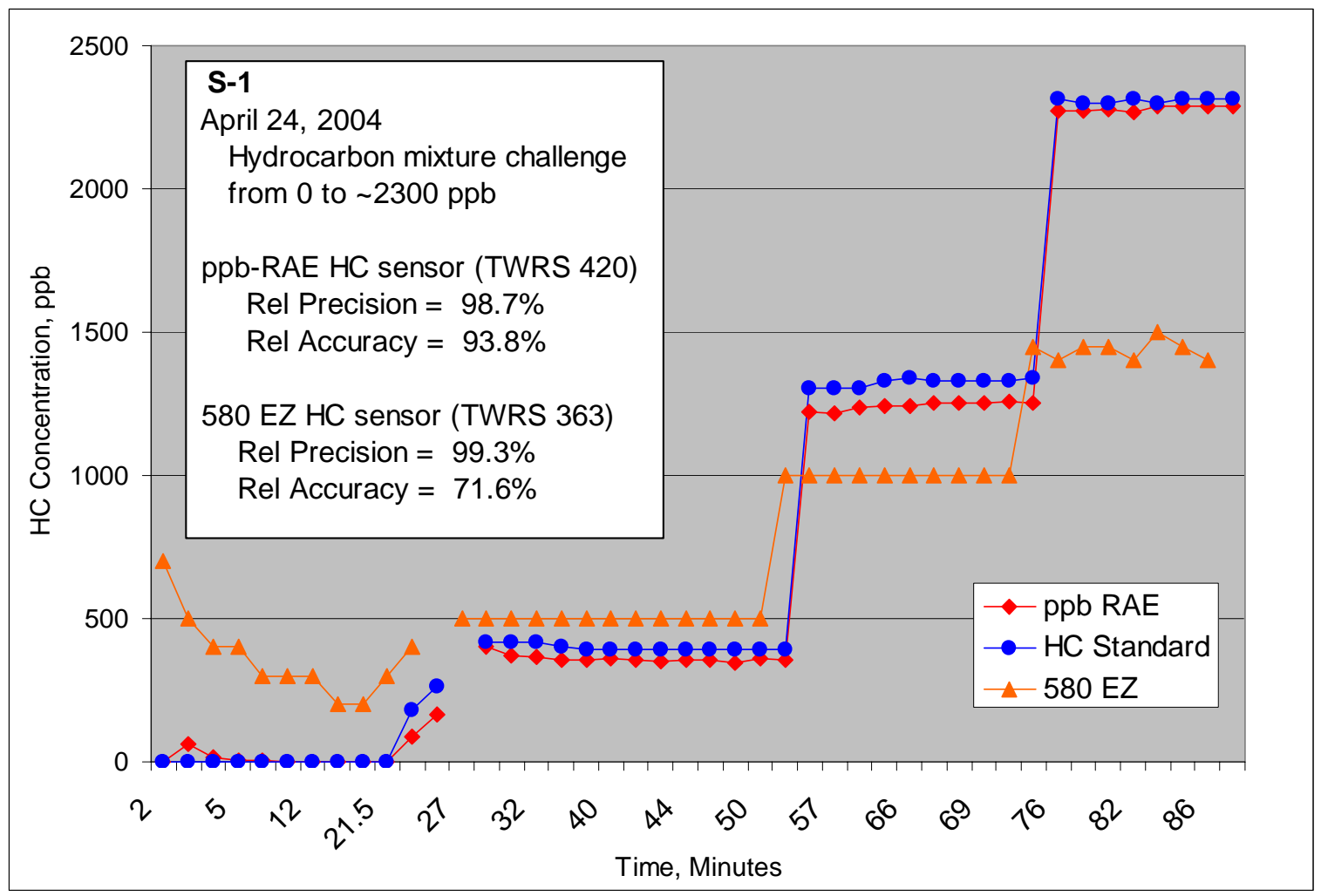

Figure 4.11. Range of Hydrocarbon Concentrations Exposed to Typical ppb-RAE and 580-EZ Monitors 4.13 


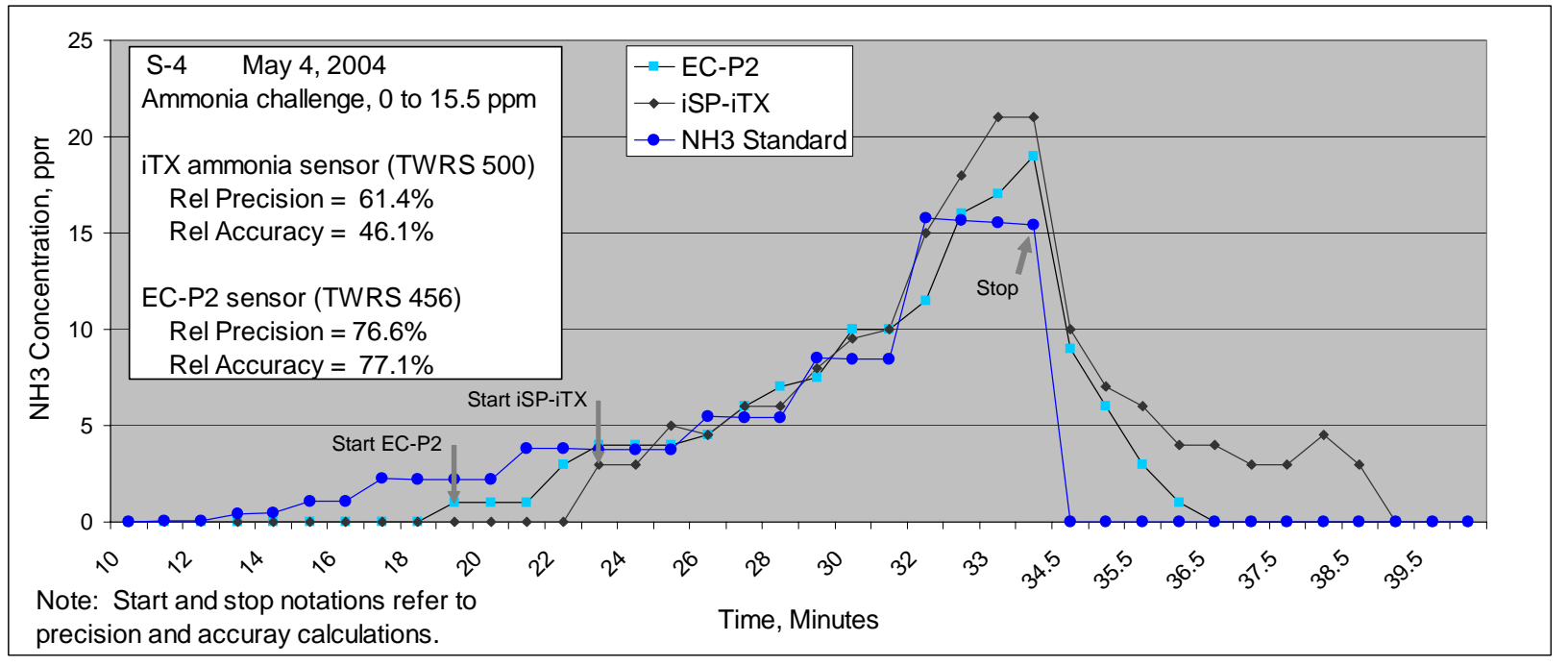

Figure 4.12. iTX and EC-P2 Ammonia Sensors at Several Ammonia Concentrations

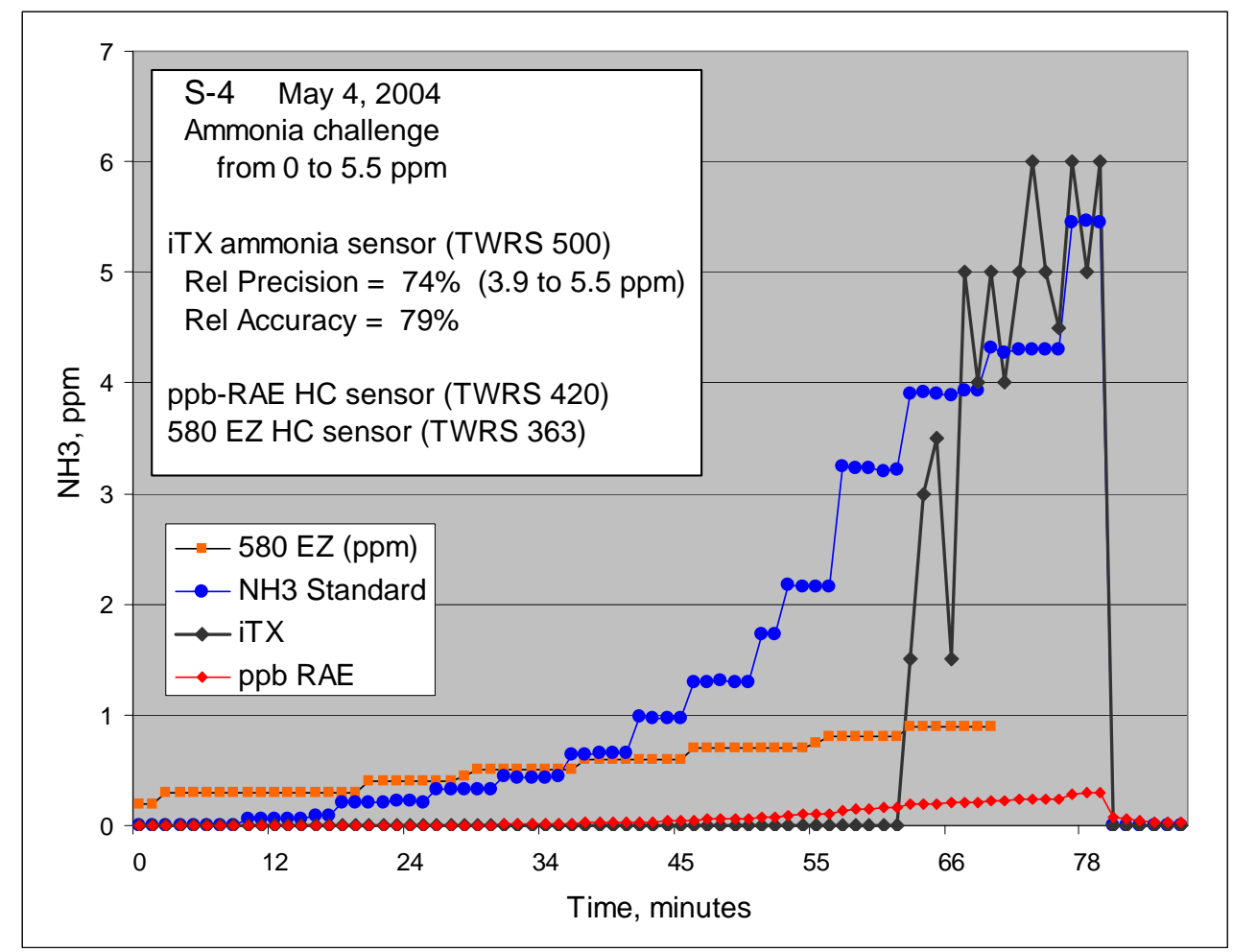

Figure 4.13. iTX Challenge with Various Ammonia Concentrations - Note the effects on the ppb-RAE and 580-EZ, which are designed to measure hydrocarbons. 


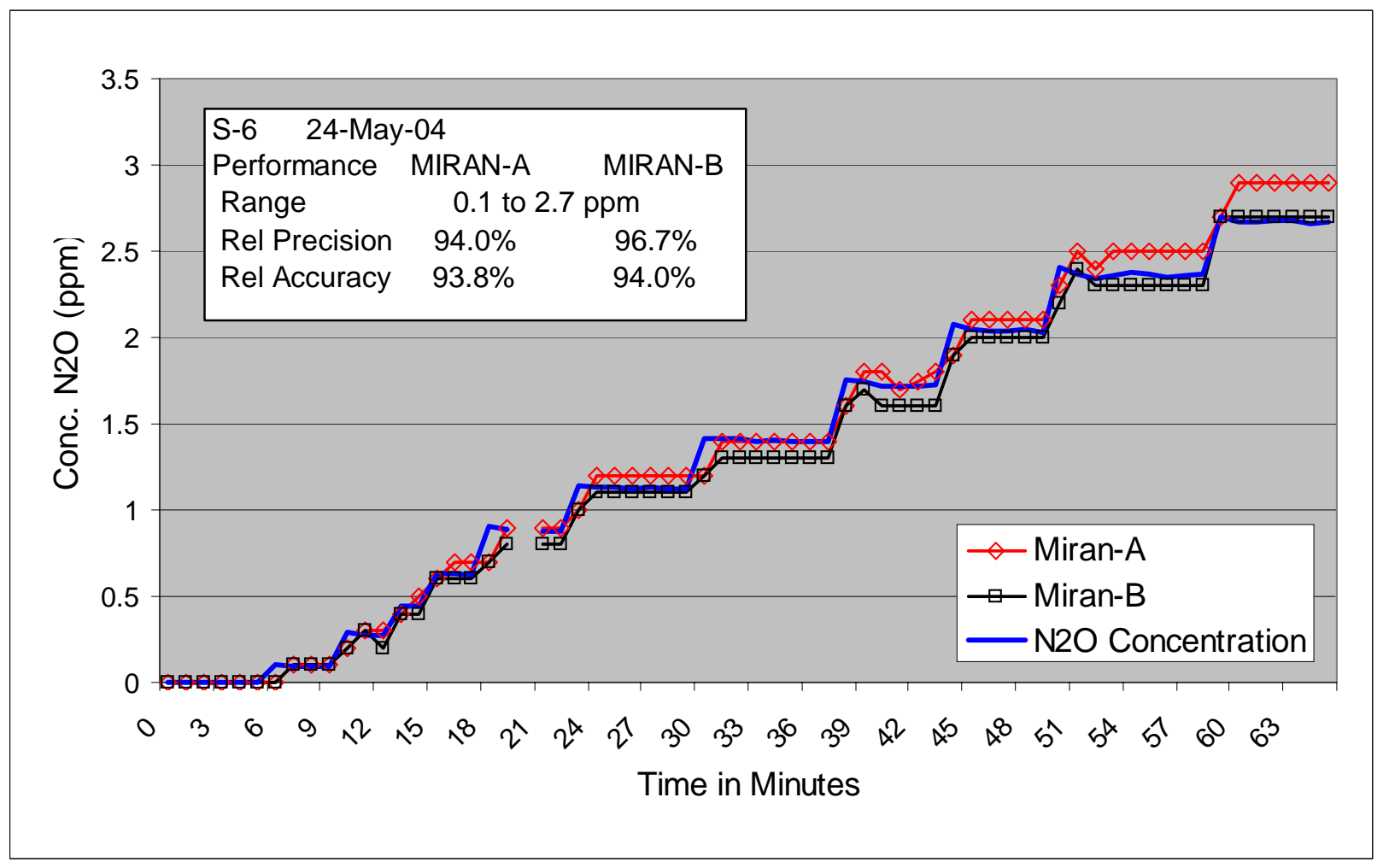

Figure 4.14. Two MIRAN Analyzers Respond to Concentrations of Nitrous Oxide

\subsubsection{Hydrocarbon Stepped Tests}

Table 4.7 summarizes the test results for the stepped tests for hydrocarbon sensors. The ppb-RAE is the primary sensor dedicated to hydrocarbon measurements and the 580-EZ has been used in the past at Hanford. Table 4.6 shows that the iTX and EC-P2 instruments were also challenged with the test gas mixture to observe if they may be influenced by hydrocarbons. Their results are not listed in Table 4.7 because they were not influenced during these tests.

Table 4.7. Summary of Hydrocarbon Sensor Results

\begin{tabular}{|c|c|c|c|c|c|c|c|c|c|}
\hline $\begin{array}{l}\text { Trial } \\
\text { Number }\end{array}$ & $\begin{array}{l}\text { Test } \\
\text { gas }\end{array}$ & Instrument & $\begin{array}{c}\text { Relative } \\
\text { Accuracy }\end{array}$ & Note & $\begin{array}{l}\text { Range of } \\
\text { Accuracy }\end{array}$ & $\begin{array}{c}\text { Relative } \\
\text { Precision }\end{array}$ & \multicolumn{3}{|c|}{ Concentration ppm } \\
\hline \multirow[t]{2}{*}{ S-1 } & HC mix & ppb-RAE & $96 \%$ & (a) & $96 \%$ to $98 \%$ & $99 \%$ & \multirow{2}{*}{\multicolumn{3}{|c|}{0.6}} \\
\hline & & 580-EZ & $-97 \%$ & (a) & $-128 \%$ to $-40 \%$ & $93 \%$ & & & \\
\hline \multirow[t]{2}{*}{ S-2 } & HC mix & ppb-RAE & $95 \%$ & & $91 \%$ to $99 \%$ & $98 \%$ & 0.4 & to & 10 \\
\hline & & 580-EZ & $62 \%$ & & $44 \%$ to $76 \%$ & $98 \%$ & & & \\
\hline \multirow[t]{2}{*}{ S-3 } & HC mix & ppb-RAE & $74 \%$ & & $67 \%$ to $76 \%$ & $97 \%$ & 1.1 & to & 8.4 \\
\hline & & 580-EZ & $85 \%$ & & $55 \%$ to $94 \%$ & $99 \%$ & & & \\
\hline
\end{tabular}


Table 4.7. (contd)

\begin{tabular}{|c|c|c|c|c|c|c|c|c|c|}
\hline \multirow{2}{*}{$\begin{array}{l}\begin{array}{l}\text { Trial } \\
\text { Number }\end{array} \\
\text { S-4 } \\
\end{array}$} & \multirow{2}{*}{$\begin{array}{c}\begin{array}{c}\text { Test } \\
\text { gas }\end{array} \\
\text { HC mix } \\
\end{array}$} & \multirow{2}{*}{$\begin{array}{l}\text { Instrument } \\
\text { ppb-RAE }\end{array}$} & \multirow{2}{*}{$\begin{array}{c}\begin{array}{l}\text { Relative } \\
\text { Accuracy }\end{array} \\
76 \% \\
\end{array}$} & \multirow{2}{*}{$\begin{array}{c}\text { Note } \\
\text { (b) } \\
\end{array}$} & \multirow{2}{*}{$\begin{array}{c}\begin{array}{c}\text { Range of } \\
\text { Accuracy }\end{array} \\
17 \% \text { to } 96 \% \\
\end{array}$} & \multirow{2}{*}{$\begin{array}{c}\begin{array}{c}\text { Relative } \\
\text { Precision }\end{array} \\
-158 \% \\
\end{array}$} & \multicolumn{3}{|c|}{ Concentration ppm } \\
\hline & & & & & & & 0.05 & to & 0.7 \\
\hline & & 580-EZ & $-351 \%$ & & $-710 \%$ to $-15 \%$ & $10 \%$ & & & \\
\hline \multirow[t]{2}{*}{ S-5 } & HC mix & ppb-RAE & $96 \%$ & & $94 \%$ to $98 \%$ & $98 \%$ & 0.4 & to & 2.2 \\
\hline & & 580-EZ & $39 \%$ & & $-11 \%$ to $93 \%$ & $62 \%$ & & & \\
\hline
\end{tabular}

\subsubsection{Ammonia Stepped Tests}

The major instruments used to measure ammonia are the EC-P2 and the iTX. Figure 4.12 shows a typical plot for Test S-4. A range of certified ammonia gas concentrations from zero to about $15 \mathrm{ppm}$ is shown at step changes of several minutes duration. Neither the iTX or the iSP-ITX measure concentrations below 2 to $3 \mathrm{ppm}$. Several phone calls to the technical support staff of the vendor indicated that the instrument should measure from zero up, but the supervisor of the support staff, David Wagoner (2004), said a 2ppm dead-time is programmed into the iTX. When this 2-ppm setpoint is coupled with an intrinsic lag time, the instrument is not able to measure concentrations below about $3.5 \mathrm{ppm}$. Wagoner said the iTX averages the previous 2 to 3 seconds of acquired data before the display is updated each second. It is unclear whether this also applies to logged data. It is observed that both instruments consistently overestimate the amounts of certified gas that is injected, particularly if more time is allowed for a step. One theory is that ammonia, a "sticky" gas, adsorbs on the inner walls of the sample transfer lines and inlet filters of the sensors. The gas molecules buildup on the inner wall surfaces until they become saturated and are then released. These delayed releases along with the entry of new gas may account for the observed excessive gas measurements for the lag times. After the gas is shut off in Figure 4.12, it requires some 5 minutes for the instrument to return to the zero concentration baseline. The instruments were disconnected from the manifold and connected directly to zero air to determine if they would return to the baseline more quickly. That test did not seem to shorten the return to zero.

Interestingly, the dead-band was observed as concentrations increased. Wagner (2004) at ISC claims that the iTX will measure declining ammonia concentrations at less than $3 \mathrm{ppm}$. However, that is not apparent here.

The Manning EC-P2 instrument responded to concentrations in Figure 4.12 but remained on the baseline in Figure 4.13. There was no explanation for this null response in Figure 4.13.

The results for the stepped tests of the ammonia sensors are summarized in Table 4.8. Figure 4.13 shows that the hydrocarbon sensors did respond to the ammonia challenges. Note that the 580-EZ erroneously measure about $2 \mathrm{ppm}$ ammonia at the beginning when $0 \mathrm{ppm}$ of the gas is input. 
Table 4.8. Summary of Ammonia Sensor Results for Stepped Tests

\begin{tabular}{|c|c|c|c|c|c|c|c|c|}
\hline $\begin{array}{l}\text { Trial } \\
\text { Number }\end{array}$ & Instrument & $\begin{array}{c}\text { Relative } \\
\text { Accuracy }\end{array}$ & Note & $\begin{array}{l}\text { Range of } \\
\text { Accuracy }\end{array}$ & $\begin{array}{c}\text { Relative } \\
\text { Precision }\end{array}$ & \multicolumn{3}{|c|}{$\begin{array}{c}\text { Concentration, ppm (basis or } \\
\text { responses) }\end{array}$} \\
\hline \multirow[t]{2}{*}{ S-6 } & iTX & $68 \%$ & & & $95 \%$ & 1 & to & 10 \\
\hline & EC-P2 & $71 \%$ & & & $93 \%$ & & & \\
\hline \multirow[t]{4}{*}{ S-7 } & iTX & $79 \%$ & & $69 \%$ to $90 \%$ & $96 \%$ & 3.9 & to & 5.5 \\
\hline & EC-P2 & & (a) & & & & & \\
\hline & ppb-RAE & $4 \%$ & & & $73 \%$ & 0.3 & to & 3.9 \\
\hline & 580-EZ & $53 \%$ & (b) & & $94 \%$ & 0.09 & to & 5.5 \\
\hline \multirow[t]{4}{*}{ S-8 } & iTX & & (a) & & & & $\begin{array}{l}\sim 2 \mathrm{ppm}, \\
\text { maximum }\end{array}$ & \\
\hline & EC-P2 & & (c) & & & & $\begin{array}{l}\sim 2 \mathrm{ppm}, \\
\text { maximum }\end{array}$ & \\
\hline & ppb-RAE & $43 \%$ & & $8 \%$ to $60 \%$ & & 1 & to & 2.1 \\
\hline & 580-EZ & $55 \%$ & & $23 \%$ to $73 \%$ & & 1 & to & 2.1 \\
\hline \multirow[t]{4}{*}{ S-9 } & iTX & $67 \%$ & & $45 \%$ to $88 \%$ & $92 \%$ & 3.8 & to & 15.6 \\
\hline & EC-P2 & $81 \%$ & & $77 \%$ to $85 \%$ & $96 \%$ & 3.8 & to & 15.6 \\
\hline & ppb-RAE & $4 \%$ & & & $95 \%$ & 2.2 & to & 15.6 \\
\hline & 580-EZ & $18 \%$ & & & $98 \%$ & 3.8 & to & 15.6 \\
\hline \multicolumn{9}{|c|}{$\begin{array}{l}\text { (a) zero response during tests } \\
\text { (b) } 0.3 \text { ppm baseline; omitted } 4 \mathrm{ppm} \text {-level; only } 1 \text { of } 6 \text { responses recorded; no vales recorded at } 5.5 \mathrm{ppm} \text { - } \\
\text { level } \\
\text { (c) EC-P2 gave } 2 \text { responses out of } 5 \text { measurements at about } 1 \mathrm{ppm}\end{array}$} \\
\hline
\end{tabular}

It can be seen in Figure 4.13 that a ppb-RAE reading of $0.2 \mathrm{ppm}$ approximately corresponded to an ammonia reading of $4.3 \mathrm{ppm}$ and that about $0.3 \mathrm{ppm}$ on the ppb-RAE corresponded to an ammonia concentration of about $5.4 \mathrm{ppm}$. A comment received on a draft of this document indicates that industrial hygiene staff at Hanford have correlated ppb-RAE readings with measurements of ammonia, absent other gases including hydrocarbons. Their assumption is that a $2 \mathrm{ppm}$ ppb-RAE reading approximates an ammonia reading of $25 \mathrm{ppm}$. Though the runs were not initially designed to consider extrapolations, it appears from this data that a ppb reading of 2 ppm would approximately correlate with ammonia concentrations of $40 \mathrm{ppm}$. Correction factors are available to help with this type of extrapolation but were not considered in this preliminary calculation.

\subsubsection{Nitrous Oxide Stepped Tests}

The two MIRAN analyzers seen in Figure 4.14 performed extremely well over the stepped range of nitrous oxide concentrations, even tracking the short-step changes of 2 minutes. The MIRAN A instrument shows a slight but consistent bias for over-estimating nitric oxide concentration over the range 
shown in Figure 4.14 while MIRAN B slightly underestimates the gas. This is most likely a calibration issue. More interesting is the clear measurement of ammonia at concentrations below the vendor's declared detection limit.

One test of the Bacharach is also shown in Table 4.9 that summarizes the stepped tests for sensors that measure nitric oxide. At first, this instrument seemed to measure only in increments of 5 ppm but it was found that it could see 1-ppm changes with considerable lag time.

Table 4.9. Summary of Stepped Tests of $\mathrm{N}_{2} \mathrm{O}$ Sensors

\begin{tabular}{|c|c|c|c|c|c|c|c|}
\hline \multirow{2}{*}{$\begin{array}{l}\begin{array}{l}\text { Trial } \\
\text { Number }\end{array} \\
\text { S-10 }\end{array}$} & \multirow{2}{*}{$\begin{array}{l}\text { Instrument } \\
\text { MIRAN B }\end{array}$} & \multirow{2}{*}{$\begin{array}{c}\begin{array}{c}\text { Relative } \\
\text { Accuracy }\end{array} \\
81 \%\end{array}$} & \multirow{2}{*}{$\begin{array}{c}\begin{array}{c}\text { Range of } \\
\text { Accuracy }\end{array} \\
31 \% \text { to } 93 \%\end{array}$} & \multirow{2}{*}{$\begin{array}{c}\begin{array}{c}\text { Relative } \\
\text { Precision }\end{array} \\
66 \%\end{array}$} & \multicolumn{3}{|c|}{$\begin{array}{c}\text { Concentration } \\
\text { Range (ppm) }\end{array}$} \\
\hline & & & & & 0.15 & to & 1.95 \\
\hline \multirow[t]{2}{*}{ S-11 } & MIRAN A & $81 \%$ & $52 \%$ to $98 \%$ & $88 \%$ & 0.1 & to & 4.4 \\
\hline & MIRAN B & $83 \%$ & $58 \%$ to $99 \%$ & $91 \%$ & 0.1 & to & 4.4 \\
\hline S-12 & MIRAN B & $75 \%$ & $52 \%$ to $92 \%$ & $71 \%$ & 0.15 & to & 0.64 \\
\hline \multirow[t]{2}{*}{ S-13 } & MIRAN B & $77 \%$ & $73 \%$ to $84 \%$ & $99 \%$ & 48 & to & 72 \\
\hline & Bacharach & $85 \%$ & $81 \%$ to $92 \%$ & $92 \%$ & 48 & to & 72 \\
\hline \multirow[t]{2}{*}{ S-14 } & MIRAN A & $71 \%$ & $70 \%$ to $71 \%$ & $94 \%$ & 22 & to & 43 \\
\hline & MIRAN B & $69 \%$ & $68 \%$ to $70 \%$ & $92 \%$ & 22 & to & 43 \\
\hline \multirow[t]{2}{*}{ S-15 } & MIRAN A & $97 \%$ & $97 \%$ to $98 \%$ & $99 \%$ & 0.49 & to & 1.85 \\
\hline & MIRAN B & $97 \%$ & $96 \%$ to $98 \%$ & $99 \%$ & 0.49 & to & 1.85 \\
\hline
\end{tabular}

\subsubsection{Graphs of Stepped Test Results}

Fourteen pairs of graphs follow (Figure 4.15) that summarize the stepped tests described in Table 4.6. S-8 is omitted because only zero values were obtained. Tolerance values, where provided on the instruments furnished for testing by CH2M-Hill, have been plotted to illustrate goodness of performance. Some plots show closely clustered data where a number of data points are stacked on top of each other these have high precision, while others show considerable scatter (see S-1b). High accuracy occurs when all of the points fall on the diagonal line which indicates absolute agreement between the certified standard and the measured values. In some cases, the values fall on the line part of the time but depart at some point, such as in S-11a and b. The ammonia plots clearly show how the iTX remains on the zero concentration level until it reaches about $3.5 \mathrm{ppm}$ of ammonia at which time it responds to the gas. The instrument is moderately accurate and precise.

S-1a shows that the ppb-RAE is highly accurate and precise with a filter installed but when the filter is removed, it is still highly precise but low in accuracy. One instrument arrived for testing without an inlet filter. In general, tests were performed on the instruments as they were delivered from the field, assuming that they may have been operated as they were received by PNNL. 

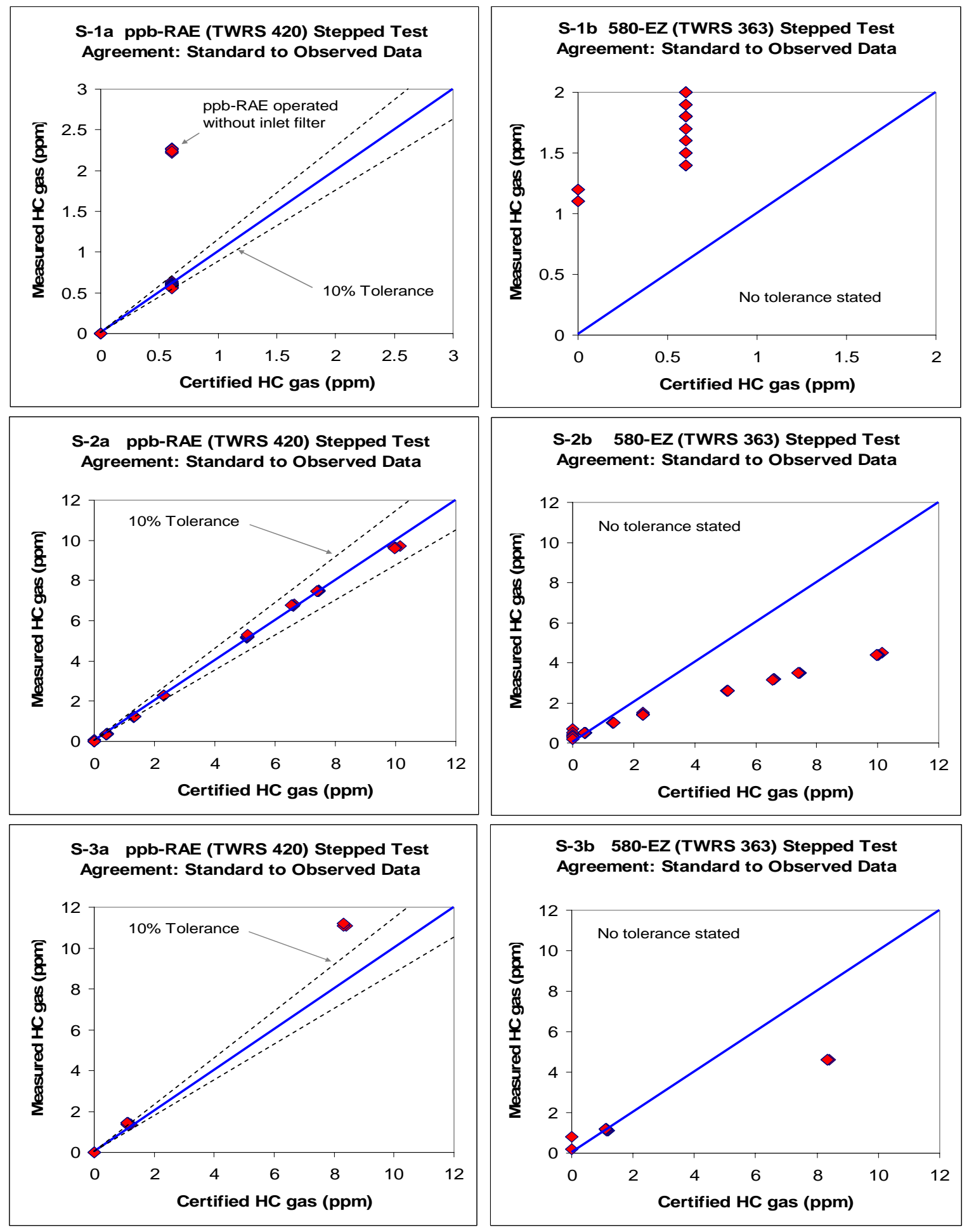

Figure 4.15. Fourteen Tests for Hydrocarbon, Ammonia, and Nitrous Oxide Responses 

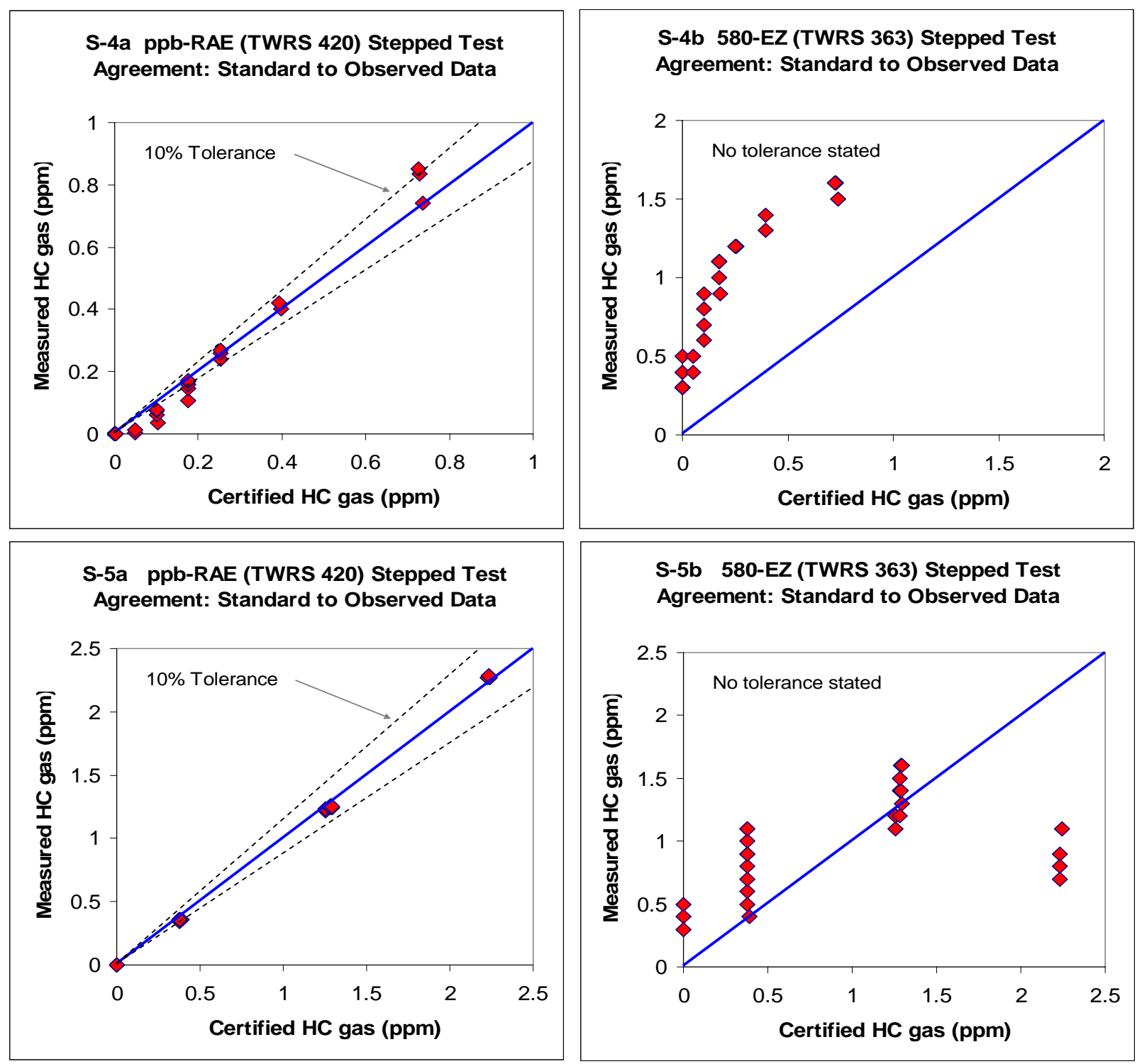

Figure 4.15. (contd) 

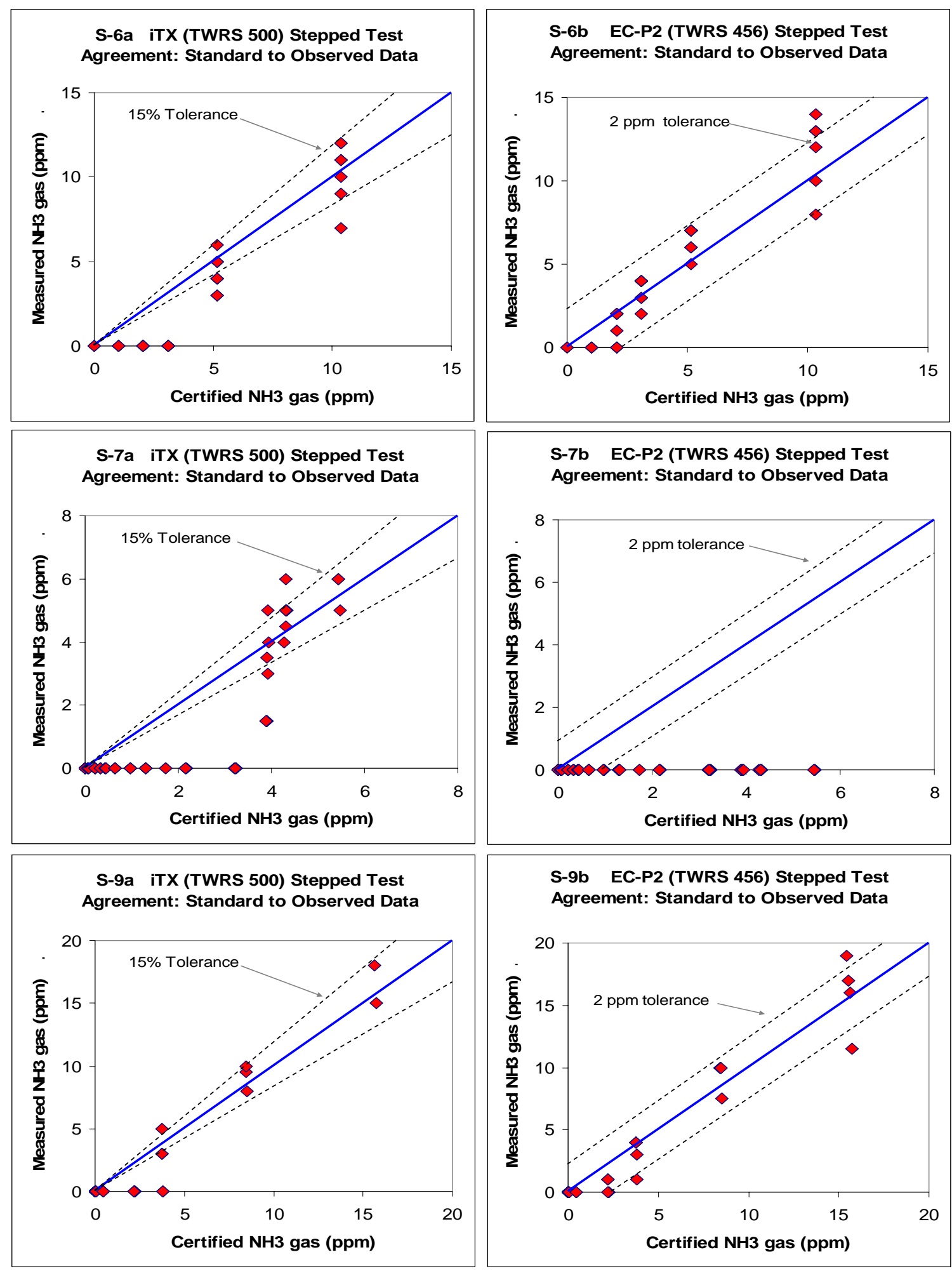

Figure 4.15. (contd) 

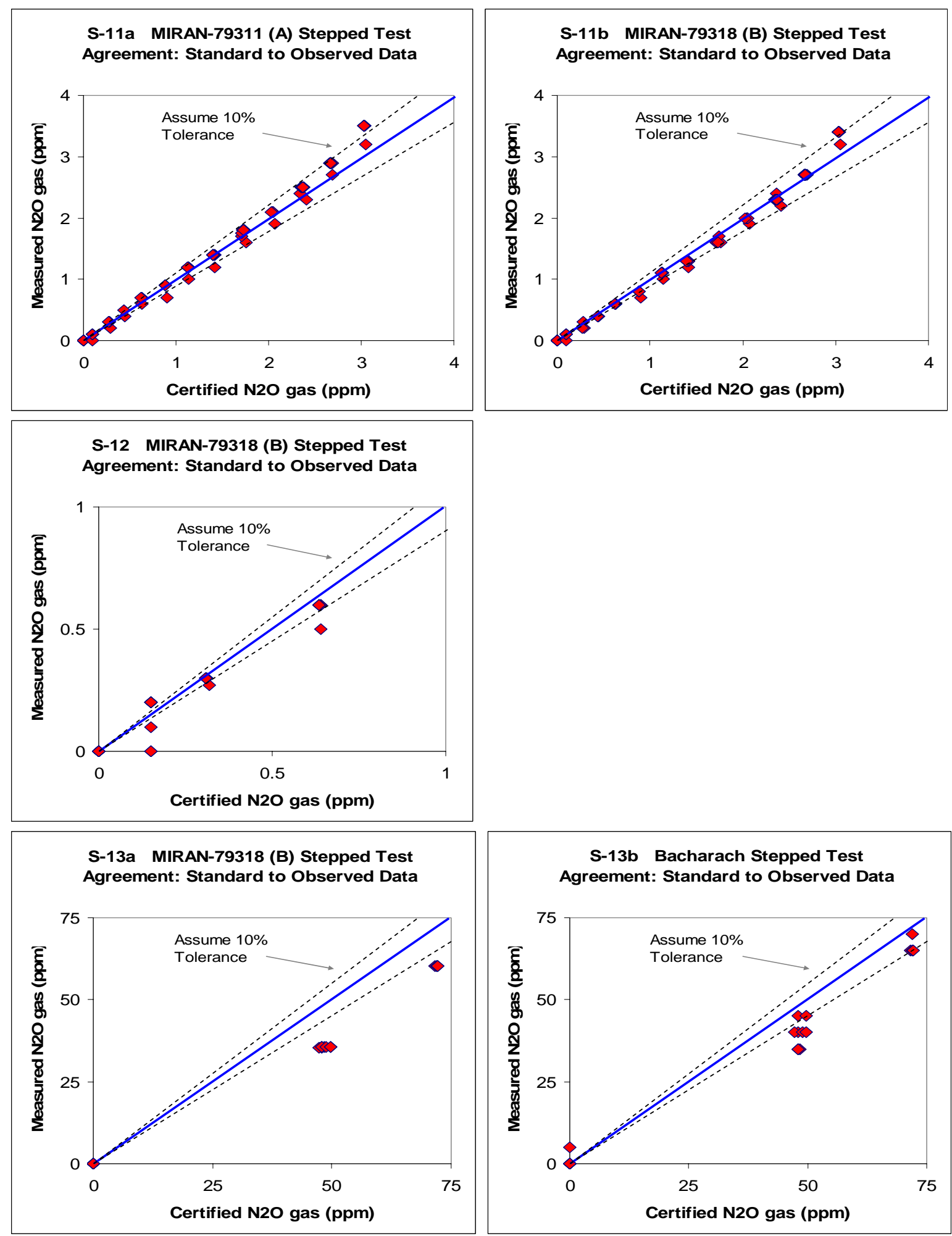

Figure 4.15. (contd) 

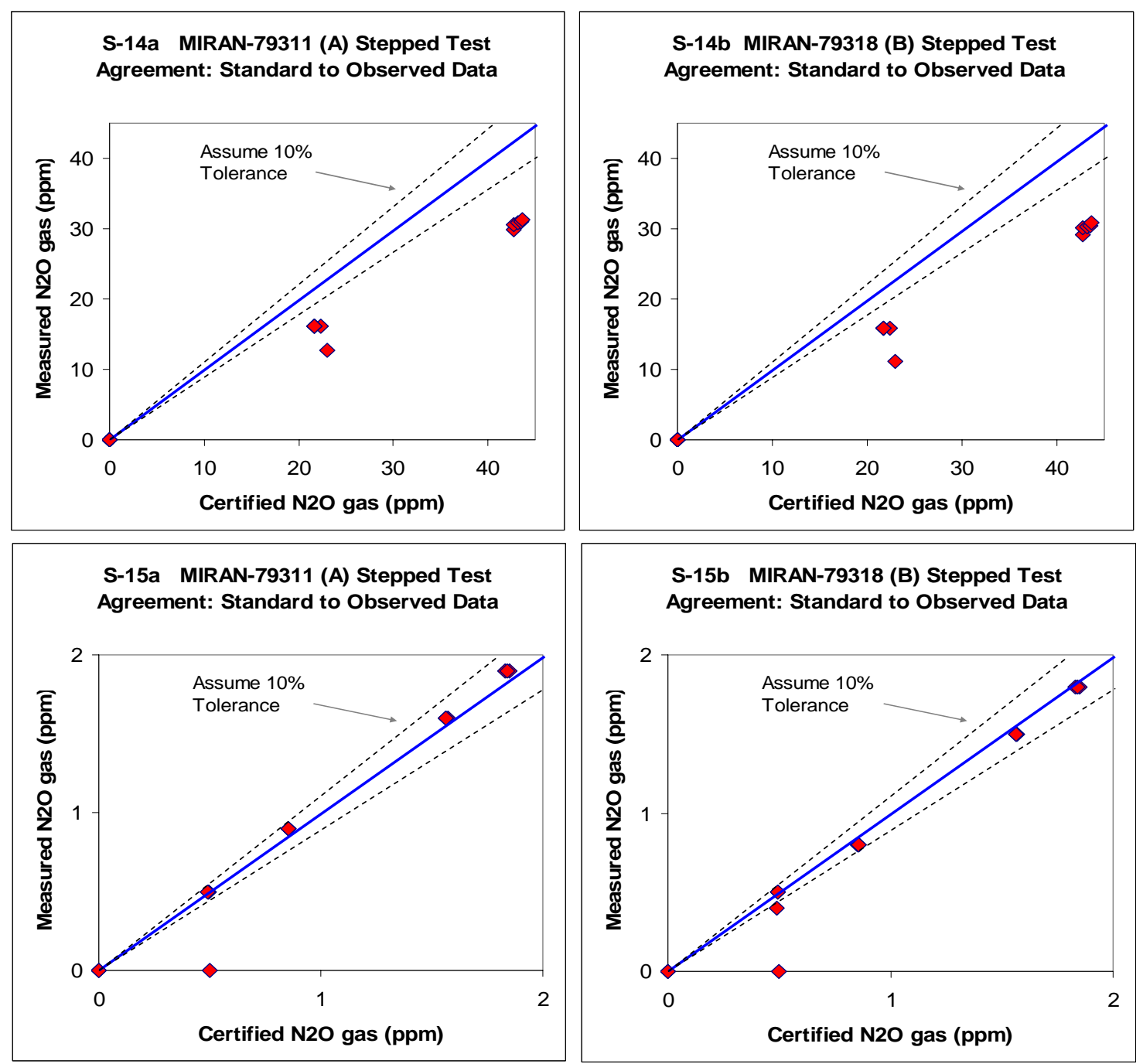

Figure 4.15. (contd)

The plots of the MIRAN tests show that they performed well at low nitrous oxide concentrations but departed from the ideal concentration values at higher concentrations. The occasional outlier seen on the zero baseline in S-15a and b are transition values that occurred because of the slow response and lag times inherent in the instrument caused by the need to exchange the gaseous contents of the large sampling cell.

\subsection{General Observations}

\subsubsection{Use of MIRAN Chemical Filters}

It was discovered when zeroing the MIRAN instruments that the supplied chemical filters did not obtain the same results as found when zeroing the instrument on pure Aadco air. Even though the instrument displayed an "OK" when zeroed using the chemical filter, its readings went negative when it was then subjected to zero air from the Aadco system in preparation for a gas trial run. The trace was driven 
negative by approximately 15\%. This was evidence that the chemical filters, which were protected from the ambient air in a Ziplok bag, as delivered to PNNL with the newly acquired instruments, were not able to obtain a true zero baseline. Except for several early runs, the chemical filter was not used during the testing. It is interesting that when the negative readings, recorded for the tests, were used as though they were good data points, the overall test results were considered satisfactory. The negative readings were zeroed out by adding the same positive number to all data points for the run.

\subsubsection{Instrument Sample Inlet Flow and Use of Filters}

In general "proper" instrument sample flow is essential to correct concentration measurement. Wagner (2004) maintains that most of the handheld instruments are diffusion mode instruments, that is, some amount of air must come in contact with a lamp or detector. If the flow is increased, the response time is shortened. Basically, a flow within a narrow range is essential for proper calibration of an instrument. The instrument should then be operated at the conditions used during the calibration.

The flowrates with the ppb-RAE varied considerably, as seen in Table 4.7. The "Perkes" instrument maintained a flow of $323 \mathrm{cc} /$ minute with the exposed filter that was installed in the instrument from the field. When replaced with a new filter, the flow jumped to $448 \mathrm{cc} /$ minute. Is the lower flow considered sufficient? According to a contacted RAE technical service representative, the pump should be rebuilt or replaced when the flow becomes less than $350 \mathrm{cc} /$ minute and the data should be invalidated. However, RAE's application chemist (Haag 2004) indicated that the flow is not so crucial so long as the inlet system does not leak. A leak would dilute the measured concentration. Haag suggested that a flow difference between 350 and 450 might correspond to a concentration difference of about $2 \%$. The calibrations should be made at flows that are approximately those obtained in the field. He said a greater concern lies, at least for the RAE instruments, with the amount of moisture in the air. Concentrations are significantly compromised when the relative humidity is greater then $50 \%$. At $40 \%$ relative humidity at $24^{\circ} \mathrm{C}$ the observed concentration will be reduced by $15 \%$ in the sensors. Note that the PNNL laboratory tests were conducted using dry certified gases and zero air and that the dilution air stream was humidified to relative humidity levels of 20 to $35 \%$ to be representative of field conditions.

Overall, sample inlet flows seemed adequate for sampling but there are questions that were not evaluated. We accepted the manufacturer's advice that the observed drops in flow of 30\% are negligible relative to measured concentrations.

However, Run S-1a, seen above in Section 4.3.4, causes concern relative to sample flow and to most of what is described within this section. In general, the vendors maintain that flow is important but not crucial. But in the ppb-RAE Run S-1a, the flow doubled when the inlet filter was removed and the measured concentration increases by about four times. It is assumed that the instruments are operated with inlet filters, but one instrument was received for PNNL testing that did not contain an inlet filter.

The instruments were tested "as received" from the field, During flow measurements the instrument were inverted, held vertical, placed on their sides, etc., during the measurement of flow to determine if position had any effect on the operation of the sensor, and particularly if position might affect on-going concentration readings. It was discovered for one ppb-RAE instrument that the flow nearly doubled when the 
instrument was held vertical. The two filter-holder o-rings that prevent sample leakage were damaged from separating and reattaching the assembly to the pump. When the o-rings were replaced, the instrument worked flawlessly.

The pumps on the test instruments were sufficient to maintain flow rates for hours to days without recharging the batteries. The pump in the iTX appears to be the only instrument tested that maintains a reasonably "constant” sample flow.

The conventional field test used by operators involves pushing in on the air inlet of the filter holder to plug it. If an alarm sounds within several seconds to indicate a flow obstruction, the instrument is assumed to function properly. This seemed to be adequate but it may not detect leaks associated with pulling on the filter assembly or pushing it to the side. On the other hand, a leak in the field may not be crucial unless a wand is used such as that provided on the MIRAN. Some of the instruments may be used with sample probes that can be inserted into vents and pipes or to sample leaks on valves and fixtures. Clearly, a leak in such a probe could be more crucial because of higher expected concentrations of gases.

The sample flow within the MIRAN instruments was not critical to correct concentration measurement. However, low flow leads to slower response times. The MIRAN contains a 2.23-liter cell that must be purged to eventually obtain correct readings (MIRAN 205B Manual 2004). PNNL measured flows at 11 liters/minute for the MIRAN, as shown in Table 4.10. The manufacturer, Thermo Electron, states in their manual that the instrument samples at 14 liters/minute with the wand and with an installed particulate filter. The vendor flow rates could not be duplicated even without the particulate filter using 3/4-inch (ID) mass-flow-meters that offer virtually no flow resistance. The vendor's technical people indicated that only they can correctly measure the flow through the instrument. With a sample inlet flow of 14 liters/minute the instrument should exchange its contents each 9.6 seconds, but an actual flow of 11 liters minute results in an exchange each 12 seconds. The manual states that a $99 \%$ purge of the sample cell requires a 5-second exchange of the cell volume.

Some attention was directed toward the condition of the sample filter and the inlet sample filter holder. Most instruments were delivered for testing with filters that were visibly soiled. It was not known how often filters are changed when the instruments are in use - clearly, one windy day at Hanford can contribute considerable dust, so a fixed schedule may not answer the question. But the tests were not designed to evaluate the conditions of the filters, so tests were not run that would evaluate concentration changes relative to the condition of a filter paper. 
Table 4.10. Measured Instrument Flowrates, Filters, Inlet Sample Lines

\begin{tabular}{|c|c|c|c|c|c|c|c|}
\hline Sensor & Test date & $\begin{array}{c}\text { Flowrate } \\
\text { cc/min }\end{array}$ & $\begin{array}{c}\text { Data points } \\
\text { avg'd after } \\
\text { warmup }\end{array}$ & Mass flow meter & $\begin{array}{c}\text { Lab } \\
\text { Temp } \\
{ }^{\circ} \mathrm{C} \\
\end{array}$ & Filter & $\begin{array}{c}\text { Sample } \\
\text { line } \\
\text { length } \\
\text { (inch) }\end{array}$ \\
\hline 580 EZ (TWRS 363) & 26-Apr-04 & 352 & 9 & Sierra500 SN 76406 & 25.7 & $\begin{array}{l}\text { No inlet filter } \\
\text { provided }\end{array}$ & 22 \\
\hline ppb-RAE (TWRS 413) & 13-Apr-04 & 223 & 8 & Sierra500 SN 76406 & 25.7 & $\begin{array}{l}\text { w/ inlet filter } \\
\text { from field }\end{array}$ & 33 \\
\hline ppb-RAE (TWRS 413) & 13-Apr-04 & 435 & 7 & Sierra500 SN 76406 & 25.7 & $\begin{array}{l}\text { w/out inlet } \\
\text { filter (no new } \\
\text { filters avail- } \\
\text { able, at test) }\end{array}$ & 33 \\
\hline ppb-RAE* (TWRS 420) & 3-May-04 & 323 & 8 & Sierra500 SN 76406 & 23.4 & $\begin{array}{l}\text { w/inlet filter } \\
\text { from field }\end{array}$ & 30 \\
\hline ppb-RAE (TWRS 420) & 3-May-04 & 448 & 17 & Sierra500 SN 76406 & 23.4 & $\begin{array}{l}\text { w/new filter } \\
\text { in inlet }\end{array}$ & 30 \\
\hline $\begin{array}{l}\text { Manning EC-P2** } \\
\text { (TWRS 456) }\end{array}$ & 3-May-04 & 249 & 17 & Sierra500 SN 76406 & 24.4 & $\begin{array}{l}\text { w/inlet filter } \\
\text { from field }\end{array}$ & 25est. \\
\hline Manning EC-P2 (TWRS 456) & 3-May-04 & 260 & 12 & Sierra500 SN 76406 & 24.4 & $\begin{array}{l}\text { w/new filter } \\
\text { in inlet }\end{array}$ & 25est. \\
\hline iTX (TWRS 551) & 3-May-04 & 486 & 11 & Sierra500 SN 76406 & 24.4 & $\begin{array}{l}\text { w/inlet filter } \\
\text { from field }\end{array}$ & 28 \\
\hline iTX (TWRS 551) & 3-May-04 & 498 & 10 & Sierra500 SN 76406 & 24.4 & $\begin{array}{l}\text { w/new filter } \\
\text { in inlet }\end{array}$ & 28 \\
\hline
\end{tabular}


Table 2-14. (contd)

\begin{tabular}{|c|c|c|c|c|c|c|c|}
\hline Sensor & Test date & $\begin{array}{c}\text { Flowrate } \\
\text { cc/min }\end{array}$ & $\begin{array}{c}\text { Data points } \\
\text { avg'd after } \\
\text { warmup }\end{array}$ & Mass flow meter & $\begin{array}{c}\text { Lab } \\
\text { Temp } \\
{ }^{\circ} \mathrm{C} \\
\end{array}$ & Filter & $\begin{array}{c}\text { Sample } \\
\text { line } \\
\text { length } \\
\text { (inch) }\end{array}$ \\
\hline iTX $^{* * *}$ (TWRS 551) & 3-May-04 & 508 & 8 & Sierra500 SN 76406 & 24.4 & $\begin{array}{l}\text { w/new filter } \\
\text { in inlet }\end{array}$ & 28 \\
\hline 580 EZ (TWRS 363) & 3-May-04 & 343 & 9 & Sierra500 SN 76406 & 24.4 & $\begin{array}{l}\text { No inlet filter } \\
\text { provided }\end{array}$ & 47.5 \\
\hline Bacharach (TWRS 828) & 26-May-04 & 253 & 13 & Sierra500 SN 76406 & 23.1 & $\begin{array}{l}\text { w/inlet filter } \\
\text { from field }\end{array}$ & 33.3 \\
\hline MIRAN-A (no TWRS no.) & 26-May-04 & $10.8 \mathrm{lpm}$ & -- & Sierra SN 70855 & 23.1 & $\begin{array}{l}\text { w/out inlet } \\
\text { filter }\end{array}$ & 63 \\
\hline MIRAN-B (no TWRS no.) & 26-May-04 & 11.3 lpm & -- & Sierra SN 70855 & 23.1 & $\begin{array}{l}\text { w/out inlet } \\
\text { filter }\end{array}$ & 63 \\
\hline \multicolumn{8}{|c|}{$\begin{array}{l}\text { * Found and corrected problem with o-ring leakage in inlet filter assembly. } \\
\text { ** Pushing or pulling on filter holder, changes the flowrate from about } 249 \mathrm{cc} / \mathrm{min} \text { to } 300 \mathrm{cc} / \mathrm{min} \text {. } \\
\text { *** Removed the clean, new filter, operated } 10 \text { minutes without a filter, then re-installed new filter. } \\
\text { Barometric P constant at about } 752-755 \mathrm{~mm} \text { Hg. } \\
25 \text { mm Filter Papers are Pall Life Sciences, Ze FluorTM, } 1 \mu \mathrm{m} \text {, Part No. P5PL025, Lot } 30451 . \\
\text { Readings made on instruments as received from the field. } \\
\text { Conventional CH2M-Hill sensor test: plug inlet filter, if instrument alarm sounds within about } 3 \text { seconds, it was considered OK. }\end{array}$} \\
\hline
\end{tabular}




\subsection{Conclusions}

The laboratory tests were designed to challenge the monitors over lower concentration regions of their nominal response ranges. The tests aimed to quantify the performance of the industrial hygiene monitors under conditions that are deemed to be close to those observed in the field. In general, each instrument was tested as it was received from the field. It was assumed that the testing would be representative of use with no initial conditioning of an instrument.

The purpose of this work was to evaluate the performance of commercially available industrial hygiene air monitoring instruments that were provided for testing. The instruments were tested to determine their accuracy and precision as well as how quickly they can respond to a range of gaseous chemical concentrations. The plots shown in the results Section 4.0 are examples of the tests performed.

No regulatory criteria were pre-established for the testing, and PNNL is not making recommendations on the acceptability of the equipment even though it has conducted the testing. These values were affixed to all instruments that were tested excepting the MIRANs. The MIRAN instruments were recently acquired by CH2M-Hill with factory calibrations and were not re-calibrated onsite prior to this testing.

The Hanford Site is supportive of this monitoring program as $\mathrm{CH} 2 \mathrm{M}-\mathrm{Hill}$ has local access to calibration and maintenance facilities as well as having informed field operators and management personnel. Table 5.1 lists the tolerances that were affixed to most instruments following onsite calibrations. PNNL did not evaluate the local calibration service capabilities.

Table 5.1. Acceptable Tolerance Values for Test Instruments

\begin{tabular}{||l|l||}
\hline Instrument & Tolerance \\
\hline Industrial Scientific iTX & $15 \%$ \\
\hline ppb-RAE & \pm 20 ppb or $10 \%$ \\
\hline MIRAN & Not determined* \\
\hline Manning EC-P2 & $\pm 2 \%$ \\
\hline $580-E Z(O V M)$ & None listed \\
\hline AreaRAE & $\pm 10 \%$ \\
\hline
\end{tabular}

Together, the acceptable tolerance values and the relative accuracies provide a measure of instrumental performance. This is a measure of the percent difference between what is observed during instrument testing and a standard that has been certified for accuracy by calibration laboratories that meet testing standards established by the National Institutes of Standards and Technology (NIST).

Tables 5.2 and 5.3 summarize the tests that were performed with the instruments tested for transient released gases and releases that were sustained at selected concentrations over time. Essentially, the transient tests represent gas releases that jump from some zero concentration to a higher value in a time-frame of a few seconds. The concentrations ranged from 0 to $100 \mathrm{ppm}$ for the hydrocarbon and nitric oxide gases. Lower concentrations of ammonia were used to minimize damage to gold-plated 
Table 5.2. Summary of Transient Test Results

\begin{tabular}{|c|c|c|c|c|c|}
\hline Gas Measured & $\begin{array}{c}\text { Test } \\
\text { Instruments }\end{array}$ & $\begin{array}{c}\text { Challenge Conc. } \\
\text { (ppm) }\end{array}$ & $\begin{array}{c}\text { Relative } \\
\text { Accuracy }\end{array}$ & $\begin{array}{c}\text { Relative } \\
\text { Precision }\end{array}$ & $\begin{array}{c}\text { T }_{90} \text { Response } \\
\text { Time }\end{array}$ \\
\hline \multirow[t]{6}{*}{ Hydrocarbon mix } & ppb-RAE & 2 & $92 \%$ & $97 \%$ & 53 \\
\hline & & 11 & $78 \%$ & $99 \%$ & 31 \\
\hline & & 104 & $89 \%$ & $99 \%$ & 13 \\
\hline & Area-RAE & 2 & $62 \%$ & $94 \%$ & 71 \\
\hline & & 11 & $92 \%$ & $98 \%$ & 63 \\
\hline & & 104 & $47 \%$ & $98 \%$ & 15 \\
\hline \multirow[t]{3}{*}{ Ammonia } & iTX & 25 & $55 \%$ & $96 \%$ & 210 \\
\hline & & 50 & $65 \%$ & $97 \%$ & 164 \\
\hline & & 50 & $90 \%$ & $98 \%$ & 101 \\
\hline \multirow[t]{4}{*}{ Nitric oxide } & MIRAN & 1 & $96 \%$ & $98 \%$ & 42 \\
\hline & & 25 & $99 \%$ & $98 \%$ & 45 \\
\hline & & 55 & $90 \%$ & $99 \%$ & 38 \\
\hline & & 101 & $96 \%$ & $99 \%$ & 59 \\
\hline
\end{tabular}

surfaces within the MIRAN cells. These tests simulated a release of a gas in a worker environment where the gas is quickly mixed with dilution air under conditions that can change very rapidly. The question answered in these tests is whether the instruments can quickly and reliably measure the variable gas concentrations seen in the field.

This work was conducted to assess the performance of the available instrumentation with regard to measurement capabilities over the spectrum of releases. While mostly zero readings are observed in worker environments, some peaks in gaseous concentrations may occur. The rise time indicates how fast an instrument can reach $90 \%$ of some delivered test gas concentration. Instruments with long rise or response times will measure averaged concentration of the gases that are exposed to workers and effectively moderate any potentially observed concentration peaks.

Relative accuracies are important because they indicate how closely an instrument can measure the actual concentration of a gas that is released. The precision measurement indicates how closely data points cluster around each other.

The test results are summarized in Table 5.2 in terms of accuracy, precision, and response time (expressed as the $\mathrm{T}_{90}$ time required for an instrument to reach $90 \%$ of the challenge concentration). The relative precisions for all transient tests are high. This parenthetically indicates that the PNNL test-bench and gasdelivery system used in the testing were adequate. Overall, the relative accuracies vary (relative to the certified gas standards) in the following order from highest to lowest: MIRAN > ppb-RAE > iTX > AreaRAE. It is interesting that the response times are lowest for the highest concentrations of hydrocarbons. This may be an artifact of the PNNL gas-delivery dilution flow. The indicated times are longer than the lag times listed in Appendix D. The response times are not explained in general, but it is clear that ammonia-sensing is associated with longer lag times. 
Best precision estimates are reflected in a low number. Here, we represent goodness of agreement using relative values that were obtained by subtracting the accuracy and precision values from 1 . Consequently, the best relative accuracy and relative precision numbers are those that are close to $100 \%$.

The General Stepped tests summarized in Table 5.3 and described in Section 4.5 proved to be much more rigorous tests of the equipment. Certified gas concentrations were delivered to the instruments over differing time periods, perhaps 3 minutes at one concentration, perhaps 5 minutes to the next concentration, and so forth. These simulations were conducted to evaluate the non-steady-state release that is judged to occur in the field. The $\mathrm{T}_{90}$ rise or response times mentioned above are important. If an instrument is only marginally able to stabilize at a level before the next step change occurs, its precision and accuracy will be lower. If the instrument can track the changes quickly and measure the delivered concentration of the test gas (ammonia, mixed hydrocarbons, or nitrous oxide), it will obtain high relative precision and accuracy scores.

Three major instruments were highlighted to show their relative accuracy over measurement concentrations used in the tests. As noted earlier, the tests were generally performed at concentrations less than about $10 \mathrm{ppm}$ of each test gas, but several runs were also made at higher levels. The ppb-RAE proves to be both precise and accurate over most hydrocarbon concentration ranges tested as seen in Figure 5.1. It is, however, less accurate below levels of about $200 \mathrm{ppb}$ or $0.2 \mathrm{ppm}$. Of all of the instruments, it has the best response time.

Table 5.3. Summary of Stepped Test Results

\begin{tabular}{|c|c|c|c|c|}
\hline Gas Measured & $\begin{array}{c}\text { Test } \\
\text { Instruments }\end{array}$ & Range (ppm) & $\begin{array}{c}\text { Relative } \\
\text { Accuracy }\end{array}$ & $\begin{array}{c}\text { Relative } \\
\text { Precision }\end{array}$ \\
\hline \multirow[t]{3}{*}{$\begin{array}{c}\text { Hydrocarbon } \\
\text { mix }\end{array}$} & ppb-RAE & low: 0.3 to 3 & $95 \%$ & $95 \%$ \\
\hline & & med: 3 to 10 & $95 \%$ & $95 \%$ \\
\hline & 580-EZ & med: 3 to 10 & 55 to $94 \%$ & $85 \%$ \\
\hline \multirow[t]{4}{*}{ Ammonia } & iTX & med: 3 to 6 & 70 to $90 \%$ & $96 \%$ \\
\hline & & med: 3 to 10 & $68 \%$ & $95 \%$ \\
\hline & & med: 3 to 15 & $67 \%$ & $92 \%$ \\
\hline & EC-P2 & med: 3 to 15 & $81 \%$ & $96 \%$ \\
\hline \multirow[t]{3}{*}{ Nitric oxide } & MIRAN & low: 0.3 to 3 & $\sim 90 \%$ & $\sim 90 \%$ \\
\hline & & med: 3 to 15 & $\sim 70 \%$ & $\sim 95 \%$ \\
\hline & & high: 20 to 70 & $\sim 75 \%$ & $\sim 95 \%$ \\
\hline
\end{tabular}




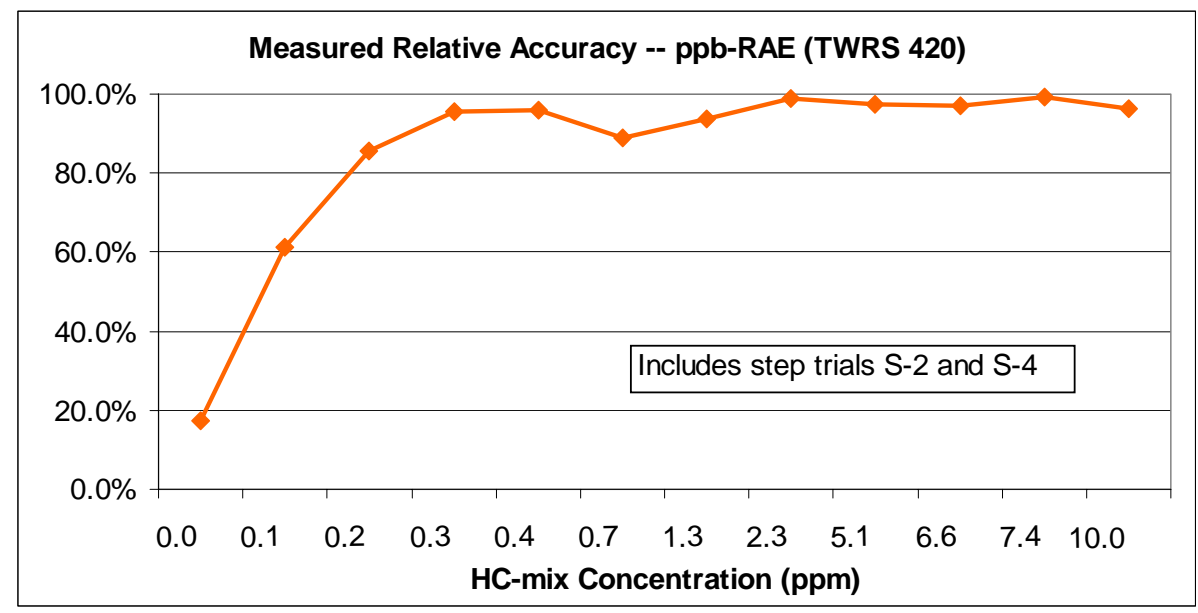

Figure 5.1. ppb-RAE Relative Accuracy versus Concentration

The iTX ammonia sensor is moderately precise and accurate at concentrations below about 15 ppm, as seen in Figure 5.2. The built-in dead-band below about 3.5 ppm ammonia clearly limits its capability for measuring the typically low concentrations expected at Hanford.

As shown in Figure 5.3, the MIRAN instrument is highly accurate and precise when measuring nitric oxide concentrations below about $3 \mathrm{ppm}$. Its lower detection limit is about $200 \mathrm{ppb}$ or $0.2 \mathrm{ppm}$. When it can be operated for more than 2 minutes, it obtains excellent results. When it was configured in one test to measure ammonia, it responded about as well as it did with nitric oxide but with a slightly longer lag time. Even though the instruments tested relied on factory calibrations, because they were either newly purchased or leased and had not been calibrated locally, they performed well. It was found that the instrument sampling flowrate ran about $80 \%$ of that reported by the vendor. Obviously, a faster flowrate would boost the instrument's response time.

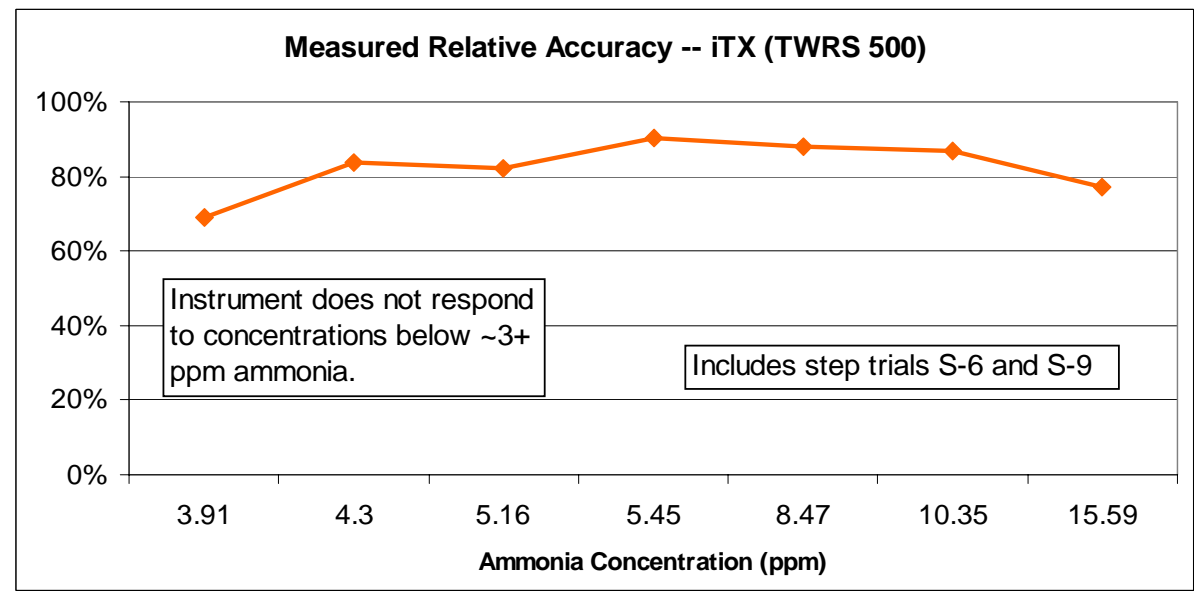

Figure 5.2. iTX Relative Accuracy versus Concentration 


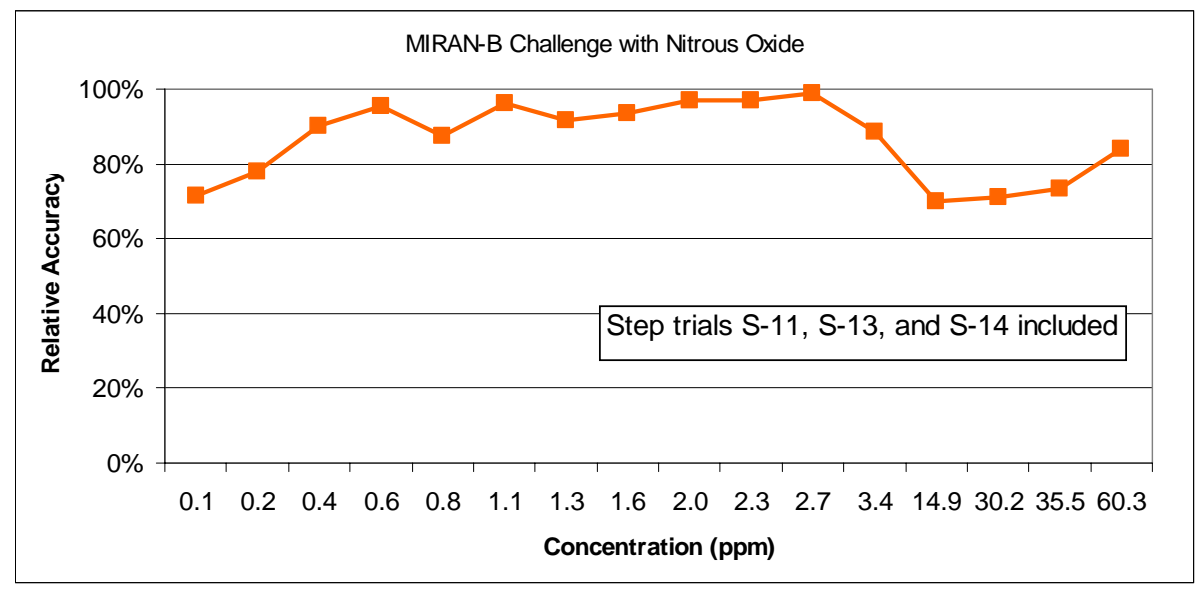

Figure 5.3. MIRAN Relative Accuracy versus Concentration

Perhaps the most important observation made during these tests relates to the response time. Most of the tested instruments can, with sufficient time, provide highly precise and reasonably accurate readings.

However, if gaseous releases with durations of a few seconds need to be measured, most of the instruments will provide only averaged results. In data-logging mode, most instruments record a maximum reading but the interpretation of the maximum reading is affected by the logging interval, the response time, and data conditioning performed by the instrument.

Recalling Figure 4.4, the MIRAN was exposed to a concentration of $1 \mathrm{ppm}$ nitrous oxide but after 15 seconds, it recorded $0.4 \mathrm{ppm}$, and after 34 seconds recorded only a maximum of $0.82 \mathrm{ppm}$. If transient releases are important, these times are examples of the performance capability of the MIRAN.

Unfortunately, available commercial instrumentation either offers quick response without specificity or good compound identification without quickness, but not both in one instrument. 


\subsection{References}

40 CFR Part 60. Standards of Performance for New Stationary Sources. Appendix B.

Section 217.16.3.1, page 1556.

Area-RAE PGM Wireless Multi-Gas Monitor. 2002. Operation and Maintenance Manual, Document Number: 029-4001, Revision A. RAE Systems, Inc., Sunnyvale, CA.

Bacharach $\mathrm{N}_{2} 0$ Monitor. 2003. Model 3010 P/N 19-7109. Instruction 19-9208. Operation and Maintenance Manual, Rev. 7. Bacharach, New Kensington, PA.

EC-P2 Gas Sensor Instruction and Installation Manual, Model EC-P2. N.d. 506-0112-d, Manning Systems, Inc., Lenexa, Kansas.

Haag, W. 2004. Personal communication with Warner Haag (1-888-723-4800) of RAE Systems, Inc. Sunnyvale, CA. November 2004.

iTX Multi-Gas Monitor. N.d. Instruction Manual. P/N 1709-5753, Rev. 3, 0803-5000, Industrial Scientific Corporation, Oakdale, PA.

Marrin, J. 2004. Personal communication with Jack Marrin (909-653-6780) of Scott-Marrin Incorporated, of Riverside, CA. May 2004.

MIRAN 205B Series SapphIRe, Portable Ambient Air Analyzer. 2004. Instruction Manual P/N BK3538, Thermo Electron Corporation, Environmental Instruments, Franklin, MA.

Model 580 EZ. Organic Vapor Meter/Datalogger. 1998. Instruction Manual, P/N 13111. Thermo Environmental Instruments, Inc., Franklin, MA.

Mukhtar S., A. Rose, S. Capareda, C. Boriack, R. Lacey, B. Shaw, C. Parnell Jr. 2003. Assessment of Ammonia Adsorption onto Teflon and LDPE Tubing used in Pollution Stream Conveyance. (Submitted to) Agricultural Engineering International CIGR Journal of Scientific Research and Development. Manuscript BC 03 012, Vol. V, December 2003.

Ppb-RAE VOC Monitor, PGM07240. 2001. Operation and Maintenance Manual, Document No.: 025-4001, Rev. C. RAE Systems, Inc., Sunnyvale, CA.

Wagner, D. 2004. Personal communication with iTX Industrial Scientific Corporation Technical Support Manager (412-788-4353), November 18, 2004. 


\section{Appendix A}




\section{Appendix A}

\section{Instruments Tested}

Table A.1. Serial Numbers and Calibration Data for Tested Instruments

\begin{tabular}{|c|c|c|c|}
\hline Instrument & $\begin{array}{c}\text { Industrial Scientific } \\
\text { iTX }\end{array}$ & $\begin{array}{c}\text { Industrial Scientific } \\
\text { iTX (Perkes) }\end{array}$ & AreaRAE \\
\hline Serial No. & 0302012-153 & SN 0208008-113 & $292-500336$ \\
\hline New & 03/03 & $11 / 03$ & $9 / 02$ \\
\hline TWRS No. & 000559 for pump & 000500 & 000431 \\
\hline Barcode & 2133 & 1986 & 1925 \\
\hline Service location & IHEL Maintenance & IHEL 2101M/200E & IHEL 2101M/200E \\
\hline Date serviced & $5 / 13 / 04$ at ISC & Not given & Not given \\
\hline Next service & $11 / 13 / 04$ & Not given & Not given \\
\hline Date calibrated & $6 / 28 / 04$ & 03/03/04 & 8/11/04 \\
\hline Next calibration & $9 / 28 / 04$ & 06/03/04 & 2/11/05 \\
\hline Readout range & $\mathrm{NH}_{3}: \quad 0-200$ & $\mathrm{NH}_{3}: \quad 0-200$ & $\begin{array}{c}\mathrm{NH}_{3}: 0-50 \\
\text { PID: } 0-2000\end{array}$ \\
\hline Tolerance & $15 \%$ & $15 \%$ & $\pm 10 \%$ \\
\hline Tech & TJB & TJB & TJB \\
\hline Dates tested & Sept to Oct 2004 & $4 / 15$ to $5 / 5 / 04$ & Sept to Oct 2004 \\
\hline Inlet tube, length & & 1/4-in OD, 28 inches & \\
\hline Notes: & $\begin{array}{c}\text { Has auxiliary air } \\
\text { sampling pump. } \\
\text { Received at PNNL w/o } \\
\text { inlet filter }\end{array}$ & $\begin{array}{l}\text { Has auxiliary air } \\
\text { sampling pump. }\end{array}$ & $\begin{array}{l}\text { Area-RAE not provided } \\
\text { for testing until Sept. }\end{array}$ \\
\hline No & & & \\
\hline
\end{tabular}




\begin{tabular}{|c|c|c|c|}
\hline Instrument & ppb-RAE (Woody) & ppb-RAE (Perkes) & ppb-RAE \\
\hline Manufacturer & RAE & RAE & RAE \\
\hline Serial No. & $* * *$ & $250-100933$ & $250-100954$ \\
\hline New & & $09 / 02$ & \\
\hline TWRS No. & 000413 & 000420 & 000405 \\
\hline Barcode & 1914 & 1912 & 1921 \\
\hline Service location & IHEL 2101M/200E & IHEL 2101M/200E & IHEL 2101M/200E \\
\hline \multicolumn{4}{|l|}{ Date serviced } \\
\hline \multicolumn{4}{|l|}{ Next service } \\
\hline Date calibrated & $4 / 21 / 04$ & $11 / 18 / 03$ & $4 / 21 / 04$ \\
\hline Next calibration & $10 / 21 / 04$ & $5 / 18 / 04$ & $10 / 21 / 04$ \\
\hline Calibration range & 0.001-199 ppm & 0.001-199 ppm & 0.001-199 ppm \\
\hline Tolerance & $\pm 20 \mathrm{ppb}$ or $10 \%$ & $\pm 20 \mathrm{ppb}$ or $10 \%$ & $\pm 20 \mathrm{ppb}$ or $10 \%$ \\
\hline Tech & TJB & TJB & TJB \\
\hline Dates tested & Apr 2-15, 04 & Apr 15 to May 4, 04 & September 2004 \\
\hline Inlet tube, length & & 1/4-in OD, 30 inches & \\
\hline
\end{tabular}

\begin{tabular}{|c|c|c|c|}
\hline Instrument & MIRAN-A & MIRAN-B & MIRAN \\
\hline Serial No. & 205B-79311-394 & 205B-79318-394 & 205B-79383-398 \\
\hline New & Spring-Summer 04 & Spring-Summer 04 & Spring-Summer 04 \\
\hline TWRS No. & Not given & Not given & 000799 \\
\hline Barcode & Not listed & Not listed & Not listed \\
\hline Service location & Not listed* & Not listed* & Not listed* \\
\hline Date serviced & Not listed* & Not listed* & Not listed* \\
\hline \multicolumn{4}{|l|}{ Next service } \\
\hline Date calibrated & Not done* & Not done* & Not done* \\
\hline Next calibration & Not done* & Not done* & Not done* \\
\hline Readout range & Not determined* & Not determined* & Not determined* \\
\hline Tolerance & Not determined* & Not determined* & Not determined* \\
\hline \multicolumn{4}{|l|}{ Tech } \\
\hline Dates tested & Apr-May-Jun 04 & Apr-May-Jun 04 & August 04 \\
\hline Inlet tube, length & 1/2-in ID, $42 * *$-inches & $1 / 2$-in ID, $42^{* *}$-inches & $1 / 2$-in ID, $42 * *$-inches \\
\hline
\end{tabular}




\begin{tabular}{|c|c|c|c|}
\hline Instrument & Manning EC-P2 & 580-EZ (OVM) & Bacharach $\mathrm{N}_{2} \mathrm{O}$ \\
\hline Manufacturer & Manning & Thermo Electron & \\
\hline Serial No. & 200305-6239-ECP2SC-1 & 68441-362 & JR10289 \\
\hline \multicolumn{4}{|l|}{ New } \\
\hline TWRS No. & 000456 & 000363 & $* * *$ \\
\hline Barcode & 1953 & & \\
\hline Service location & IHEL 2101M/200E & & \\
\hline \multicolumn{4}{|l|}{ Date serviced } \\
\hline \multicolumn{4}{|l|}{ Next service } \\
\hline Date calibrated & 02-06-04 & & $* * *$ \\
\hline Next calibration & 08-06-04 & & \\
\hline Readout range & $0-25 \mathrm{ppm}$ & & $* * *$ \\
\hline Tolerance & $\pm 2 \mathrm{ppm}$ & & $* * *$ \\
\hline Tech & TJB & & \\
\hline Dates tested & Late April 2004 & & \\
\hline Inlet tube, length & & 1/4-inch, 471/2-in & 1/4-in OD, 33 inches \\
\hline Notes & $\begin{array}{c}\text { EC-P2-Smart Cell, NH3: } \\
\text { 0-500 ppm SN 200305-6239- } \\
\text { ECP2SC-1 }\end{array}$ & & $\begin{array}{c}* * * \text { New instrument, not } \\
\text { calibrated or entered into } \\
\text { CH2M-Hill system }\end{array}$ \\
\hline
\end{tabular}


Appendix B 


\section{Appendix B}

\section{Mass Flowmeters Used in Dynamic Dilution System}

The flowmeters available for use in the dynamic dilution system are listed in Table B.1.

Table B.1. Flowmeters Used in Dynamic Dilution System

\begin{tabular}{|c|c|c|c|c|}
\hline \multicolumn{5}{|c|}{ Mass flow meters used in the performance tests } \\
\hline $\begin{array}{l}\text { Manufacturer } \\
\text { Serial No. }\end{array}$ & Model & Flow Range & Annual Certification & $\begin{array}{l}\text { Full-scale } \\
\text { Accuracy }\end{array}$ \\
\hline Sierra $76406^{(\mathrm{a})}$ & 822S-L-2-OV1-PV1-V3 & 0 to $500 \mathrm{sccm}$ & $4 / 12 / 2004$ & $\pm 1.5 \%$ \\
\hline Sierra 77833 & $\begin{array}{l}\text { 810S-L-DR-2-0V1-SV1-V4- } \\
\text { S4-MP }\end{array}$ & 0 to $2000 \mathrm{sccm}$ & Edison $^{(b)}$ & $\pm 1.5 \%$ \\
\hline Sierra 77832 & 822S-L-2-OV1-PV1-V4-MP & 0 to 5 liter/min & Edison $^{(b)}$ & $\pm 1.5 \%$ \\
\hline Sierra1 70856 & 826-NX-OV1-PV1-V4 & 0 to 3 SCFM & NW Std Lab ${ }^{(\mathrm{c})} 7 / 26 / 04$ & $\pm 1.5 \%$ \\
\hline Sierra2 70855 & 826-NX-0V1-PV1-V4 & 0 to 3 SCFM & NW Std Lab $\quad 7 / 26 / 04$ & $\pm 1.5 \%$ \\
\hline $\begin{array}{l}\text { Omega } \\
116023-5 \\
\end{array}$ & FMA 1806 & $0-50 \mathrm{sccm}$ & Omega $^{(\mathrm{d})_{*}}$ & $\pm 1.5 \%$ \\
\hline $\begin{array}{l}\text { Omega } \\
119556-1\end{array}$ & FMA 1844 & 0-500 liter/min & Omega $^{(\mathrm{b}) *}$ & $\pm 1.5 \%$ \\
\hline
\end{tabular}

(a) Sierra Instruments of Monterey, CA

(b) Edison = Edison ESI/SCE Metrology of Westminster, CA

(c) Northwest Standards Laboratory of Richland, WA

(d) Omega Engineering, Inc. of Stamford, CT

B.1 
Appendix C 


\section{Appendix C}

\section{Methods Used to Calculate Accuracy and Precision}

The statistical calculations used to verify monitor performance are described below, including those for relative accuracy, relative precision, interference effects, response time, uncertainty, and data analysis. All calculations were performed using Microsoft Excel ${ }^{\mathrm{TM}}$.

\section{C.1 Relative Accuracy}

The relative accuracy (RA) of the ammonia monitor with respect to the compressed gas standards were assessed using Equation 1:

$$
R A=\frac{1}{n}\left[\sum_{i=1}^{n} \frac{\left|d_{i}\right|}{x_{i}}\right] \times 100
$$

Equation 1 (40 CFR 60)

where $d$ refers to the difference between the standard gas concentration and the average of the ammonia monitor measurements recorded during sampling period, and $x$ corresponds to the standard gas concentration. For open path monitors, relative accuracy was based on the observed increase in signal over the background concentration measured. Relative accuracy was calculated and reported independently for each of the two phases.

Equations 1 and 2 were obtained from the document: Verification of Ambient Ammonia Monitors at Animal Feeding Operations dated September 2, 2003 and prepared by Battelle-Columbus, OH with technical and U.S. EPA review. The study conducted under the auspices of the U.S. EPA Environmental Technology Program provides objective and quality assured performance data for advanced technologies. The document can be found on the U.S. EPA WEB site at http://www.epa.gov/etv/verifications/testqa-index.html. An author of the document, Kenneth A. Cowen, Ph. D., of Battelle-Columbus (phone 614-424-5547), acknowledges that Equation 1 is basically a relative percent difference equation even though the U.S. EPA refers to it as an accuracy term.

Some consideration was given for the use of other appropriate equations. However, accuracy calculations usually require a fixed standard concentration while the observations can vary. During these tests both the injected certified gas standard and the observation varied so Equation 1 was used because it allows changes in both the standard and the observation and handles them in a time dependent paired manner.

\section{C.2 Relative Precision}

Precision was calculated in terms of the percent relative standard deviation (RSD) of a series of sensor measurements made over the duration of linear portions of gas injection. Before and following challenges, a zero reading was checked for each monitor to assess baseline conditions, such as baseline drift. The mean and standard deviation of those readings were calculated. Precision $(P)$ was then determined as: 


$$
P=\frac{S D}{\bar{X}} \times 100 \quad \text { Equation } 2
$$

where $S D$ is the standard deviation of the monitor readings and $X$-bar is the mean of the monitor readings. The precision was calculated independently for each set of runs.

\section{C.3 Interference Effects}

Interference effects were noted qualitatively when an apparent effect was seen.

\section{C.4 Response Time}

The response time in seconds was assessed in terms of the rise time of each gas monitored when sampling the gas standards. The $\mathrm{T}_{90}$ rise time (i.e., the time related to the change in gas concentrations from $0 \%$ to $90 \%$ is the response time) was determined as the difference in time between the start of the pulse and the $\mathrm{T}_{90}$ point. The $\mathrm{T}_{90}$ was calculated as a $\mathrm{ppb}$ or $\mathrm{ppm}$ value that is $90 \%$ of the concentration value recorded when the pulse ends. The calculate $T_{90}$ was rounded up or down to the closest observed value logged in the data set.

\section{C.5 Data Analyses and Review}

Records generated in the performance tests were reviewed by a separate independent PNNL staff member after the completion of testing, before the records were used to calculate, evaluate, or report results. These records may have included laboratory record books and data from the monitors.

\section{Special Note on the Location of the T90 Point using Trend Analyses in EXCEL.}

Refer to Figure 17 in the Text: Illustration of Points Used in Pulse Tests

\section{Determine coordinates of Points 2 and 3 on the chart:}

The rise time is taken as the time at which $90 \%$ of the end concentration (Point 2) is achieved. If there is scatter in the data near Point 2 , the TREND function ${ }^{(a)}$ is used to determine the ultimate concentration recorded by the instrument. Choose a segment of the plot corresponding to the end of the run, where the curve is approaching a final value. Use the range of $x$ - and $y$-values in that part of the curve, and use TREND to calculate the $\mathrm{Y}$ value for the final value of $\mathrm{X}$.

Ninety percent of this concentration, the y value at Point 3, is then calculated. The time (x value) at which the $90 \%$ concentration (y value) is achieved can be determined from the plot. When data is scattered, the TREND function may be used to determine the time corresponding to Point $3^{(\mathrm{b})}$.

(a) The EXCEL TREND function returns values along a linear trend. It fits a straight line (using the method of least squares) to the arrays known $y$ values and known $\mathrm{x}$ values. The function returns the $y$-values along that line for the array of new $x$ values that you specify: 
Syntax: TREND(known_y's,known_x's, new_x's, const) Known_y's is the set of yvalues you already know in the relationship $y=m x+b$. New_x's are new $x$-values for which you want TREND to return corresponding $y$-values. Const is a logical value specifying whether to force the constant $b$ to equal 0 .

(b) Choose a range of $x$ values (times) around Point 3 ( $y=90 \%$ of ultimate value) by inspection. Choose a value for $\mathrm{x}$, and calculate $\mathrm{y}$ using the TREND function. Iterate to determine the $\mathrm{x}$-value that results in $\mathrm{y}=90 \%$ of the Point $2 \mathrm{y}$-value.

\section{Precision and Accuracy:}

Precision and accuracy for pulse tests are calculated between Point 3 (the $90 \%$ concentration) and Point 2 (final concentration) illustrated in Figure 17. The relative precision is calculated by using the standard deviation ${ }^{(\mathrm{c})}$ of the concentration values between Points 2 and 3 , and dividing the result by the average of concentration measurements between Points 2 and 3 .

Relative accuracy is the average deviation of each value from the standard. It is calculated for each point as the absolute difference between the measured and the standard concentrations, divided by the concentration of the standard The average of this value over the range of interest (between Point 2 and Point 3) is the relative accuracy.

(c) The STDEV function estimates standard deviation based on a sample. The standard deviation is a measure of how widely values are dispersed from the average value (the mean). Syntax: STDEV (number1,number2,...) 
Appendix D 


\section{Appendix D}

\section{Estimated Lag Times in Tests}

Table D.1. Lag Times in Laboratory Tests for Certified Gases to Travel to Instruments

\begin{tabular}{|c|c|c|c|c|c|c|}
\hline \multirow[b]{2}{*}{ Gas } & \multirow[b]{2}{*}{$\begin{array}{c}\text { Target gas } \\
\text { (ppm) }\end{array}$} & \multirow[b]{2}{*}{ Instrument } & \multirow[b]{2}{*}{ Run Date } & \multicolumn{3}{|c|}{ Estimated transit time* (sec) } \\
\hline & & & & Test gas & Diluted & Total \\
\hline \multirow[t]{3}{*}{$\mathrm{N}_{2} \mathrm{O}$} & 1 & Miran SapphIRe & 7/29/2004-A & 3.04 & 0.52 & 3.56 \\
\hline & 25 & Miran SapphIRe & 7/29/2004-B & 0.09 & 0.46 & 0.55 \\
\hline & 55 & Miran SapphIRe & 7/30/2004 & 0.03 & 0.40 & 0.43 \\
\hline \multirow[t]{11}{*}{$\mathrm{NH}_{3}$} & 25 & Miran SapphIRe & 8/3/2004 & 0.91 & 0.45 & 1.36 \\
\hline & 25 & Miran SapphIRe & $8 / 4 / 2004$ & 0.91 & 0.45 & 1.36 \\
\hline & 25 & Miran SapphIRe & 8/6/2004 & 0.91 & 0.45 & 1.36 \\
\hline & 25 & Area-RAE & 9/8/2004-A & 0.4 & 3.9 & 4.3 \\
\hline & 50 & Area-RAE & 9/8/2004-B & 0.2 & 3.9 & 4.1 \\
\hline & 1 & Area-RAE & 9/9/2004-A & 9 & 4 & 13 \\
\hline & 25 & Area-RAE & 9/9/2004-B & 0.4 & 3.9 & 4.3 \\
\hline & 25 & iTX & 9/8/2004-A & 0.4 & 1.2 & 1.6 \\
\hline & 50 & iTX & 9/8/2004-B & 0.2 & 1.2 & 1.4 \\
\hline & 1 & iTX & 9/9/2004-A & 9.2 & 1.3 & 10.5 \\
\hline & 25 & iTX & 9/9/2004-B & 0.4 & 1.2 & 1.6 \\
\hline \multirow[t]{12}{*}{$\begin{array}{l}\text { Hydro- } \\
\text { carbon mix }\end{array}$} & 11 & Miran SapphIRe & $8 / 6 / 2004$ & 0.6 & 0.8 & 1.4 \\
\hline & 2 & ppb-RAE & $9 / 2 / 2004$ & 3.5 & 2.6 & 6.1 \\
\hline & 11 & ppb-RAE & 9/6/2004-A & 0.4 & 2.4 & 2.8 \\
\hline & 104 & ppb-RAE & 9/6/2004-B & 0.2 & 3.7 & 3.9 \\
\hline & 32 & ppb-RAE & 9/6/2004-C & 0.7 & 3.9 & 4.6 \\
\hline & 0.012 & ppb-RAE & 9/9/2004-A & 115 & 3 & 118 \\
\hline & 0.011 & ppb-RAE & 9/9/2004-B & 115 & 3 & 118 \\
\hline & 2 & Area-RAE & $9 / 2 / 2004$ & 3.5 & 4.1 & 7.6 \\
\hline & 11 & Area-RAE & 9/6/2004-A & 0.36 & 3.81 & 4.17 \\
\hline & 104 & Area-RAE & 9/6/2004-B & 0.18 & 5.09 & 5.27 \\
\hline & 32 & Area-RAE & 9/6/2004-C & 0.67 & 5.33 & 6 \\
\hline & 0.012 & Area-RAE & 9/9/2004-A & 115 & 4 & 119 \\
\hline
\end{tabular}



Appendix E 


\section{Appendix E}

\section{Data Analyzed for Stepped Tests of Instruments}

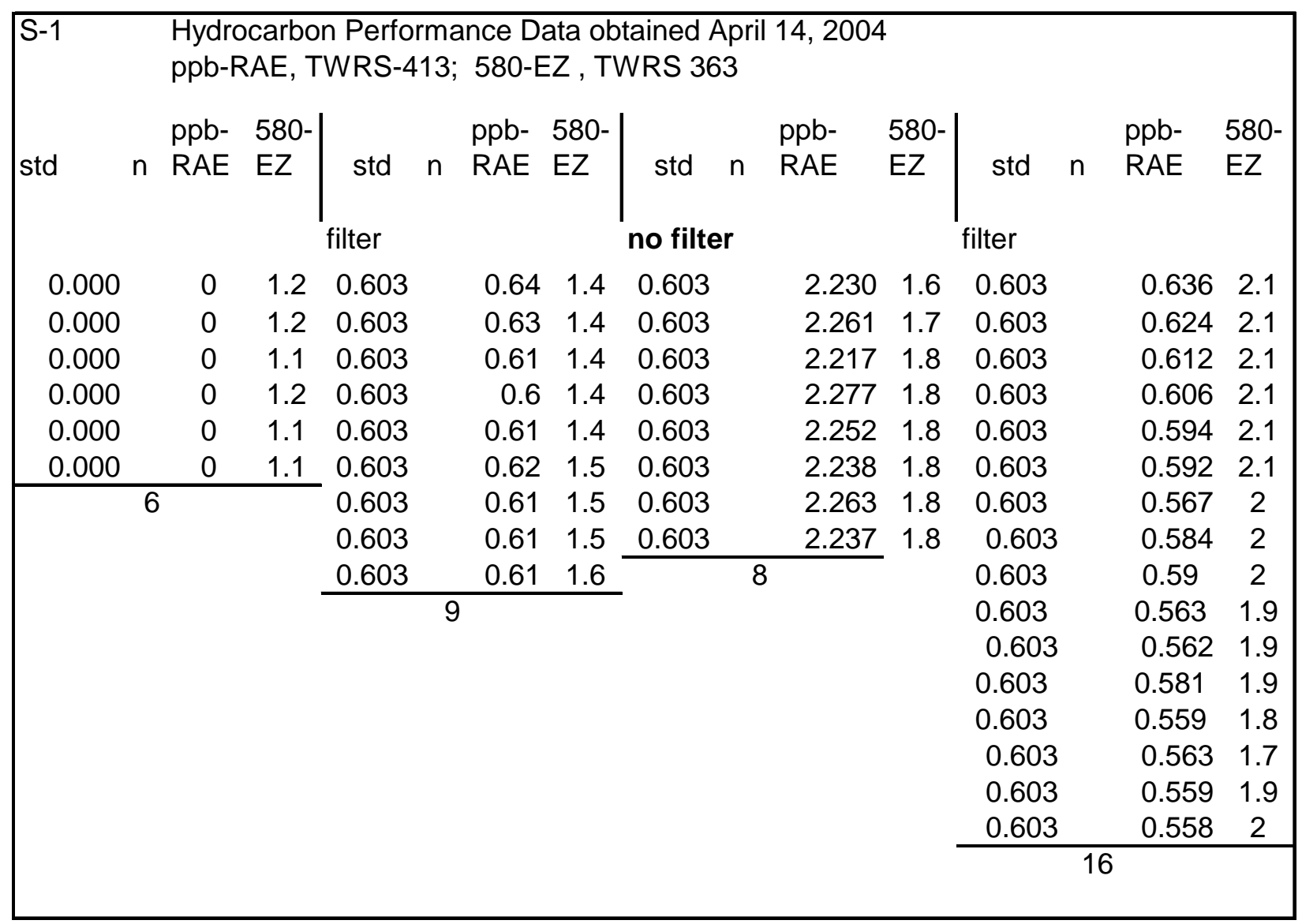




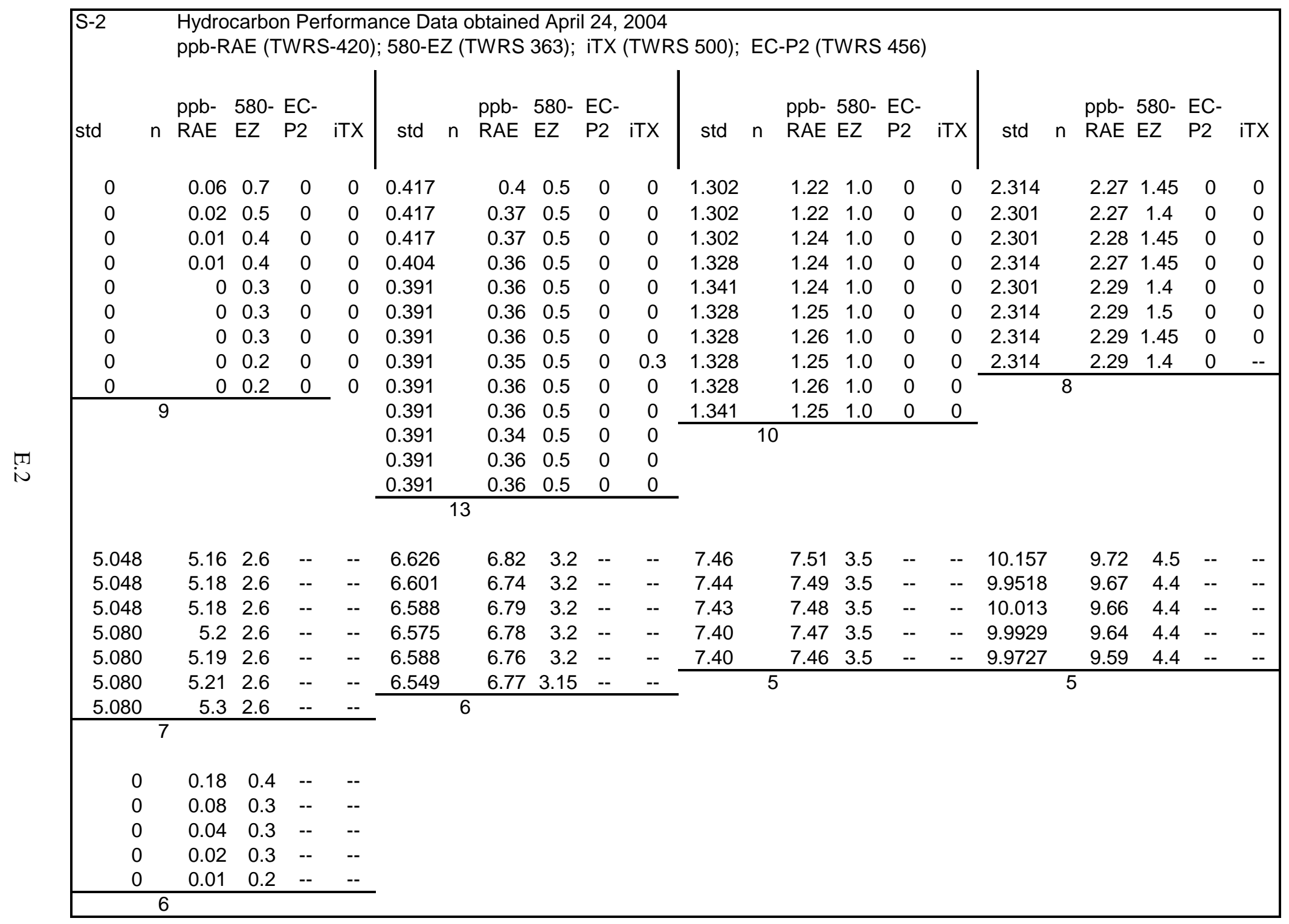




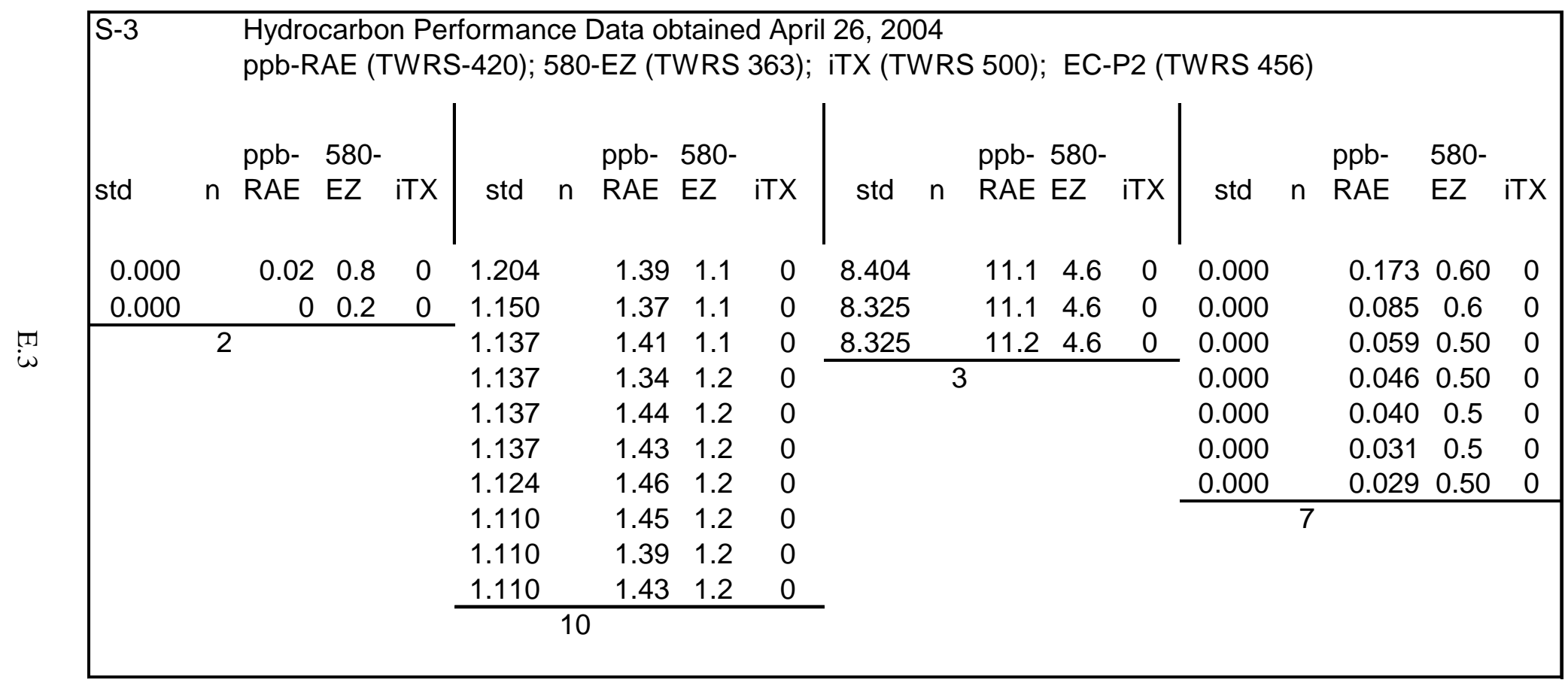




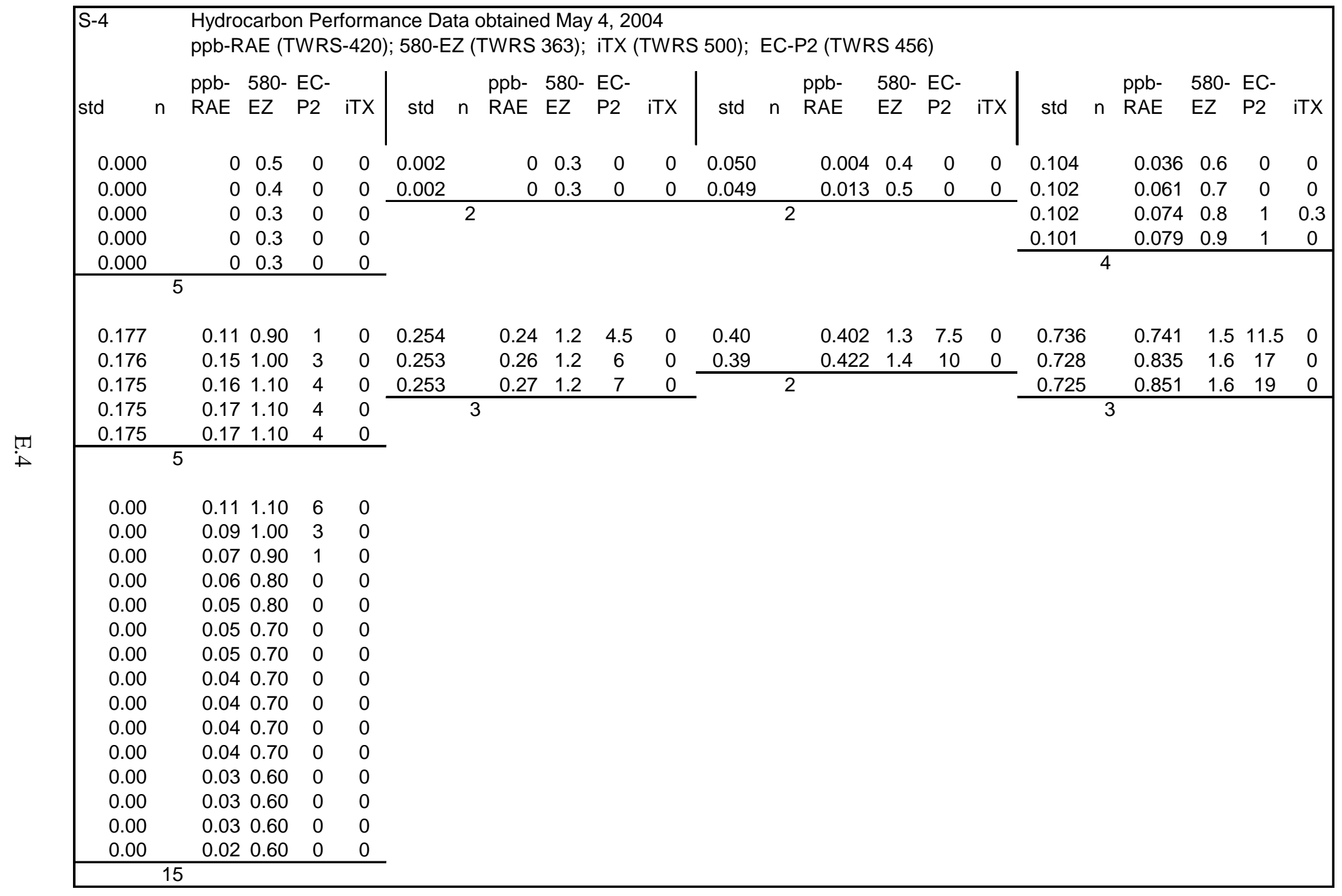




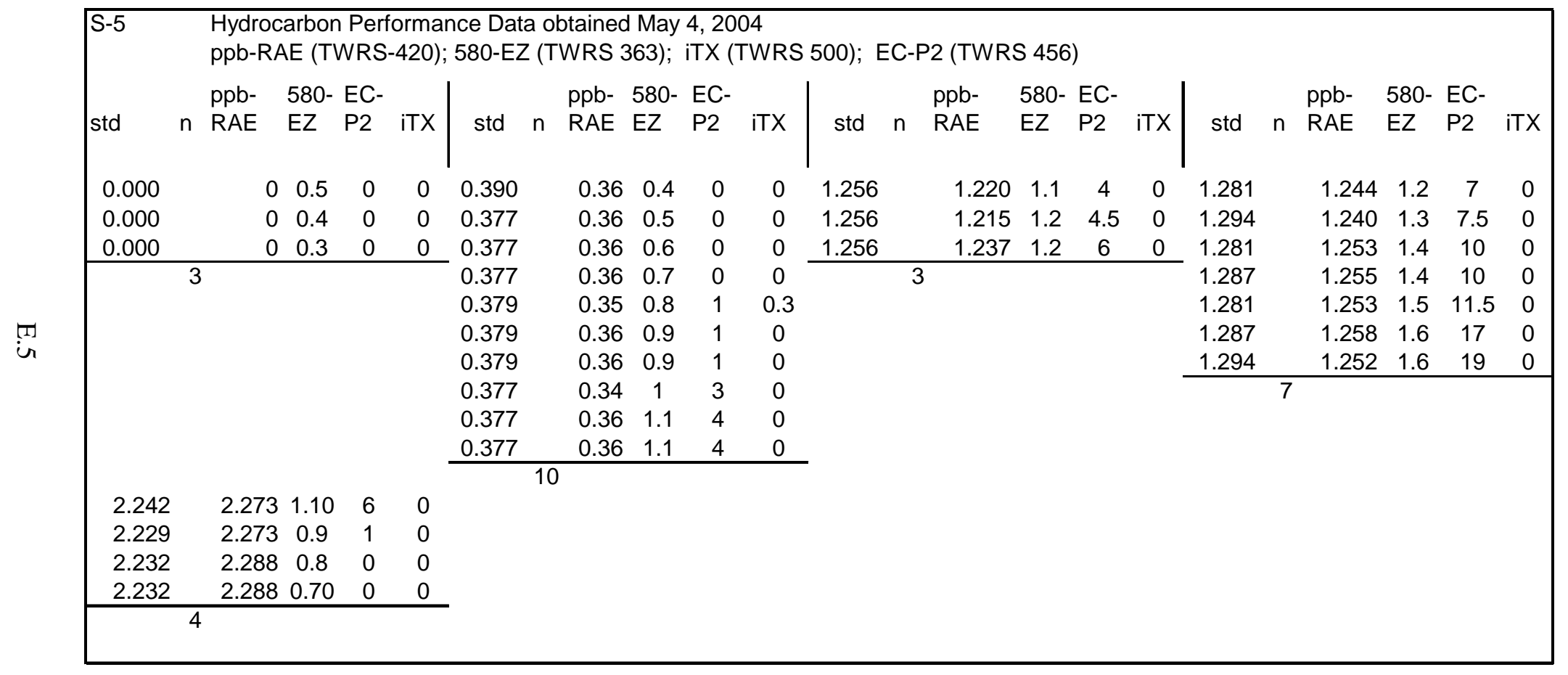




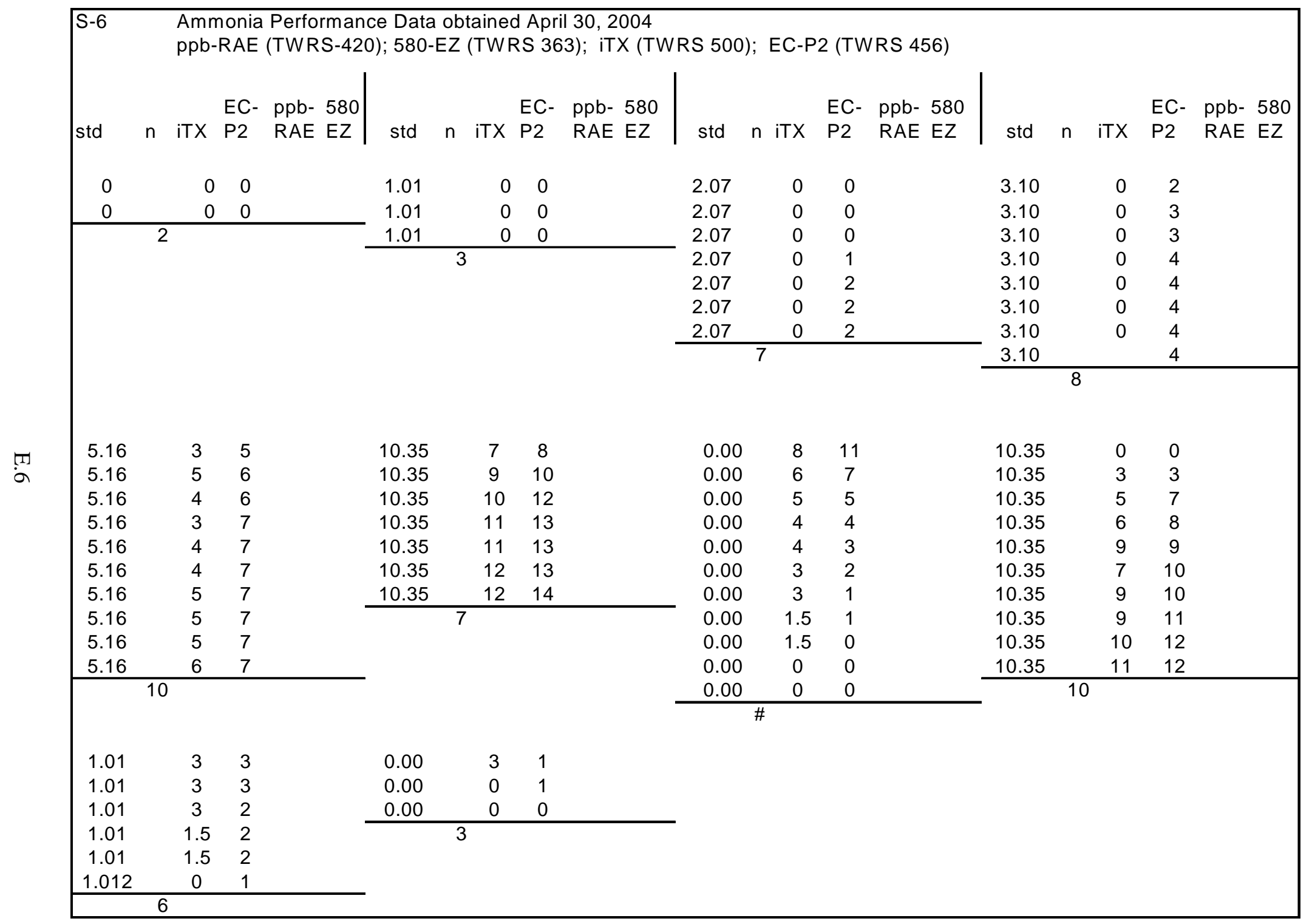




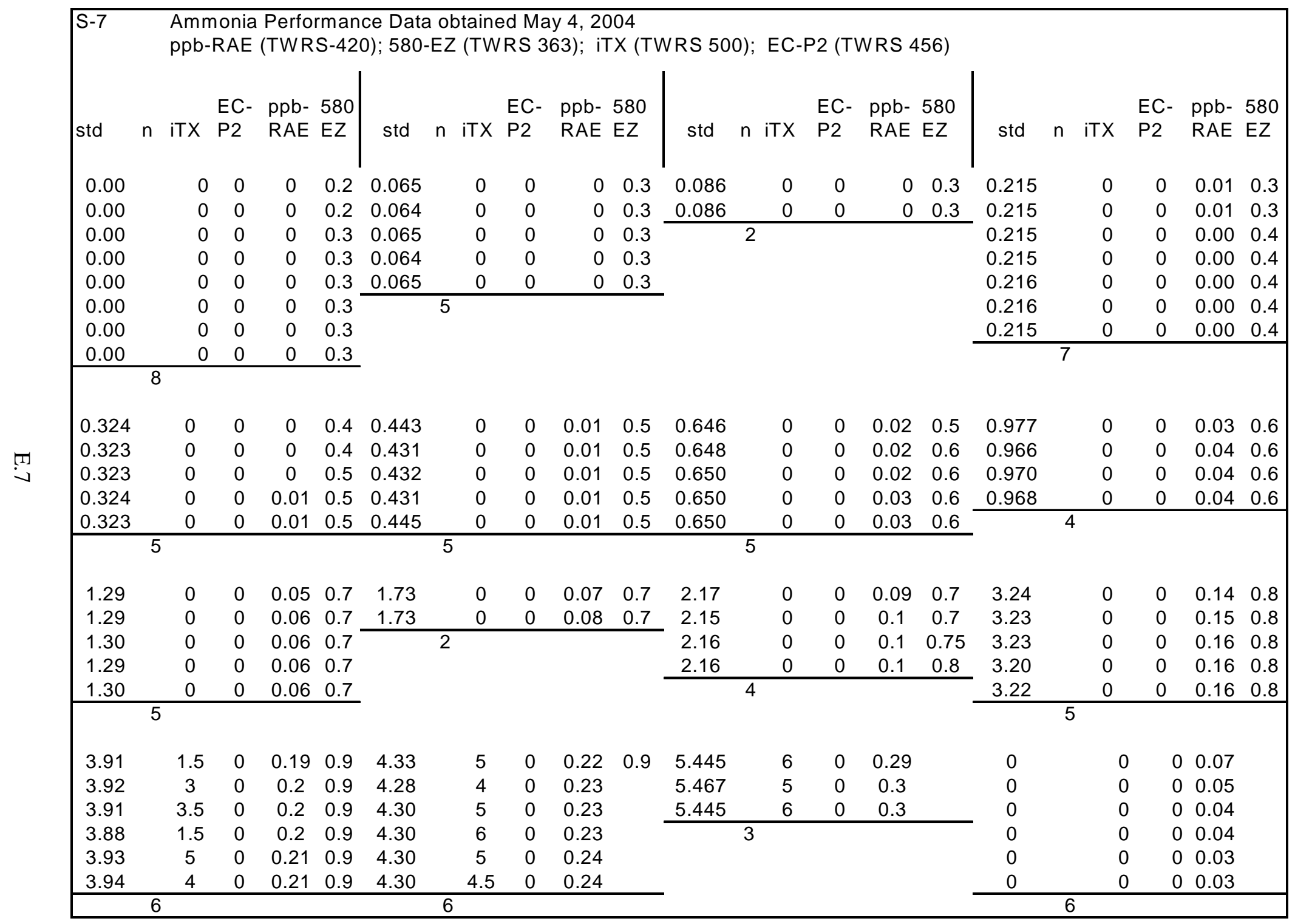




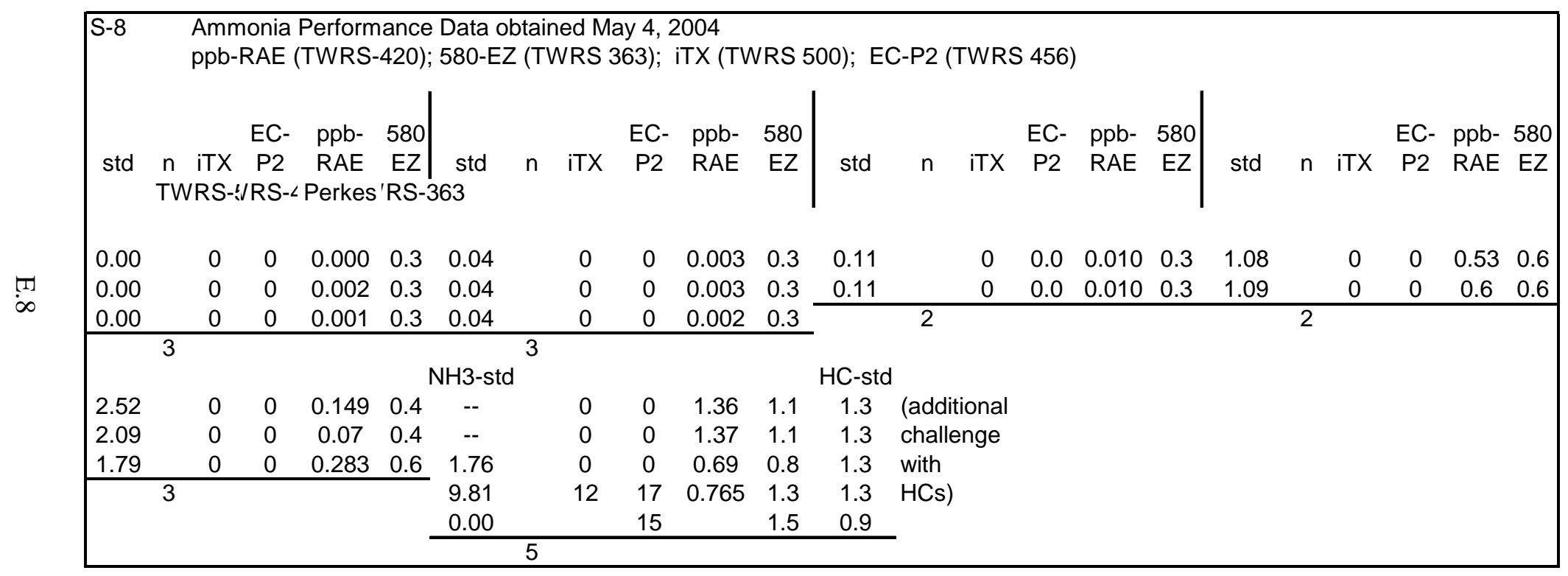




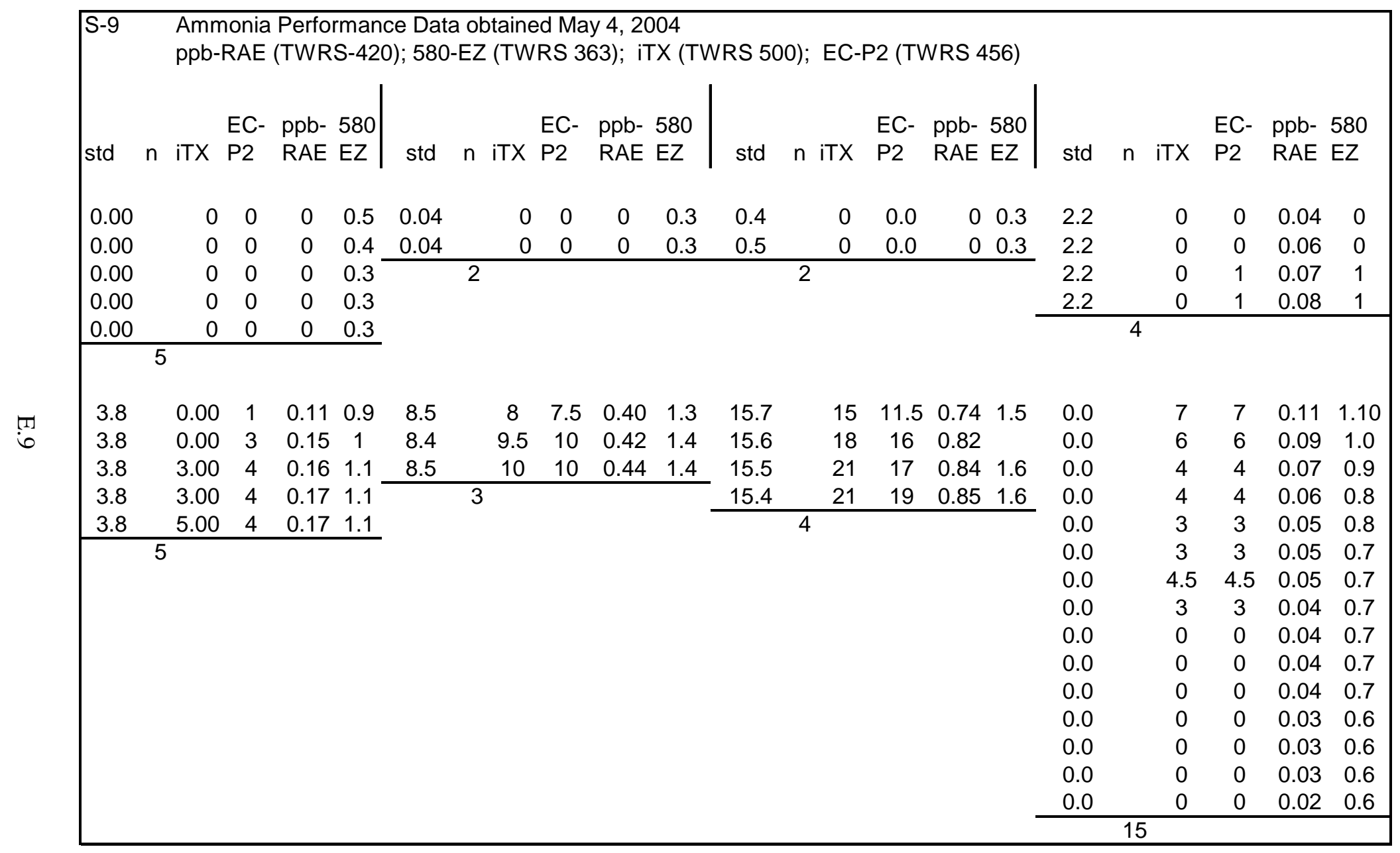




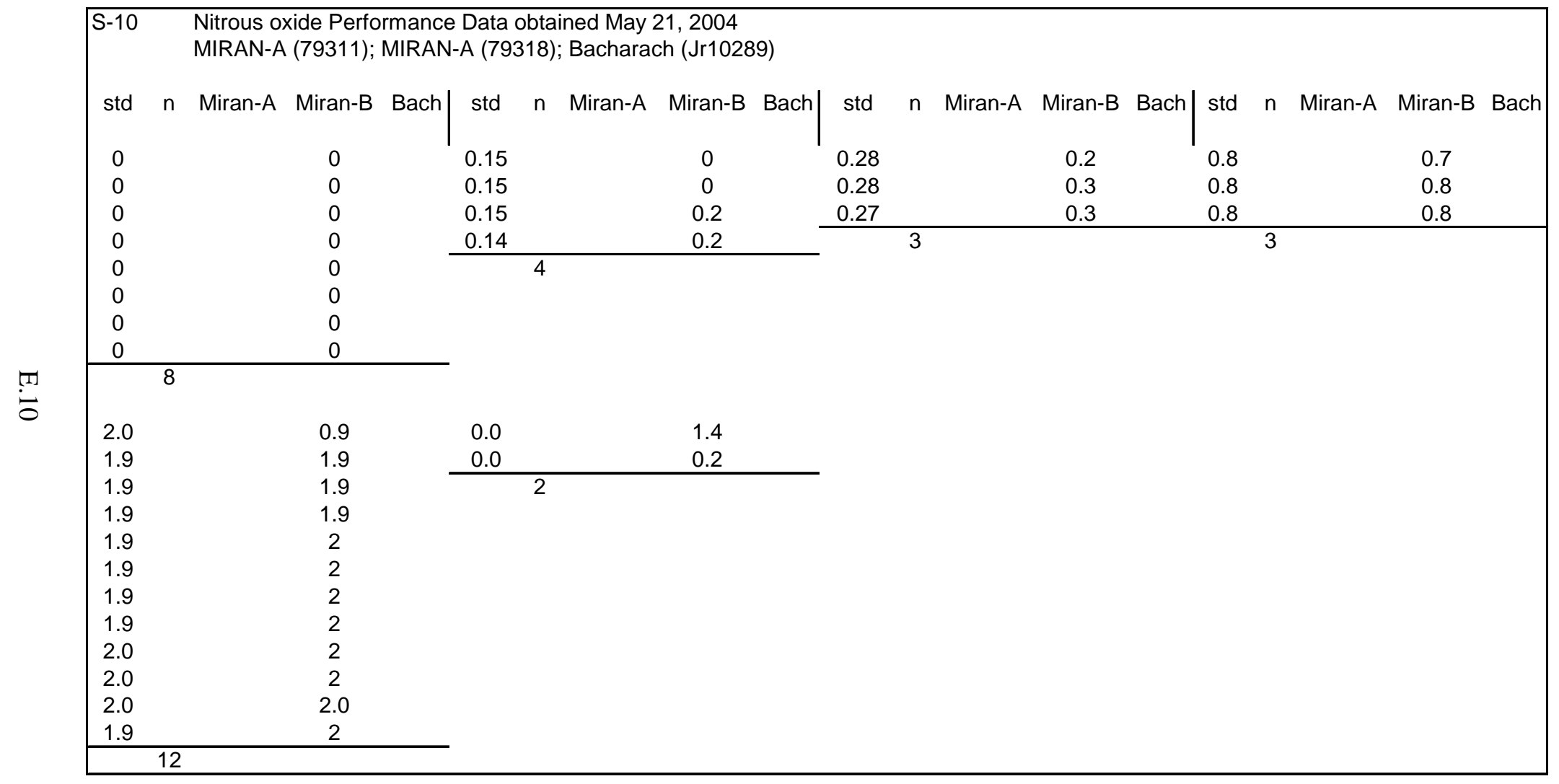




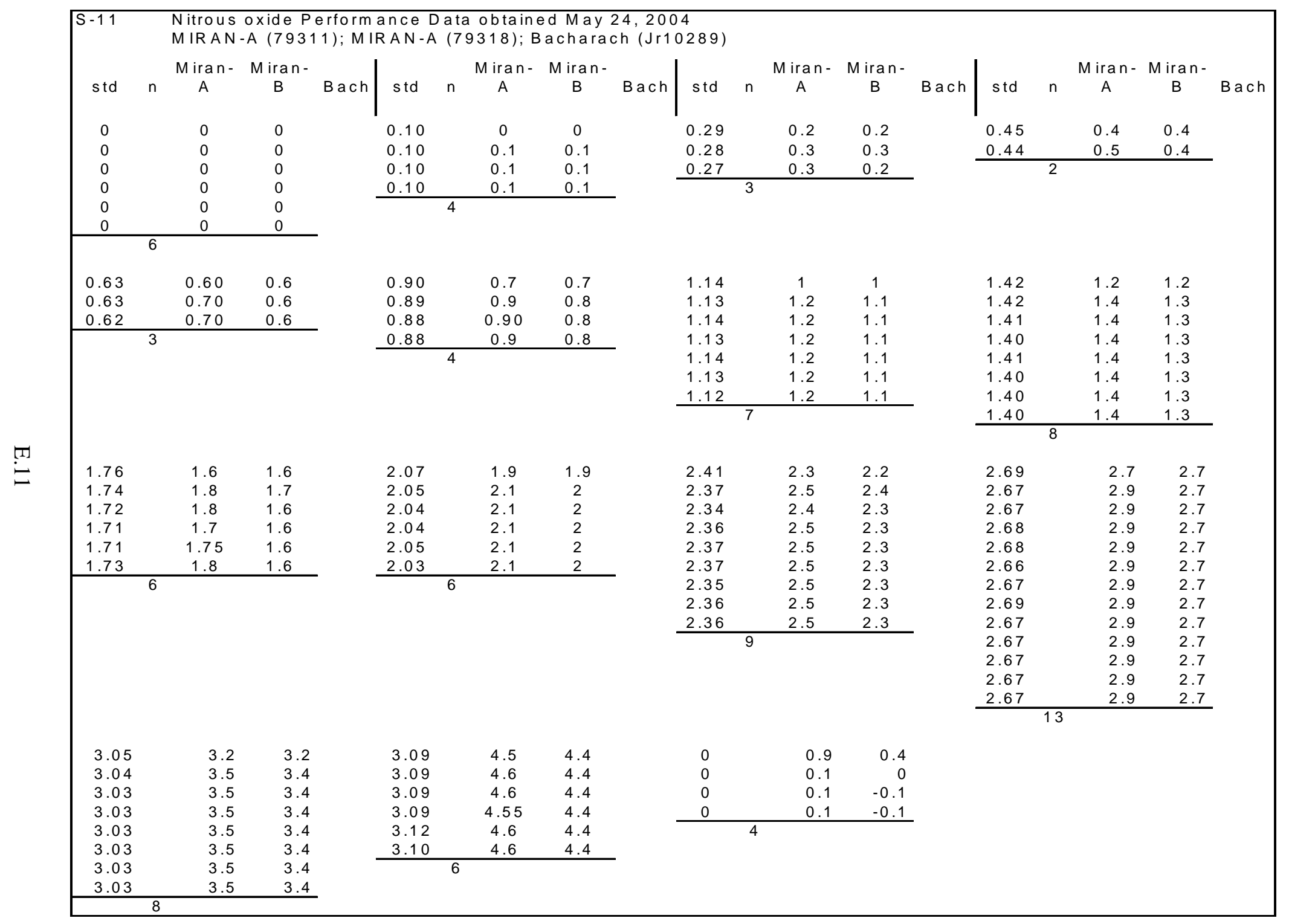




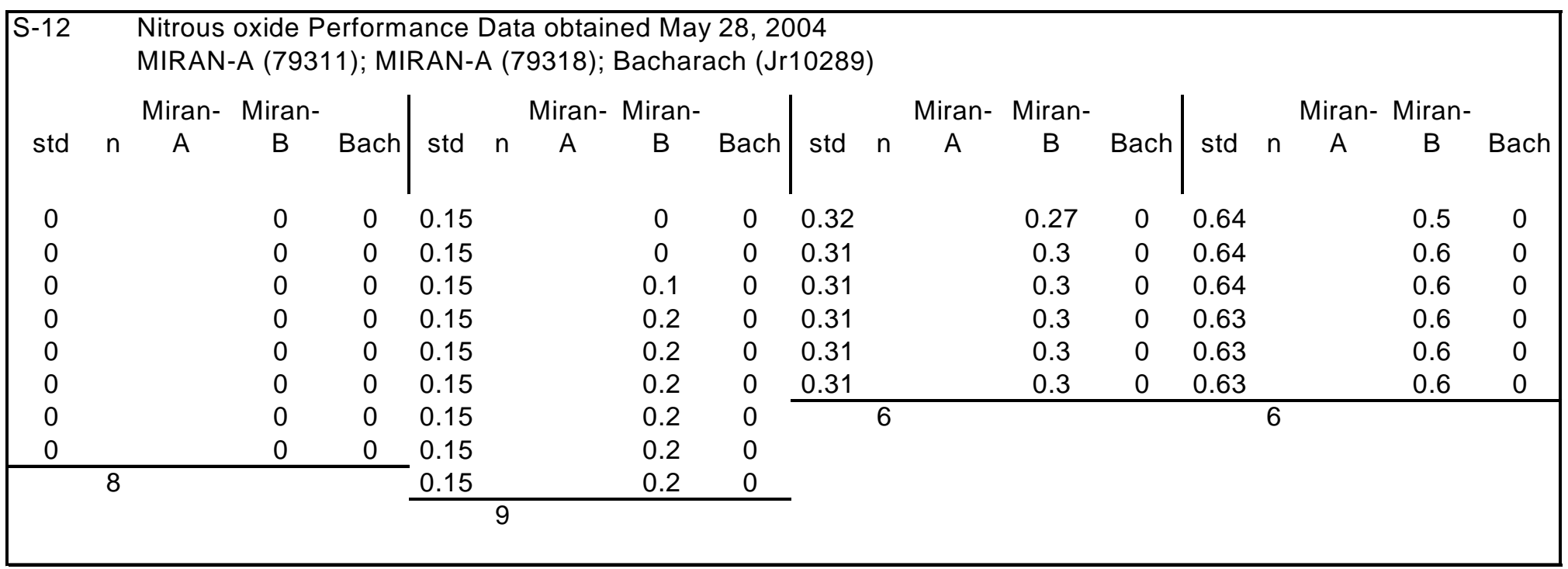

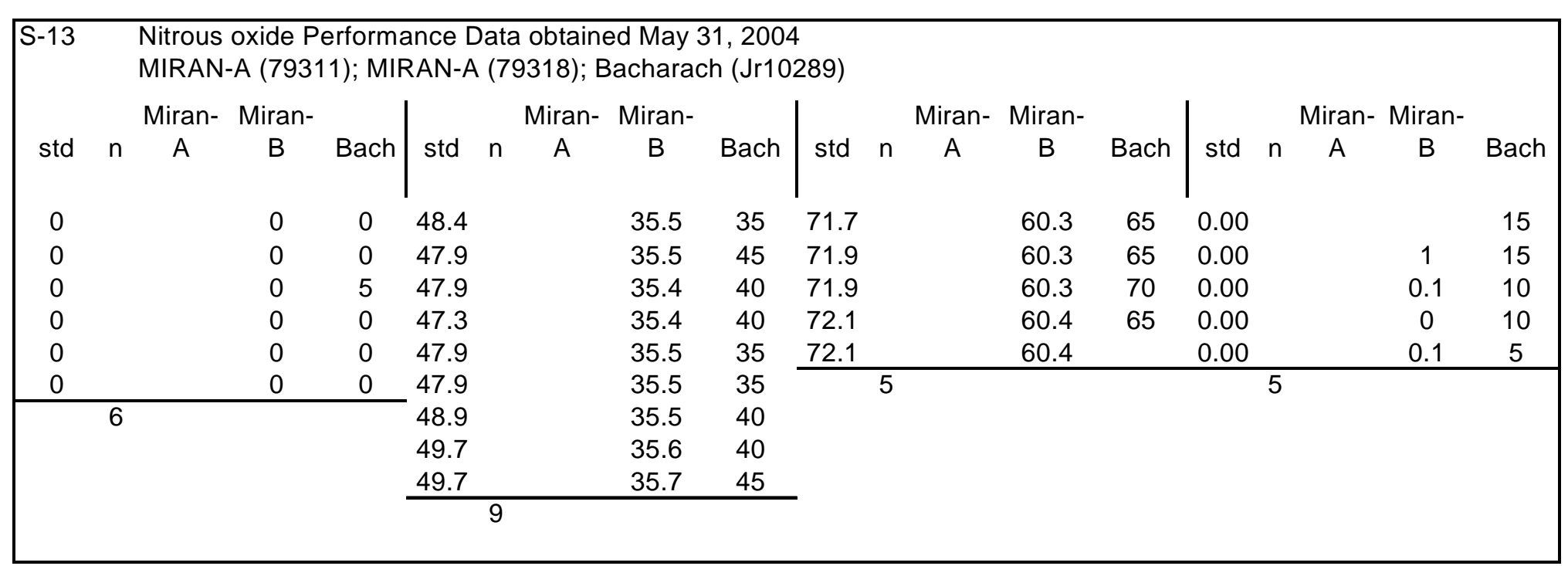




\begin{tabular}{|c|c|c|c|c|c|c|c|c|c|c|c|c|c|c|c|c|c|c|c|}
\hline S-14 & & $\begin{array}{l}\text { Nitrous } \\
\text { MIRAN }\end{array}$ & $\begin{array}{l}\text { oxide } P \\
-A(7931\end{array}$ & $\begin{array}{l}\text { erform } \\
\text { L1); MI }\end{array}$ & $\begin{array}{l}\text { ance } \\
\text { RAN- }\end{array}$ & $\mathrm{Dat}$ & $\begin{array}{l}\text { a obtain } \\
9318)\end{array}$ & $\begin{array}{l}\text { ed May } \\
\text { Bachar? }\end{array}$ & $\begin{array}{l}31,20 \\
\text { ich (Jr. }\end{array}$ & $\begin{array}{l}04 \\
10289)\end{array}$ & & & & & & & & & \\
\hline std & $n$ & $\begin{array}{c}\text { Miran- } \\
\text { A }\end{array}$ & $\begin{array}{c}\text { Miran- } \\
\text { B }\end{array}$ & Bach & std & $\mathrm{n}$ & $\begin{array}{c}\text { Miran- } \\
\text { A }\end{array}$ & $\begin{array}{c}\text { Miran- } \\
\text { B }\end{array}$ & Bach & std & $n$ & $\begin{array}{c}\text { Miran- } \\
\text { A }\end{array}$ & $\begin{array}{c}\text { Miran- } \\
\text { B }\end{array}$ & Bach & std & $n$ & $\begin{array}{c}\text { Miran- } \\
\text { A }\end{array}$ & $\begin{array}{c}\text { Miran- } \\
\text { B }\end{array}$ & Bach \\
\hline 0 & & 0 & 0 & & 23.0 & & 12.7 & 11.1 & & 42.7 & & 29.9 & 29.2 & & 0.00 & & 0.5 & 1.5 & \\
\hline 0 & & 0 & 0 & & 22.4 & & 16.2 & 15.9 & & 42.7 & & 30.6 & 30.1 & & 0.00 & & 0.1 & 0 & \\
\hline 0 & & 0 & 0 & & 21.7 & & 16.1 & 15.8 & & 43.2 & & 30.8 & 30.3 & & & 2 & & & \\
\hline 0 & & 0 & 0 & & 21.7 & & 16.1 & 15.8 & & 43.5 & & 31 & 30.5 & & & & & & \\
\hline 0 & & 0 & 0 & & 21.7 & & 16.1 & 15.8 & & 43.7 & & 31.3 & 30.8 & & & & & & \\
\hline & 5 & & & & & 5 & & & & & 8 & & & & & & & & \\
\hline
\end{tabular}

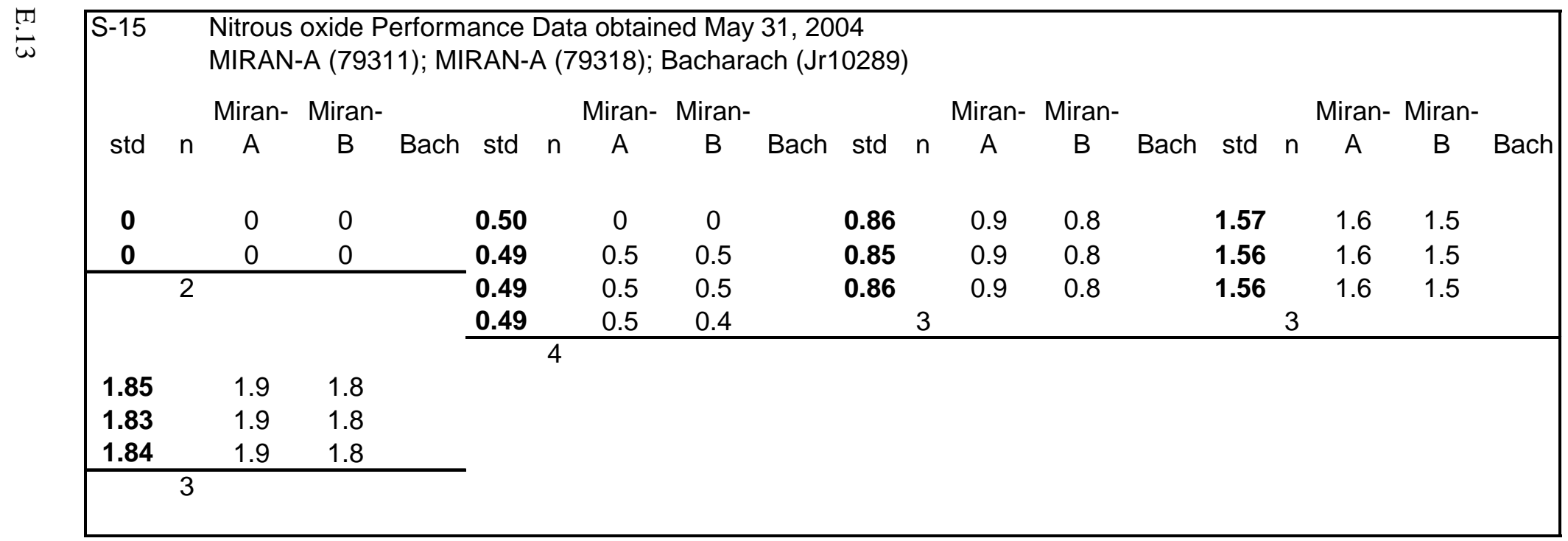




\section{Distribution}

No. of

Copies

OFFSITE

1 Dade Moeller \& Associates, Inc.

Bump, S.L.

B8-24

21 CH2MHill Hanford Company

Anderson, T.

S7-83

Boyajian, $\mathrm{S}$.

S7-83

Butler, N.

T6-03

Cash, R.

H6-04

Cruz, J.

Cutforth, K.

Dombrowski, L.

R3-86

S5-12

S7-83

Honeyman, J.

Hughey, M.

Jabara, J.

Lavaty, K.

Liston, S.

McAfee, O.

McKinney, J.

McLellan, G.

Nardinger, A.

Phillips, J.

Raymond, R.E.

Wilson, R.

Zabel, M.

CH2M Hill Correspondance

Processing
S7-83

S7-83

S7-75

R3-86

H1-11

S7-12

S7-83

K1-01

S7-83

H6-08
No. of

Copies

ONSITE

20 Pacific Northwest National Laboratory

Berkowitz C.M. K9-30

Birnbaum J.C. K2-44

Brouns T.M. K9-69

Droppo J.G. K9-30

Evans J.C. K6-96

Glissmeyer J.A. (5) K3-54

Huckaby J.L. K7-15

Josephson G.B. $\quad$ K9-69

Maughan A.D. (2) K3-54

Sheffield K.J. J2-40

Soldat K.L. K3-53

Walton T.L. K9-46

Weimer W.C. K9-09

Information Release (2) 